\title{
The role of $\alpha$-neurexins in $\mathrm{Ca}^{2+}$-dependent synaptic transmission and plasticity
}

\section{PhD Thesis}

\author{
in partial fulfilment of the requirements \\ for the degree "Doctor of Philosophy (PhD)/Dr. rer. nat." \\ in the Neuroscience Program \\ at the Georg August University Göttingen, \\ Faculty of Biology \\ submitted by \\ Mohiuddin Ahmad \\ born in \\ Kota, India
}




\section{Declaration}

The thesis has been written independently and the content in the thesis is contributed by my own work with no other sources and aids than quoted.

Mohiuddin Ahmad

March $15^{\text {th }}, 2006$ 


\section{Table of contents}

$\begin{array}{ll}\text { Abbreviations } & 7\end{array}$

1 Introduction 11

$\begin{array}{lll}1.1 & \text { Molecular structure of neurexins } & 13\end{array}$

1.2 The role of $\alpha$-neurexins in neurotransmitter release 16

$\begin{array}{lll}1.3 & \text { Aims of the present study } & 19\end{array}$

2 Materials and Methods 20

$\begin{array}{lll}2.1 & \text { Materials } & 20\end{array}$

2.1.1 Solutions and media for molecular biology 20

$\begin{array}{lll}2.1 .2 & \text { Solutions for biochemistry }\end{array}$

$\begin{array}{lll}2.1 .3 & \text { Solutions and media for cell culture }\end{array}$

$\begin{array}{lll}2.1 .4 & \text { Solutions for electrophysiology }\end{array}$

$\begin{array}{lll}2.1 .5 & \text { DNA material }\end{array}$

$\begin{array}{lll}\text { 2.1.5.1 Vectors } & 24\end{array}$

$\begin{array}{lll}\text { 2.1.5.2 } & \text { cDNA plasmids }\end{array}$

$\begin{array}{lll}\text { 2.1.5.3 Genomic clones } & 25\end{array}$

$\begin{array}{lll}\text { 2.1.5.4 Oligonucleotides } & 25\end{array}$

2.1.5.5 Newly constructed clones 26

$\begin{array}{lll}2.1 .6 & \text { Eukaryotic cell lines } & 28\end{array}$

$\begin{array}{lll}2.1 .7 & \text { Bacterial strains } & 29\end{array}$

$\begin{array}{lll}2.1 .8 & \text { Apparatus } & 29\end{array}$

$\begin{array}{lll}2.1 .9 & \text { General chemicals } & 30\end{array}$

2.1.10 Chemicals for cell culture 32

$\begin{array}{lll}2.1 .11 & \text { Consumables } & 33\end{array}$

2.1.12 Kits for molecular biology 34

$\begin{array}{lll}2.1 .13 & \text { Primary antibodies } & 34\end{array}$

$\begin{array}{lll}2.1 .14 & \text { Secondary antibodies } & 35\end{array}$ 
$\begin{array}{ll}\text { Methods } & 35\end{array}$

2.2.1 Molecular biology methods 35

2.2.1.1 Restriction enzyme digestion of DNA 36

2.2.1.2 Agarose gel electrophoresis 36

2.2.1.3 Purification of DNA from preparative digestion 36

$\begin{array}{lll}\text { 2.2.1.4 Dephosphorylation of 5' DNA ends } & 37\end{array}$

$\begin{array}{lll}\text { 2.2.1.5 Ligation } & 37\end{array}$

$\begin{array}{lll}\text { 2.2.1.6 Blunt-end cloning } & 37\end{array}$

2.2.1.7 Electro-transformation of bacteria with plasmid DNA 37

$\begin{array}{lll}\text { 2.2.1.8 DNA mini-prep } & 38\end{array}$

$\begin{array}{lll}\text { 2.2.1.9 DNA maxi-prep } & 38\end{array}$

2.2.1.10 DNA adaptor synthesis 38

2.2.1.11 Colony hybridization $\quad 39$

2.2.1.12 Polymerase chain reaction (PCR) for cloning 40

2.2.1.13 Preparation of mouse tail DNA for PCR 41

2.2.1.14 Polymerase chain reaction (PCR) for genotyping 41

2.2.1.15 DNA sequencing 42

2.2.1.16 Southern blot 42

2.2.1.17 DNA database search 44

$\begin{array}{lll}\text { 2.2.2 } & \text { Biochemistry methods } & 44\end{array}$

2.2.2.1 SDS-polyacrylamide gel electrophoresis 44

2.2.2.2 Western blotting 45

2.2.2.3 Expression of GST-fusion proteins 46

2.2.2.4 Expression of proteins in HEK cells 48

2.2.2.5 HEK cell lysate preparation 48

2.2.2.6 Membrane protein extraction from rodent brain 48

2.2.2.7 GST fusion protein pulldown experiments 49

$\begin{array}{lll}\text { 2.2.2.8 Dialysis } & 50\end{array}$

$\begin{array}{lll}2.2 .3 & \text { Cell culture } & 50\end{array}$

2.2.3.1 Embryonic stem cell culture $\quad 50$

2.2.3.1.1 Preparation of feeder layer $\quad 50$ 
2.2.3.1.2 Culture of ES cells over feeder layer 51

2.2.3.1.3 Preparation of DNA for electroporation $\quad 51$

2.2.3.1.4 Preparation of cells for electroporation 51

2.2.3.1.5 Electroporation procedure $\quad 51$

2.2.3.1.6 Selection of clones $\quad 52$

2.2.3.1.7 Collection of resistant clones $\quad 52$

2.2.3.1.8 Preparation of ES cells for injection 53

2.2.3.1.9 Microinjection of positive ES cell clones 54

2.2.3.2 Cell culture and transfection of HEK293_Ca 2.2

2.2.3.3 Cell culture and transfection of tsA201 cells 54

2.2.4 Electrophysiological recordings 55

2.2.4.1 Whole-cell patch-clamp on HEK293_Ca 2.255

2.2.4.2 Whole-cell patch-clamp on tsA201 cells 56

2.2.4.3 Extracellular field potential recordings in acute 56

$\begin{array}{llr}3 & \text { Results } & 59\end{array}$

3.1 The effect of $\alpha$-neurexins on $\mathrm{Ca}^{2+}$ channels 59

3.1.1 Basic characterization of HEK293 cells stably transfected 59

3.1.2 Investigation of the influence of $\alpha$-neurexins on the functional 61 properties of $\mathrm{N}$-type $\mathrm{Ca}^{2+}$ channels in HEK293_Ca 2.2

3.1.3 Investigation of the influence of $\alpha$-neurexins on the functional 65 properties of $\mathrm{N}$-type $\mathrm{Ca}^{2+}$ channels in tsA201 cells

3.2 Synaptic transmission at Schaffer collateral-CA1 synapses in $\alpha-$ neurexin knockout mice

3.2.1 Basal synaptic transmission at Schaffer collateral-CA1 synapses in $\alpha$-neurexin $\mathrm{KO}$ mice

3.2.2 Short-term synaptic plasticity at Schaffer collateral-CA1 synapses in $\alpha$-neurexin $\mathrm{KO}$ mice

3.2.3 Long-term potentiation (LTP) at at Schaffer collateral-CA1 75 synapses in $\alpha$-neurexin $\mathrm{KO}$ mice

3.3 Biochemical interaction of neurexins with RIM1 $\alpha$

$3.4 \quad$ Generation of $\alpha$-neurexin conditional knockout mice 86

3.4.1 Characterization of genomic clones 86 
3.4.2 Embryonic stem cell experiments $\quad 88$

3.4.3 Establishment of knock-in mouse line 93

3.4.4 Establishment of conditional knockout mouse line 96

4 Discussion 100

4.1 Neurexin $1 \alpha$ does not alter the functional properties of $\mathrm{N}$ - type 100 $\mathrm{Ca}^{2+}$ channels in HEK cells

4.2 Impaired synaptic transmission at hippocampal Schaffer 104 collateral-CA1 synapses in adult $\alpha$-neurexin double knockouts

4.3 Altered short-term synaptic plasticity at hippocampal Schaffer

105 collateral-CA1 synapses in adult $\alpha$-neurexin double knockouts

4.4 LTP at hippocampal Schaffer collateral-CA1 synapses in adult 107 $\alpha$-neurexin double knockouts

4.5 Phenotype of $\alpha$-neurexin KOs shows partial resemblance to RIM1 $\alpha \mathrm{KO}$

4.6 RIM1 $\alpha$ is a novel interaction partner of $\alpha$ - and $\beta$-neurexins 


\section{Abbreviations}

ACSF

AMBA

APS

ATP

bp

BSA

CA

cDNA

CMV

C-terminal

C-terminus

dATP

dCTP

dGTP

$\mathrm{dH}_{2} \mathrm{O}$

DKO

DL-APV

DMEM

DNA

D-PBS

DTT

dNTPs

dTTP

E. coli

EDTA

EGFP

fEPSP

et al.

ES cells
Artificial cerebrospinal fluid

Acrylamide/N,N'-methylene-bis-Acrylamide

Ammonium persulfate

Adenosine triphosphate

Base pair

Bovine serum albumin

Cornu ammonis, a region of hippocampus

Complementary DNA

Cytomegalovirus

at the $\mathrm{COOH}$-terminus of a protein

$\mathrm{COOH}$-terminus of a protein

Deoxyadenosine triphosphate

Deoxycytidine triphosphate

Deoxyguanosine triphosphate

Distilled $\mathrm{H}_{2} \mathrm{O}$

Double knockout

DL-2-Amino-5-phosphonovaleric acid

Dulbecco's Modified eagle Medium

Deoxyribonucleic acid

Dulbecco's PBS

Dithiothreitol

Deoxynucleotide triphosphates

Deoxythymidine triphosphate

Escherichia coli

Ethylenedinitrilo-tetraacetic acid

Enhanced Green Fluorescent Protein

Field excitatory postsynaptic potential

et alteres

Embryonic stem cells 
FCS

g

GABA

GFP

GST

HEK

HFS

IPTG

IRES

$\mathrm{kb}$

$\mathrm{kDa}$

$\mathrm{KO}$

LB

LB agar

LTP

MAGUK

MEF cells

NCBI

neoR

NGS

NMDA

Nrxn

$\mathrm{N}$-terminal

$\mathrm{N}$-terminus

OD

$\omega$-CTX

$\mathrm{o} / \mathrm{n}$

PAGE

PBS

PCR

$\mathrm{pH}$
Fetal calf serum

Gravitational acceleration, or gram

$\gamma$-aminobutyric acid

Green Fluorescent Protein

Glutathione-S-transferase

Human Embryonic Kidney

High frequency stimulus

Isopropyl-b-thiogalactopyranoside

Internal ribosomal entry site

Kilobase pair

Kilodalton

Knock-out

Luria-Bretani bacterial growing medium

Luria-Bretani bacterial growing agarose

Long-term potentiation

Membrane associated guanylate kinase

Mouse embryonic fibroblast cells

National Centre for Biotechnology Information

Neomycin resistance gene

Normal goat serum

$\mathrm{N}$-methyl-D-Aspartate

Neurexin

At the $\mathrm{NH}_{2}$-terminus of a protein

$\mathrm{NH}_{2}$-terminus of a protein

Optical density

$\omega$-conotoxin

Over night

Polyacrylamide gel electrophoresis

Phosphate buffer saline

Polymerase chain reaction

Negative logarithm of $\mathrm{H}^{+}$concentration 
PDZ

PPD

PPF

PTP

RIM

RT

SDS

SKO

STP

TK

TKO

Tris

U

UTR

UV

WT

$5^{\prime}$

$3^{\prime}$
Protein interaction domain, acronym for PSD-95, Dlg, ZO-1

Paired-pulse depression

Paired-pulse facilitation

Post-tetanic potentiation

Rab3-interacting molecule

Room temperature

Sodium dodecyl sulfate

Single knockout

Short-term potentiation

Thymidine kinase

Triple knockout

Tris-hydroxymethyl-aminomethane

Enzymatic unit

Untranslated region

Ultraviolet

Wild type

5 prime

3 prime 


\section{INTRODUCTION}

The brain mediates the complexities of our personalities, the thoughts we have and the emotions we feel. It underlies our sensory perceptions and much of our motor behaviour. We are quite sure of this, as we have come a long way since the debates about mind and matter among idealists and materialists. However as they say, the devil lies in the details. We still lack a lot in comprehensive understanding of almost all aspects of brain function. This project is a modest attempt to gain further knowledge about this 'universe within'.

The mammalian brain is a complex structure. It contains billions of basic units called neurons along with glial cells. Neurons are connected to each other through multiple synapses. The synapse is a structure specialized for information transfer between neurons. It is not a simple mediator of information and its efficacy is dependent on the history of its activity, giving rise to plasticity phenomena. The synapse performs all these functions on the basis of a complicated molecular organization.

A typical synapse is composed of three compartments: the presynaptic bouton, the synaptic cleft and the postsynaptic specialization. Synaptic transmission involves the release of neurotransmitter from the presynaptic bouton into the synaptic cleft, where it diffuses and binds to the receptors present on the postsynaptic membrane. The directional nature of synaptic transmission entails an asymmetric structure of the synapse. The postsynaptic specialization is localized to dendrites and cell body. It is characterized by a segment of plasma membrane containing an array of neurotransmitter receptors and by an underlying electron-dense thickening called postsynaptic density (PSD). The PSD consists of a scaffold of proteins that anchor the neurotransmitter receptors to the cytoskeleton and also perform signalling functions.

The presynaptic bouton is either present at the end of an axonal branch or along the axonal branch as a varicosity. The presynaptic bouton is characterized by the presence of numerous small ( $\sim 40 \mathrm{~nm}$ diameter) and electron-lucent organelles called synaptic vesicles. The synaptic vesicles serve to take up and release the neurotransmitter. Another characteristic feature of presynaptic boutons is the presence of active zones, which are specialized regions of presynaptic plasma membranes where synaptic vesicles fuse to release the neurotransmitters into the synaptic cleft (Landis et al., 1988; Dresbach et al., 2001; Harlow et al., 2001). The active zones contain an electron-dense meshwork of proteins, called cytoskeletal matrix at the 
active zone (CAZ). Cell adhesion molecules that bridge the synaptic cleft provide a link between the presynaptic and postsynaptic apparatus. They can potentially guide the development of the specializations on either side of synaptic cleft at the correct location. Many families of cell adhesion molecules have been found at synapses (Brose, 1999; Missler, 2003; Scheiffele, 2003; Yamagata et al., 2003). These are membranous proteins present on pre- or postsynaptic membranes and participate in a heterophilic or homophilic interaction with their partners on the opposite side of the synaptic cleft. These include cadherins (e.g Ncadherin and cadherin-related neuronal receptors, CNRs), immunoglobulin superfamily adhesion molecules (e.g. N-CAM, synCAM and L1), syndecans and neurexins-neuroligins.

The central function of the presynaptic bouton is to release the neurotransmitter in high spatial and temporal precision. This involves a series of coordinated steps. The arrival of an action potential at the presynaptic bouton causes depolarization which leads to the opening of voltage gated $\mathrm{Ca}^{2+}$ channels present at the active zone. The $\mathrm{Ca}^{2+}$ ions that move in then bind to a $\mathrm{Ca}^{2+}$ sensor residing on synaptic vesicles. The binding of $\mathrm{Ca}^{2+}$ to the $\mathrm{Ca}^{2+}$ sensor initiates a fusion reaction in which the readily releasable vesicles fuse with the plasma membrane, and release their content of neurotransmitter molecules into the synaptic cleft. After fusion-pore opening, synaptic vesicles endocytose and recycle by different pathways (Jahn and Sudhof, 1994; Sudhof, 2004).

The strength of synaptic transmission depends on the number of release sites $(\mathrm{N})$, the probability of release $\left(\mathrm{P}_{\mathrm{r}}\right)$ and the quantal size $(\mathrm{Q})$ (Regehr and Stevens, 2001). N is equivalent to the number of active zones that participate in release. $\mathrm{P}_{\mathrm{r}}$ is the probability that a synaptic vesicle will fuse with the plasma membrane in response to an action potential. Both $\mathrm{N}$ and $\mathrm{P}_{\mathrm{r}}$ are presynaptic determinants. $\mathrm{Q}$ is the size of the response of the postsynaptic cell upon the release of a single vesicle. Quantal size depends on both presynaptic (size of the vesicle, neurotransmitter amount within a vesicle) and postsynaptic (number and density of postsynaptic receptors) factors.

The probability of release $\left(\mathrm{P}_{\mathrm{r}}\right)$ varies widely among synapses (Hessler et al., 1993; Rosenmund et al., 1993; Allen and Stevens, 1994). Even presynaptic terminals formed by the same axon display different release probabilities depending on the target cell (Reyes et al., 1998; Scanziani et al., 1998; Gupta et al., 2000; Rozov et al., 2001). For example, the nerve terminals of layer $2 / 3$ pyramidal cells connected to bitufted interneurons show low release 
probability, while the nerve terminals of layer $2 / 3$ pyramidal cells connected to multipolar interneurons display high release probability (Rozov et al., 2001). This implies that the postsynaptic specialization provides a retrograde signal to the presynaptic bouton to define the release parameters. Some secreted molecules, e.g., nitric oxide (NO), neurotrophins and endocannabinoids released from postsynaptic side have been proposed as the retrograde messengers (Tao and Poo, 2001; Wilson and Nicoll, 2002). Another candidate for providing the retrograde signal are cell adhesion molecules linking the presynaptic active zone to the postsynaptic density.

$\alpha$ - and $\beta$-Neurexins are a family of synaptic cell adhesion molecules. Previous studies in our laboratory found that deletion of $\alpha$-neurexins in mouse caused a reduction in neurotransmitter release at synapses with evidence for impaired $\mathrm{Ca}^{2+}$ channel function at the presynaptic terminal (Missler et al., 2003). This makes $\alpha$-neurexins one of the candidate molecules that is involved in the organization and functional specialization of the presynaptic active zone.

\subsection{Molecular structure of neurexins}

Neurexins are cell surface proteins specifically expressed in neurons and neuroendocrine cells. Neurexins are encoded by 3 large genes in vertebrates (Nrxn1, Nrxn2 and Nrxn3). Each gene contains two promoters, an upstream promoter that directs the transcription of the larger $\alpha$-neurexins, and a promoter in the middle of the gene where the transcription of shorter $\beta$ neurexins is initiated (Rowen et al., 2002; Tabuchi and Sudhof, 2002). $\alpha$ - and $\beta$-neurexins are type I membrane proteins with a large extracellular region and a small intracellular part. $\alpha$ neurexins contain longer extracellular sequence than $\beta$-neurexins but both have the identical transmembrane region and intracellular part (Ushkaryov et al., 1992; Missler and Sudhof, 1998b) (Figure 1.1). 


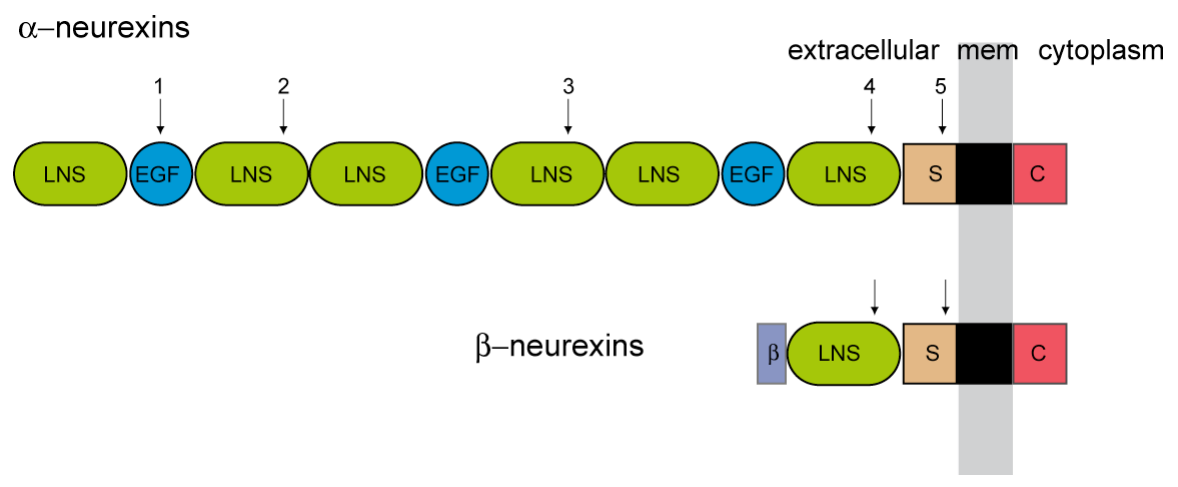

Figure 1.1 The domain structure of $\alpha$ - and $\beta$-neurexins. The extracellular region of $\alpha$ neurexins consists of three overall repeats. Each repeat contains two LNS domains and a central EGF-like domain. The three LNS-EGF-LNS repeats in $\alpha$-neurexins are followed by a serine-threonine rich sequence (abbreviated $S$ ) that is O-glycosylated. The extracellular region of $\beta$-neurexins has a single LNS domain preceded by a short $\beta$-specific sequence (abbreviated $\beta$ ). The intracellular region of $\alpha$ - and $\beta$-neurexins is identical (abbreviated $C$ ). Arrows indicate the sites for alternative splicing.

The transcripts of neurexins are alternatively spliced extensively, giving rise to thousands of potential isoforms. There are 5 positions for alternative splicing in $\alpha$-neurexins and 2 in $\beta$ neurexins (Missler et al., 1998a). The positions for alternative splicing as well as the splice insert sequences are evolutionary conserved, pointing to a functional role for this alternative splicing. $\alpha$-neurexins are evolutionary conserved but $\beta$-neurexins are not (Tabuchi and Sudhof, 2002). As compared to three Nrxn genes in vertebrates, Caenorhabditis elegans and Drosophila melanogaster have one Nrxn gene that only codes for an $\alpha$-neurexin-like molecule.

Neurexins are expressed throughout the brain with differential and overlapping distribution of different isoforms (Ullrich et al., 1995). In-situ hybridization studies in hippocampus also show a mixed distribution of neurexins. CA1 pyramidal cells express neurexin $1 \alpha, 2 \alpha, 2 \beta$ and $3 \beta$ but lack neurexin $3 \alpha$ and $1 \beta$. The interneurons in CA1 region express all three $\alpha$-neurexins and neurexin $3 \beta$. CA3 pyramidal neurons express all six principal neurexin isoforms (Ullrich et al., 1995). This implies that Schaffer collaterals, which are axons from CA3 pyramidal cells might contain all six principal neurexin isoforms. In addition to brain, neurexins are also expressed in spinal cord motor neurons (Sons et. al., 2006) and neuroendocrine cells (Dudanova, Sedej, Ahmad et al., manuscript submitted). In brain, neurexins have been shown 
to be enriched at synapses by immunolocalization studies (Ushkaryov et al., 1992; Dean et al., 2003), and biochemical fractionation methods (Butz et al., 1998). They are believed to be localized at presynaptic boutons on the basis of the action of their ligand $\alpha$-latrotoxin, which causes massive neurotransmitter release from presynaptic terminals (Ushkaryov et al., 1992; Sugita et al., 1999). However a precise ultrastructural localization of neurexins has not been published. The developmental expression of neurexins follows synaptogenesis. Their levels increase dramatically after birth and reach peak expression during the second postnatal peak, which is a period of intense synaptogenesis. The levels then decrease to reach a steady level in older animals (Puschel and Betz, 1995; Sugita et al., 2001).

The particular domain structure of neurexins points towards its role as a receptor for ligands. Some interaction partners for $\alpha$ - and $\beta$-neurexins have been discovered. Extracellularly $\alpha$ and $\beta$-neurexins bind to cell surface protein dystroglycan (Sugita et al., 2001) and to the exogenous toxin, $\alpha$-latrotoxin (Ushkaryov et al., 1992; Sugita et al., 1999). $\beta$-neurexins have been shown to bind to the cell surface protein neuroligin (Ichtchenko et al., 1995, 1996). A recent report described the binding of $\alpha$-neurexins also to neuroligins (Boucard et al., 2005). In addition, $\alpha$-neurexins but not $\beta$-neurexins interact with a secreted protein called neurexophilin (Missler and Sudhof, 1998a; Missler et al., 1998b; Beglopoulus et al., 2005). The interactions of neurexins with dystroglycan and neuroligins might be involved in providing trans-synaptic adhesion.

The intracellular region of $\alpha$ - and $\beta$-neurexins is identical. It has the terminal -EYYV sequence which is predicted to be a class II-PDZ binding motif (Hung and Sheng, 2002). Two MAGUK proteins, CASK and Mint have been found to associate with neurexins at their PDZ domains (Hata et al., 1996; Butz et al., 1998; Biederer and Sudhof, 2000). Many other interaction partners for CASK and Mint have also been found (Cohen et al., 1998; Hsueh et al., 1998; Setou et al., 2000; Tabuchi et al., 2002). One important interaction partner is $\alpha 1 \mathrm{~B}$ $\mathrm{Ca}^{2+}$ channel subunit which interacts through a proline-rich sequence to the $\mathrm{SH} 3$ domain of CASK and through the C-terminus to the PDZ domain of Mint1 (Maximov et al., 1999). Importantly, CASK and Mint1 also interact with each other (Butz et al., 1998), thus forming a potential complex of these adaptor proteins with neurexins and $\mathrm{Ca}^{2+}$ channel subunits. Inspite of the detailed genetic and biochemical information about neurexins, there was serious lack of functional data about the physiological role of $\alpha$-neurexins until recently. 


\subsection{The role of $\alpha$-neurexins in neurotransmitter release}

To gain insight into the functions of $\alpha$-neurexins, knockout mice were generated that had deletion of one, two or all three $\alpha$-neurexins (Missler et al., 2003). $\alpha$-Neurexin deficient mice have impaired postnatal survival. Triple knockout mice die on the first day of birth due to respiratory problems, and most double knockout mice die within the first week. The survival is in the order of neurexin $2 \alpha / 3 \alpha \mathrm{KO}>$ neurexin $1 \alpha / 2 \alpha \mathrm{KO}>$ neurexin $1 \alpha / 3 \alpha$. Only a few double $\mathrm{KO}$ mice survive to adulthood. The neurexin $2 \alpha$ single $\mathrm{KO}$ has the best survival, quite similar to a wildtype mouse. Morphological analysis of the brains did not reveal any gross anatomical defects. Ultrastructural studies of synapses demonstrated no abnormalities in the structure of asymmetric type I and symmetric type II synapses. The size of the active zone, vesicle numbers or vesicle size, and the width of synaptic cleft were not altered. The only ultrastructural change that was detected was a $50 \%$ decrease in the number of symmetric (inhibitory) synapses in the brainstem and neocortex of neonatal triple $\mathrm{KO}$ and adult neurexin $1 \alpha / 2 \alpha \mathrm{KO}$ mice respectively. There was no change in the number of asymmetric (excitatory) synapses. These results suggested that $\alpha$-neurexins are not essential for synapse formation and maintenance. Since their discovery, the cell surface expression and multiple isoforms of neurexins has indicated that they might be the molecules which provide the combinatorial code for synaptic recognition and development. These results suggested otherwise. However $\beta$-neurexins are still expressed in these mice and the lack of a strong affect on synaptogenesis might be because of redundancy between $\alpha$ - and $\beta$-neurexins.

Synaptic transmission in $\alpha$-neurexin deficient animals was investigated using two systems: cultured slices from neocortex and acute slices from brainstem. Neurexin $1 \alpha / 2 \alpha \mathrm{KO}$, neurexin $2 \alpha / 3 \alpha \mathrm{KO}$, and triple $\mathrm{KO}$ mice were used for experiments, with neurexin $2 \alpha$ single $\mathrm{KO}$ acting as littermate control. Whole-cell patch-clamp recordings from neocortex demonstrated that evoked neurotransmitter release was severely reduced (by 95\%) in triple $\mathrm{KO}$ mice at inhibitory GABAergic synapses (Figure 1.2A). Also the frequency of spontaneous miniature postsynaptic currents (minis), both $\mathrm{GABA}_{\mathrm{A}^{-}}$and AMPA-receptor mediated, was reduced. This implied that deletion of $\alpha$-neurexins impaired synaptic transmission at both excitatory and inhibitory synapses and the defect lay on the presynaptic side. There was no change in the amplitude of minis, indicating that factors influencing quantal size (size and content of vesicles, and postsynaptic receptors) were not grossly altered. The reduced release from the 
presynaptic boutons could be due to a reduction in the sites mediating release or a decrease in release probability. The decrease in the density of GABAergic synapses might have contributed to the decrease in the frequency of $\mathrm{GABA}_{\mathrm{A}}$-receptor-dependent minis. However a similar change in AMPA-receptor-dependent mini frequency without a change in the density of excitatory synapses suggested that the decrease in synaptic transmission was caused by a decrease in release probability of synapses. Similar results were obtained from excitatory and inhibitory synapses from brainstem (Figure 1.2B).

A

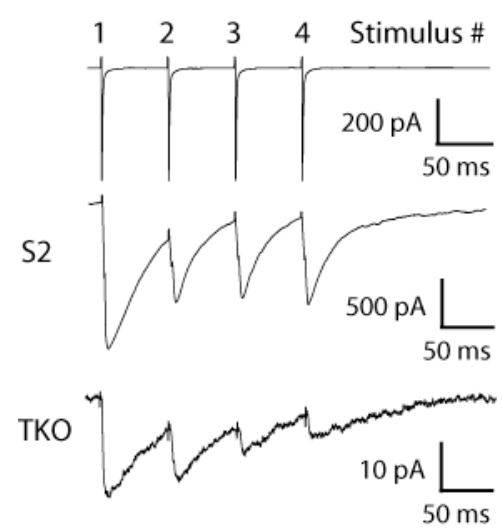

B

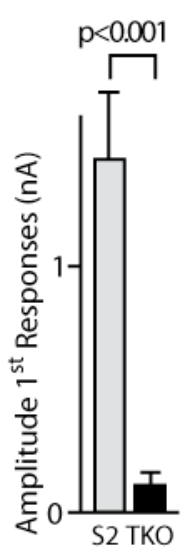

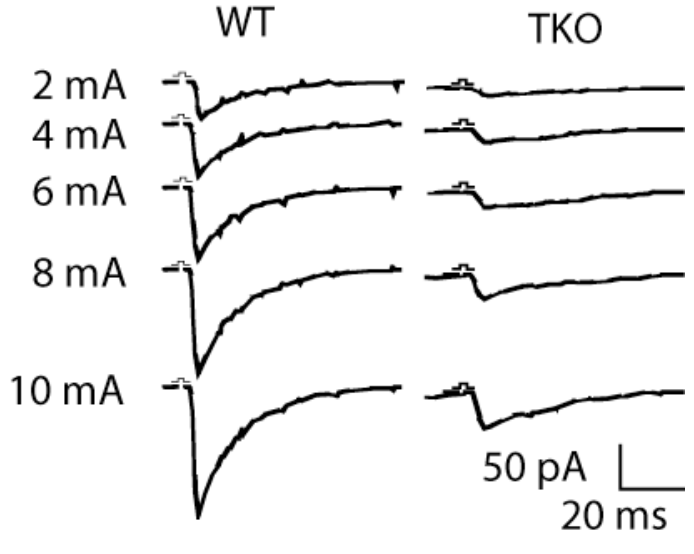

Figure 1.2 The evoked release is reduced in $\alpha$-neurexin deficient synapses (Missler et al., 2003). (A) Paired recordings of evoked $G_{A B A}$-receptor-mediated postsynaptic currents in pyramidal neurons of cultured neocortical slices from neurexin $2 \alpha \mathrm{KO}$ (S2) and triple KO TKO) mice. (B) Glutamatergic evoked responses in hypogoglossal motor neurons after field stimulation of axons from the pre-Bötzinger complex.

The transgenic neurexin $1 \alpha: H R P$ allele crossed into various $\alpha$-neurexin KO mice, partly rescued the impaired synaptic transmission in the brainstem (Zhang et al., 2005). Both evoked and spontaneous release were improved, confirming that $\alpha$-neurexins are directly involved in maintaining neurotransmission. In contrast to the extensive characterization of basal synaptic transmission in $\alpha$-neurexin KOs, very little was studied in terms of synaptic plasticity. The only feature studied was the response to a short train of stimuli at GABAergic synapses in neocortical slices. $\alpha$-neurexin triple KOs showed enhanced depression in response to a short train (Missler et al., 2003). More detailed study of synaptic plasticity, both short-term and long-term is required to clarify the role $\alpha$-neurexins play at the synapse. 
To understand the reasons underlying reduced synaptic transmission, response of neocortical GABAergic synapses to hypertonic sucrose was measured. The sucrose response was moderately reduced (by 30\%) in triple KO mice. This result could be explained by smaller pool of readily releasable vesicles in triple KO neurons. However the decrease in evoked response (by 95\%) was much severe than this reduction in sucrose response (by 30\%). Rather this moderate defect resembled the decrease in the number of GABAergic synapses (by $50 \%$ ). The next step to be investigated was the $\mathrm{Ca}^{2+}$ triggering of exocytosis. It was found that neocortical synapses from triple KO mice showed reduced sensitivity to $\omega$-conotoxin GVIA (Figure 1.3A). Since $\omega$-conotoxin GVIA is a specific blocker of $\mathrm{N}$-type of $\mathrm{Ca}^{2+}$ channels which are involved in mediating neurotransmitter release, its application should reduce synaptic transmission. However very little decrease in release was seen in triple KO mice upon application of $\omega$-conotoxin GVIA. Similar effect was seen on evoked and spontaneous release at brainstem synapses. These results demonstrated that deletion of $\alpha$-neurexins causes a strong defect in $\mathrm{Ca}^{2+}$ triggering of exocytosis.

A
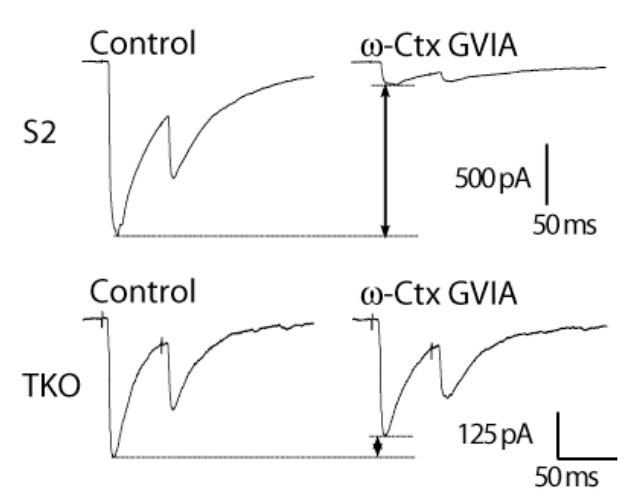

B

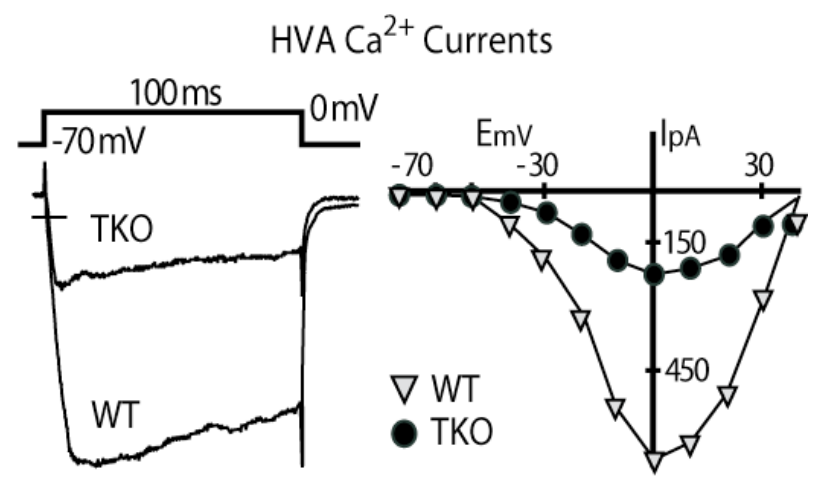

Figure 1.3 Impaired $\mathrm{Ca}^{2+}$ channels in $\alpha$-neurexin knockout mice (Missler et al., 2003). (A) Reduced sensitivity of neurotransmitter release to $\omega$-conotoxin GVIA on GABAergic synaptic responses in pyramidal neurons of cultured neocortical slices from triple KO (TKO) mice as compared to neurexin $2 \alpha \mathrm{KO}$ (S2). (B) $\mathrm{Ca}^{2+}$ current densities are reduced in the brainstem neurons from triple KO (TKO) mice as compared to wild type (WT).

There are two possibilities of how this could happen. 1) The presynaptic $\mathrm{Ca}^{2+}$ channels are reduced or functionally impaired. 2) The coupling of $\mathrm{Ca}^{2+}$ channels to the release machinery is disturbed. The expression of N-type $\mathrm{Ca}^{2+}$ channels was measured in brain membrane 
fractions using ${ }^{125}$ I-labelled $\omega$-conotoxin GVIA. The levels of $\mathrm{N}$-type $\mathrm{Ca}^{2+}$ channels were found to be similar between wild type and $\alpha$-neurexin deficient mice. The membrane expression of $\mathrm{N}$-type $\mathrm{Ca}^{2+}$ channels was also found to be normal in hippocampal cultures derived from $\alpha$-neurexin KO mice. The idea that deletion of $\alpha$-neurexins causes a functional impairment of $\mathrm{Ca}^{2+}$ channels was suggested by the finding that whole-cell $\mathrm{Ca}^{2+}$ currents recorded from the soma of neurons in the brainstem were reduced in triple $\mathrm{KO}$ mice as compared to controls (Figure 1.3B). The amplitude of all types of $\mathrm{Ca}^{2+}$ channel currents tested (L-, N- and P/Q-type) was reduced. N-type of $\mathrm{Ca}^{2+}$ channels were the most severely affected and almost completely abolished. Moreover, transgenic neurexin $1 \alpha:$ HRP allele crossed into various $\alpha$-neurexin $\mathrm{KO}$ mice, partly rescued the decrease in whole-cell currents. Both N-type and P/Q-type currents (but not L-type currents) were improved (Zhang et al., 2005). These results implied that $\alpha$-neurexins might be positive modulators of the activity of $\mathrm{Ca}^{2+}$ channels, and the deletion of $\alpha$-neurexins removes this positive influence, thereby inhibiting the $\mathrm{Ca}^{2+}$ channels. To investigate this hypothesis, it is important to test the direct effect of $\alpha$-neurexins on $\mathrm{Ca}^{2+}$ channels in a minimalistic and easily accessible system.

\subsection{Aims of the present study}

In order to better understand the function of $\alpha$-neurexins at synapses, we have followed two approaches. One is a reductionist approach, to investigate the action of $\alpha$-neurexins at the mechanistic level, i.e. to study whether biophysical properties of $\mathrm{Ca}^{2+}$ channels are regulated by $\alpha$-neurexins. The heterologous expression system, e.g. HEK293 cell line, is a simple system to investigate the basic features of interaction at the functional level and was used for this purpose. The other is a more in-vivo approach to understand the action of $\alpha$-neurexins at the network level. Electrophysiological recordings were done from acute hippocampal slices derived from adult $\alpha$-neurexin knockout mice to understand the role of $\alpha$-neurexins in shortterm and long-term synaptic plasticity. Since the investigation of $\alpha$-neurexin function using adult $\alpha$-neurexin $\mathrm{KO}$ mice is limited to the use of surviving double $\mathrm{KO}$ mice, we have overcome this limitation by generating a conditional knockout mouse line of neurexin $1 \alpha$ to obtain deletion of all three $\alpha$-neurexins in the hippocampus of an adult animal. 


\subsubsection{Solutions and media for molecular biology}

TAE buffer $50 x$ (for $1 \mathrm{~L}$ )

$242.28 \mathrm{~g}$ Tris, $18.61 \mathrm{~g}$ EDTA-Na $2,40 \mathrm{ml}$ Acetic acid, $\mathrm{pH} 8.5$

10x DNA loading buffer

$100 \mathrm{mM}$ Tris (pH 8.0), $10 \mathrm{mM}$ EDTA (pH 8.0), 57\% glycerol, bromophenol blue

TE buffer

$10 \mathrm{mM}$ Tris (pH 8.0), 1 mM EDTA (pH 8.0)

\section{LB medium}

$20 \mathrm{~g} \mathrm{LB}$ broth base (Invitrogen) dissolved in 1 Liter $\mathrm{dH}_{2} \mathrm{O}$, autoclaved and kept at room temperature. Composition: $1 \%$ SELECT peptone 140, 0.5\% SELECT yeast extract, $0.5 \%$ $\mathrm{NaCl}$

\section{LB agar plates}

$32 \mathrm{~g} \mathrm{LB}$ agar powder (Invitrogen) dissolved in $1 \mathrm{Liter}^{\mathrm{d}} \mathrm{d}_{2} \mathrm{O}$ and autoclaved. The solution cooled till hand warm, antibiotics added at $50 \mu \mathrm{g} / \mathrm{ml}$ final concentration and poured into 100 $\mathrm{mm}$ plates. Plates kept at room temperature till agar solidify and then stored at $4^{\circ} \mathrm{C}$. Composition: $1 \%$ SELECT peptone $140,0.5 \%$ SELECT yeast extract, $0.5 \% \mathrm{NaCl}, 1.2 \%$ SELECT agar

SNET buffer (for $1 \mathrm{~L})$

$1.86 \mathrm{~g} \mathrm{Na}_{2}$ EDTA.2 $\mathrm{H}_{2} \mathrm{O}, 10 \mathrm{~g}$ SDS, $23.4 \mathrm{~g} \mathrm{NaCl}, 20 \mathrm{mM}$ Tris (pH 8.0)

5x PCR buffer for Red Taq polymerase

$83 \mathrm{mM}\left(\mathrm{NH}_{4}\right)_{2} \mathrm{SO}_{4}, 335 \mathrm{mM}$ Tris $(\mathrm{pH} \quad 8.8), 33.5 \mathrm{mM} \mathrm{MgCl} \mathrm{Mg}_{2} \cdot 6 \mathrm{H}_{2} \mathrm{O}, 25 \mathrm{mM} \beta-$ mercaptoethanol, $33.5 \mu$ M EDTA $\cdot \mathrm{Na}_{2} \cdot 2 \mathrm{H}_{2} \mathrm{O}$ 
For Southern blot and colony hybridization

Denaturing buffer

$1.5 \mathrm{M} \mathrm{NaCl}, 0.5 \mathrm{M} \mathrm{NaOH}$

Neutralization buffer

$1.5 \mathrm{M} \mathrm{NaCl}, 1 \mathrm{M}$ Tris

20x SSC buffer

$0.3 \mathrm{M}$ Tri-sodium citrate. $2 \mathrm{H}_{2} \mathrm{O}, 3 \mathrm{M} \mathrm{NaCl}, \mathrm{pH} 7.0$

$50 \%$ Hybe buffer

$50 \mathrm{ml}$ Denhardt's buffer 100x, $150 \mathrm{ml}$ 10\% SDS, $500 \mathrm{ml}$ formamide, $250 \mathrm{ml}$ 20x SSPE, $50 \mathrm{ml}$ $\mathrm{dH}_{2} \mathrm{O}, \mathrm{pH}$ 7.0-7.4.

20x SSPE buffer

$3 \mathrm{M} \mathrm{NaCl}, 0.2 \mathrm{M} \mathrm{NaH}_{2} \mathrm{PO}_{4} \cdot \mathrm{H}_{2} \mathrm{O}, 0.02 \mathrm{M}$ EDTA, $\mathrm{pH}$ 7.0-7.4

100x Denhardt's buffer

$0.02 \%$ Polyvinylpyrrolidon, $0.02 \%$ BSA, $0.02 \%$ Ficoll400

Salmon sperm DNA

Dissolved in $\mathrm{dH}_{2} \mathrm{O}$ at $1 \%$ concentration, sonicated $3 \times 40 \mathrm{sec}$ at power 50 , cycle $50 \%$ and stored at $-20^{\circ} \mathrm{C}$. Before use DNA was denatured at $100^{\circ} \mathrm{C}$ for $5-10$ minutes.

\subsubsection{Solutions for biochemistry}

Upper Tris (for stacking gel)

0.5 M Tris (pH 6.8), $0.4 \%$ SDS

Lower Tris (for seperation gel)

1.5 M Tris (pH 8.8), 0.4\% SDS

SDS-PAGE running buffer 10x (for $1 \mathrm{~L}$ )

$30 \mathrm{~g}$ Tris, $144 \mathrm{~g}$ Glycine (adjusted to $\mathrm{pH}$ 8.8), then add $10 \mathrm{~g}$ SDS 
Transfer buffer (for $1 \mathrm{~L}$ )

$80 \%$ of solution $(3 \mathrm{~g} / \mathrm{L}$ Tris, $14.4 \mathrm{~g} / \mathrm{L}$ Glycine), $20 \%$ methanol

$2 x$ protein sample buffer

$20 \%$ glycerol, $4.6 \%$ SDS, $0.125 \mathrm{M}$ Tris $\mathrm{pH}$ 6.8, 5\% $\beta$-mercaptoethanol, bromophenol blue

Coomassie stain

$25 \%$ isopropanol, $10 \%$ acetic acid, $0.05 \%$ Coomassie

Ponceau-S stain

$0.2 \%$ Ponceau-S, $5 \%$ acetic acid

\section{Blocking buffer}

5\% milk powder, 5\% normal goat serum in PBS-Tween.

\subsubsection{Solutions and media for cell culture}

HEK293_Ca 2.2 cell culture medium

\begin{tabular}{|l|l|}
\hline $20 \mathrm{ml}$ & Fetal bovine serum \\
\hline $2 \mathrm{ml}$ & L-Glutamine $200 \mathrm{mM}$ \\
\hline $2 \mathrm{ml}$ & $\begin{array}{l}\text { penicillin }(10000 \text { units } / \mathrm{ml}) \\
\text { /streptomycin }(10000 \mathrm{mg} / \mathrm{ml})\end{array}$ \\
\hline $0.4 \mathrm{ml}$ & Hygromycin B $50 \mathrm{mg} / \mathrm{ml}$ \\
\hline Upto $200 \mathrm{ml}$ & DMEM \\
\hline
\end{tabular}

tsA201 cell culture medium

\begin{tabular}{|l|l|}
\hline $20 \mathrm{ml}$ & Fetal bovine serum \\
\hline $4 \mathrm{ml}$ & $\begin{array}{l}\text { penicillin }(5000 \text { units } / \mathrm{ml}) \\
/ \text { streptomycin }(5000 \mathrm{mg} / \mathrm{ml})\end{array}$ \\
\hline Upto $200 \mathrm{ml}$ & DMEM \\
\hline
\end{tabular}

$2 x$ freezing medium

$60 \%$ cell culture medium, $20 \%$ fetal bovine serum, $20 \%$ DMSO 
$\underline{\text { For Embryonic stem (ES) cell culture }}$

\section{DMEM preparation}

The stock medium (Gibco) in the form of powder was used to prepare DMEM. $13.38 \mathrm{~g}$ of powder was mixed with $2.3 \mathrm{~g}$ of sodium bicarbonate and cell culture grade water was added till 1.08 Liter. The solution was filter purified and stored at $4{ }^{\circ} \mathrm{C}$ for upto 4 weeks.

\section{ES cell medium}

\begin{tabular}{|l|l|}
\hline $500 \mathrm{ml}$ & DMEM preparation \\
\hline $95 \mathrm{ml}$ & Fetal calf serum \\
\hline $6 \mathrm{ml}$ & MEM-non essential amino acids \\
\hline $6 \mathrm{ml}$ & $\begin{array}{l}\beta \text {-mercaptoethanol solution }(7 \mathrm{ml} \beta \text {-mercaptoethanol in } \\
10 \mathrm{ml} \text { PBS })\end{array}$ \\
\hline $3.3 \mathrm{ml}$ & penicillin $(10000$ units $/ \mathrm{ml}) /$ streptomycin $(10000 \mathrm{mg} / \mathrm{ml})$ \\
\hline $63 \mathrm{ml}$ & Leukemia inhibitory factor $($ LIF $)\left(10^{7}\right.$ units $\left./ \mathrm{ml}\right)$ \\
\hline
\end{tabular}

$2 x$ freezing medium

$60 \%$ ES cell medium, 20\% fetal calf serum, 20\% DMSO

Lysis buffer for 96-well DNA preparation

$10 \mathrm{mM}$ Tris (pH 7.5), $10 \mathrm{mM}$ EDTA, $10 \mathrm{mM} \mathrm{NaCl}, 0.5 \%$ N-lauroylsarcosine (sodium salt), $0.1 \%$ Proteinase K (added just before use).

\subsubsection{Solutions for electrophysiology}

HEK293_Ca 2.2 external bath solution (in $\mathrm{mM}$ )

$140 \mathrm{NaCl}, 10 \mathrm{BaCl}_{2}, 1 \mathrm{MgCl}_{2}, 10$ Hepes, 10 Glucose (7.4 pH, $312 \mathrm{mOsm} / \mathrm{kg}$ osmolarity)

HEK293_Ca 2.2 internal pipette solution (in $\mathrm{mM}$ )

125 Cesium methane sulphonate, 20 TEA-Cl, 5 EGTA, $2 \mathrm{MgCl}_{2}$, 10 Hepes, 4 Na-ATP, 0.5 Na-GTP (7.4 pH, $280 \mathrm{mosm} / \mathrm{kg}$ osmolarity) 
$65 \mathrm{CsCl}, 40 \mathrm{TEA}-\mathrm{Cl}, 20 \mathrm{BaCl}_{2}$ or $10 \mathrm{CaCl}_{2}$ (as indicated), $1 \mathrm{MgCl}_{2}$, 10 Hepes, 10 Glucose $(\mathrm{pH} 7.2)$

tsA201 internal pipette solution (in $\mathrm{mM}$ )

108 Cesium methane sulphonate, $4 \mathrm{MgCl}_{2}$, 9 EGTA, 9 Hepes

Artificial cerebrospinal fluid (ACSF)- bath solution for extracellular recordings (in $\mathrm{mM}$ )

$130 \mathrm{NaCl}, 3.5 \mathrm{KCl}, 1.2 \mathrm{CaCl}_{2}, 1.2 \mathrm{MgSO}_{4}, 1.25 \mathrm{NaH}_{2} \mathrm{PO}_{4}, 24 \mathrm{NaHCO}$, 10 Dextrose (constantly aerated with $95 \% \mathrm{O}_{2}-5 \% \mathrm{CO}_{2}$ )

\subsubsection{DNA material}

\subsubsection{Vectors}

\begin{tabular}{ll}
\hline pBluescript II SK & Stratagene, La Jolla, California, USA \\
pCMV5 & Kindly provided by Dr. David Russel, UTSW, Dallas, Texas, USA \\
pTKNeolox & Kindly provided by Dr. TC Südhof, UTSW, Dallas, Texas, USA \\
pIRES-hrGFP-1a & Stratagene, Heidelberg, Germany \\
pEGFP-C1 & BD Biosciences, Heidelberg, Germany \\
pET-42b(+) & Novagen, Madison, Wisconsin, USA \\
pGex KG & Amersham Pharmacia Biotech, Little Chalfont, UK \\
\hline
\end{tabular}

\subsubsection{2 cDNA plasmids}

pCMV- Nrxn1 $\alpha$

pCMV- Flag Nrxn1 $\alpha$

pCMV-Nrxn1 $\alpha$-IRES-GFP

pCMV-Flag Nrxn1 $\alpha$-IRESGFP

pCMV-N EGFP-Nrxn1 $\alpha$

pCMV-Nrxn1 $\beta$
cDNA of rat Nrxn $1 \alpha$, kindly provided by Dr. TC Südhof, UTSW, Dallas, Texas, USA

cDNA of rat Nrxn1 $\alpha$ with a Flag epitope after the signal peptide, generated by $\mathrm{H}$. Masius, AG Missler, Goettingen

cDNA of rat Nrxn $1 \alpha$ in an IRES-GFP vector (pIRES-hrGFP-1a), generated by $\mathrm{H}$. Masius, AG Missler, Goettingen

cDNA of rat Flag-Nrxn $1 \alpha$ in an IRES-GFP vector (generated in this study, see 2.1.5.5)

cDNA of rat Nrxn $1 \alpha$ with EGFP after the signal peptide, generated by $\mathrm{H}$. Masius, AG Missler, Goettingen

cDNA of rat Nrxn $1 \beta$, kindly provided by Dr. TC Südhof, UTSW, Dallas, Texas, USA 
pCMV-N EGFP-Nrxn1 $\beta$

PCMV-CASK

pCMV-Mint1

pa1B ${ }^{\text {rat }}$

$\mathrm{p} \beta 1 b^{\text {rat }}$

pa2 $\delta^{\text {rat }}$

pGEX-Nrx1

pCMV-RIM1(1-730)

pCMV-Myc RIM1 (1-730)

pCMV-Myc RIM1 $\triangle$ PDZ

pET-RIM1-PDZ

pCMV-NL1
cDNA of rat Nrxn1 $\beta$ with EGFP after the signal peptide, generated by $\mathrm{H}$. Masius, AG Missler, Goettingen

cDNA of rat CASK, kindly provided by Dr. TC Südhof, UTSW, Dallas, Texas, USA

cDNA of rat Mint1, kindly provided by Dr. TC Südhof, UTSW, Dallas, Texas, USA

cDNA of rat $\mathrm{Ca}_{\mathrm{v}} 2.2$ a1B subunit, kindly provided by Dr. T. Snutch, University of British Columbia, Canada

cDNA of rat $\beta 1 \mathrm{~b}$ subunit, kindly provided by $\mathrm{Dr}$. T. Snutch, University of British Columbia, Canada

cDNA of rat $\alpha 2 \delta$ subunit, kindly provided by Dr. T. Snutch, University of British Columbia, Canada

cDNA of rat $C$ terminus of neurexin 1 fused to GST, kindly provided by Dr. TC Südhof, UTSW, Dallas, Texas, USA

cDNA of rat RIM1 C-terminal truncated, includes the zinc finger and PDZ domains, kindly provided by Dr. TC Südhof, UTSW, Dallas, Texas, USA

cDNA of rat RIM1 C-terminal truncated, fused to the myc epitope at the Nterminus, includes the zinc finger and PDZ domains (generated in this study, see 2.1.5.5)

cDNA of rat RIM1 fused to the myc epitope at the N-terminus, without the PDZ and C2A domains (generated in this study, see 2.1.5.5)

cDNA of rat RIM1 PDZ fused to GST (generated in this study, see 2.1.5.5)

cDNA of rat Neuroligin 1, kindly provided by Dr. N. Brose, MPI Experimental Medicine, Goettingen

\subsubsection{Genomic clones}

pmYLL3-1b

pmYLL13-1

pmYLL14\#A
Genomic clone of 5' end of mouse Nrxn1 gene, cloned into pBluescript vector. It includes the 5' half of first coding exon of Nrxn $1 \alpha$. Kindly provided by Dr. TC Südhof, UTSW, Dallas, Texas, USA

Genomic clone of 5' end of mouse Nrxn1 gene, cloned into pBluescript vector. It includes the 3' half of first coding exon of Nrxn $1 \alpha$. Kindly provided by Dr. TC Südhof, UTSW, Dallas, Texas, USA

Genomic clone of $5^{\prime}$ end of mouse Nrxn1 gene, cloned into pBluescript vector. It includes the 3' half of first coding exon of Nrxn $1 \alpha$. Kindly provided by Dr. TC Südhof, UTSW, Dallas, Texas, USA

\subsubsection{Oligonucleotides $\left(5^{\prime} \rightarrow 3^{\prime}\right)$}




\begin{tabular}{|c|c|}
\hline & ATGTATGCTATACGAAGTTATG \\
\hline MM02-30/3795 & $\begin{array}{l}\text { GATCCATAACTTCGTATAGCATACATTATACGAAGTTATTGTCTTGAA } \\
\text { ACATCTCACACTGTAACGCGTG }\end{array}$ \\
\hline MM02-21/3727 & CGGATATCTTATGGCTGCAGGTCGAGCAGTG \\
\hline MM02-22/3728 & GGGATATCATCCTGCAGGATGCATATAACTTCG \\
\hline MM03-11/3975 & GGCTGATGGTGAGAATGTATC \\
\hline MM03-16/4062 & GGACCCCCATTTCTCTGTGAAG \\
\hline MM03-17/4063 & GCCTTCACCCAGAGGCTTCCG \\
\hline MM02-31/3802 & CCATCAGCATTGTTCTGAACATTC \\
\hline MM02-32/3803 & CCAAGCCAAGCCAATACTTCTG \\
\hline MM03-55/4874 & CAGTTAAGAGTGAAGAAAGCCTGC \\
\hline MM03-56/4875 & CTTCTGGGAAGACAGACTATGCC \\
\hline 2875 & TGGCTCGTCCTGCAGTTCATTC \\
\hline MM03-57/4897 & GGTATTGCTGCTGTGTTCCAGAAG \\
\hline 1948 & TATCGCCGCTCCCGATTCGCAGC \\
\hline MM04-33/6116 & GGCTGATGGTGAGAATGTATCAGTC \\
\hline MM04-34/6117 & CCAAGCCAATACTTCTGGGAAGAC \\
\hline MM05-93/7633 & GGGAGGTAGGAAGAGCGATG \\
\hline MM05-94/7634 & CCATGAGTGAACGAACCTGG \\
\hline MM05-183/8341 & CCGAATTCGCATCCTGTAACGTGGCAGCCGTC \\
\hline MM05-184/8342 & CCGTCGACCCTTGAAACAATAATCTCAACTTG \\
\hline MM05-206/8499 & CCGAATTCCGCATCCTGTAACGTGGCAGCCGTC \\
\hline MM05-208/8501 & CCGTCGACTTACCTTGAAACAATAАTCTCAАCTTG \\
\hline
\end{tabular}

\subsubsection{Newly constructed clones}

Neurexin $1 \alpha$ conditional knockout vector

The targeting vector for the conditional knock-out of neurexin $1 \alpha$ gene was designed to include $11.1 \mathrm{~kb}$ of genomic DNA so as to provide sufficient region for homologous recombination to take place. The cloning strategy involved the sequential addition of the desired elements into the pTKNEOlox plasmid. It was done in the following steps: 
1) The $5.9 \mathrm{~kb}$ Nhe1-Not1 fragment from $\mathrm{p} 3-1 \mathrm{~b}$ was excised and ligated into Nhe1-Not1 digested pTKNEOlox. This was named pTK3-1b. This led to the excision of Neomycin resistance cassette and the loxP sites from the plasmid.

2) Insertion of 5' loxP site

- A construct having the loxP sequence (5'-BamHI-MluI-spacer-loxP-BamHI-3') was made by adaptor duplex cloning using the primers, MM02-29/3794 and MM02$30 / 3795$.

- The adaptor duplex was ligated into BamH1 in pTK3-1b. This generated pTK31b5'loxP. The insertion was checked by Mlu1 and the orientation of the insert by MluI-XbaI (in the right orientation, the $1 \mathrm{~kb}$ band runs lower).

3) Insertion of NeoR cassette with 3' loxP

- An ERI deletion clone of pBluescipt was made by digesting with ERI, blunt-ending and religating. The clone was named pBS $\triangle E R I$.

- The $5.2 \mathrm{~kb}$ NotI fragment from p13-1 was cloned into NotI of pBS $\Delta$ ERI. The clone was named as p13-1/BS $\Delta \mathrm{ERI}$.

- Neomycin resistance cassette along with the $3^{\prime}$ loxP site was amplified by PCR from pTKNEOlox as 5'-EcoRV-neo-loxP-EcoRV-3'. The primers that were used were MM02-21/3727 and MM02-22/3728. The amplified product was ligated into bluntended EcoRI site of p13-1/BS $\triangle$ ERI. The orientation was checked with NdeI-MluI (in the right orientation, there was a $0.9 \mathrm{~kb}$ band in contrast to the $1.8 \mathrm{~kb}$ band in the opposite orientation). This created p13-1NeoloxP/BS $\Delta$ ERI. The clone was sent for sequencing to rule out the incorporation of some mutation during PCR reaction. The sequence obtained was compared to the sequence information available for the neo cassette of the plasmid pTKNEOlox. It showed a mismatch ( $\mathrm{G}$ to $\mathrm{A})$ in the 10th base from the start of the neo cassette coding sequence. This mutation changed the 4th amino acid of the product from alanine to threonine. It was however found that this mutation was present already in the template plasmid. This mutation does not interfere with the function of the neomycin resistance cassette (Dr Andrea Betz, personal communication).

4) Finally the $6.3 \mathrm{~kb}$ NotI fragment from p13-1Neolox/BS $\Delta$ ERI was cloned into NotI digested pTK3-1b5'loxP. The orientation was checked with BamHI (in the right orientation, there was a $2.7 \mathrm{~kb}$ band that was replaced by a $7.5 \mathrm{~kb}$ band in the opposite orientation). This created the complete targeting vector for the conditional knock-out of mouse neurexin $1 \alpha$ gene. 
The complete targeting vector was sequenced to look for the integrity of critical regions. The sequence results for coding region of the exon, the $5^{\prime}$ loxP fragment and the neoR cassette along with the $3^{\prime}$ loxP site showed the sequence as expected.

\section{pCMV-Flag Nrxn1 $\alpha$-IRES-GFP}

Flag-Nrxn1 $\alpha(\sim 5 \mathrm{~kb})$ was excised from pCMV-Flag-Nrxn1 $\alpha$ using ClaI and BstBI. PvuI was used in addition to cut the vector backbone. The $5 \mathrm{~kb}$ fragment was blunt-ended and cloned into the vector pIRES-GFP-1a at its SmaI site.

pET-RIM1_PDZ

RIM1 PDZ amplified from pCMV-RIM1 by PCR using primers MM05-183/8341 and MM05-184/8342. The PCR fragment ( $\sim 320$ bp) was digested with EcoRI and SalI and cloned into $\mathrm{pET} 42 \mathrm{~b}$ vector at EcoRI/SalI.

pCMV-Myc RIM1(1-730)

RIMI was excised from pCMV-RIM1(1-730) using EcoRI and was cloned into pCMV-Myc vector at EcoRI site. This fuses the myc-epitope tag at the N-terminus of RIM1. RIM1 cDNA in pCMV-RIM1(1-730) has a premature stop codon after the PDZ domain, therefore this construct produces a truncated protein.

\section{pCMV-Myc RIM1 $1 \Delta \mathrm{PDZ}$}

pCMV-Myc RIM1(1-730) was digested with SacI. >4 kb and $1.5 \mathrm{~kb}$ bands were excised from the gel and mixed together for ligation reaction. This deleted the PDZ and C2A domain including the premature stop codon. This construct therefore codes for zinc finger and $\mathrm{C} 2 \mathrm{~B}$ domain of RIM1.

\subsubsection{Eukaryotic cell lines}

E14.1

MEF

HEK FIp-In

tsA201
Mouse embryonic stem cells, from male SV/129 mouse embryos. They were derived by Professor Klaus Rajewsky, University of Cologne

Mouse embryonic fibroblasts. Genome systems, St. Louis, Missouri, USA

Invitrogen, Karlsruhe, Germany

Human embryonal kidney cells, SV40 transformed. European Collection of Cell Cultures (ECACC). ECACC No: 96121229 


\subsubsection{Bacterial Strains}

\begin{tabular}{ll}
\hline Escherichia coli XL1-Blue MRF' & Stratagene, La Jolla, California, USA \\
Escherichia coli BL21(DE3) & Novagen, Madison, Wisconsin, USA \\
\hline
\end{tabular}

\subsubsection{Apparatus}

Autoclave

Balances

Cell culture hood

Centrifuges

DNA sequencer

Electrophoresis chambers (for DNA)

Electrophoresis chambers (for proteins)

Electrophoresis power supply

\section{Electroporators}

Film development machine

Freezers

Heat block

Incubators, for bacterial culture

Incubator, for cell culture

Ligation chamber

Light microscopes

Magnetic stirring plates

Microwave oven

Multipipette

Oligonucleotide synthesizer

PCR machine

$\mathrm{pH}$ meter
Fedegari, Pavia, Italy

Sartorius, Göttingen

Kendro, Asheville, North Carolina, USA

Eppendorf, Hamburg; Kendro, Asheville, North Carolina, USA; Beckman Coulter, Krefeld, Germany

Applied Biosystems, Foster City, California, USA

Amersham Pharmacia Biotech, Little Chalfont, UK

BioRad, Hercules, California, USA

Biometra, Göttingen

Bio-Rad, Hercules, California, USA

Protec, Oberstenfeld

Sanyo, Gunma, Japan

Unitek, USA/Scientific Plastics (Europe), Milton Keynes, UK

New Brunswick Scientific, Edison, USA; WTC binder, Tuttlingen

Sanyo, Gunma, Japan

Techne, Cambridge, UK

Carl Zeiss, Jena

Heidolph, Kelheim; H+P Labortechnik, Oberschleißheim/München

Bosch, Stuttgart

Brand, Wertheim/Main

Applied Biosystems, Foster City, California, USA

Biometra, Göttingen

WTW-inoLab, Weilheim 
Pipettes

Pipetting device

Polytron

Radiocativity counter

Refrigerators

Rotators

Shakers

Sonicator

Spectrophotometer

Sterilization oven

UV

documentation/crosslinker

Vortexer

Waterbaths
Brand, Wertheim/Main; Gilson, Villiers-le-Bel, France

Brand, Wertheim/Main

Kinematica, Littau/Luzern, Switzerland

Perkin-Elmer, Boston, Massachusetts, USA

Sanyo, Gunma, Japan, Liebherr, Biberach an der Riß

Snijders, Almere, The Netherlands

GFL, Burgwedel; Heidolph, Kelheim

Bandelin, Berlin

Eppendorf, Hamburg

Memmert, Schwabach

INTAS, Göttingen

IKA, Wilmington, North Carolina, USA

Julabo, Seelbach; Lauda, Lauda-Königshofen

\subsubsection{General chemicals}

\begin{tabular}{|c|c|}
\hline Agarose & Invitrogen, Groningen, The Netherlands \\
\hline Alkaline phophatase & Roche, Mannheim \\
\hline AMBA & Roche, Mannheim \\
\hline Ampicillin, sodium salt & Amersham Pharmacia Biotech, Little Chalfont, UK \\
\hline APS & BioRad, Hercules, California, USA \\
\hline ATP & Invitrogen, Groningen, The Netherlands \\
\hline Bromophenol blue & Amersham Pharmacia Biotech, Little Chalfont, UK \\
\hline BSA & Amersham Pharmacia Biotech, Little Chalfont, UK \\
\hline CHAPS & USB Corporation, Cleveland, Ohio, USA \\
\hline Coomassie & Merck, Darmstadt \\
\hline dATP & Invitrogen, Groningen, The Netherlands \\
\hline dCTP & Invitrogen, Groningen, The Netherlands \\
\hline$\left[\alpha-{ }^{32} \mathrm{P}\right] \mathrm{dCTP}$ & Amersham Pharmacia Biotech, Little Chalfont, UK \\
\hline Developer & Tetenal, Norderstedt \\
\hline
\end{tabular}


dGTP

DMSO

DNA standard

dTTP

ECL system

EDTA $\cdot \mathrm{Na}_{2} \cdot 2 \mathrm{H}_{2} \mathrm{O}$

EGTA

Ethanol

Ethidium bromide

Faramount (aqueous mounting medium)

Formamide

Gelatin

Glucose

Glutathione agarose beads

Glutathione, reduced form

Glycerol

HEPES, sodium salt

Hexanucleotide mix

Imidazole

IPTG

Isopropanol

Kanamycin sulfate

Klenow enzyme

LB broth base

LB agar

Lysozyme

Milk powder

NGS

Phenol
Invitrogen, Groningen, The Netherlands

Sigma, Taufkirchen

Invitrogen, Groningen, The Netherlands

Invitrogen, Groningen, The Netherlands

Amersham Pharmacia Biotech, Little Chalfont, UK

Amersham Pharmacia Biotech, Little Chalfont, UK

Roche, Mannheim

Calbiochem, San Diego, California, USA

Roche, Mannheim

DAKO, Hamburg

Calbiochem, San Diego, California, USA

Sigma, Taufkirchen

Sigma, Taufkirchen

Novagen, Madison, Wisconsin, USA

Sigma, Taufkirchen

Amersham Pharmacia Biotech, Little Chalfont, UK

Sigma, Taufkirchen

Roche, Mannheim

Amersham Pharmacia Biotech, Little Chalfont, UK

Roche, Mannheim

ICN, Costa Mesa, California, USA

Amersham Pharmacia Biotech, Little Chalfont, UK

Roche, Mannheim

Invitrogen, Groningen, The Netherlands

Invitrogen, Groningen, The Netherlands

Roche, Mannheim

Nestle Deutschland, Frankfurt/Main; BioRad, Hercules, California, USA

Invitrogen, Groningen, The Netherlands

Amersham Pharmacia Biotech, Little Chalfont, UK 


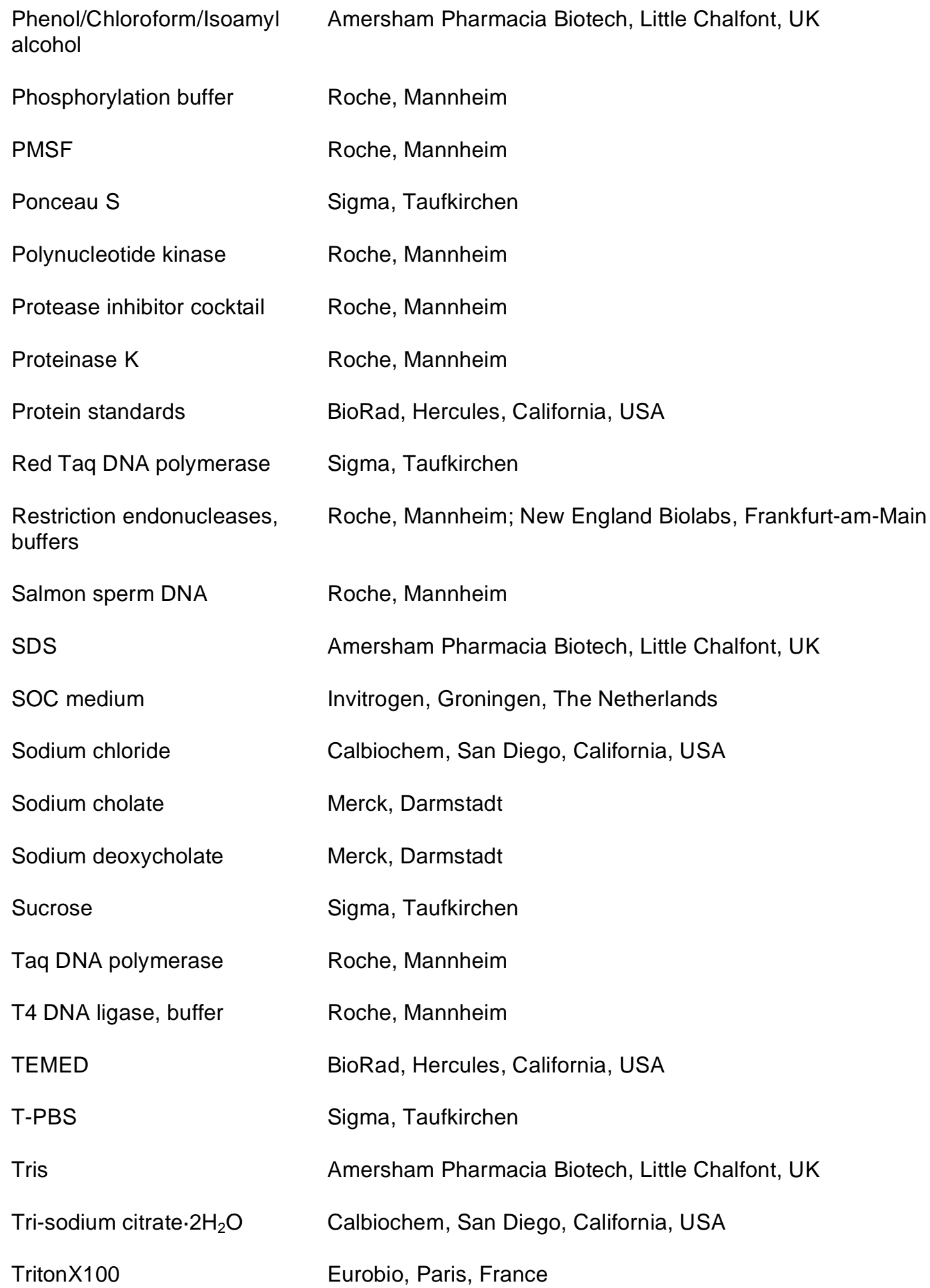

\subsubsection{Chemicals for cell culture}

$\mathrm{dH}_{2} \mathrm{O}$

DMEM medium

DMEM powder
Invitrogen, Groningen, The Netherlands

Invitrogen, Groningen, The Netherlands

Invitrogen, Groningen, The Netherlands 


\begin{tabular}{|c|c|}
\hline D-PBS & Invitrogen, Groningen, The Netherlands \\
\hline FBS (for HEK cell culture) & Invitrogen, Groningen, The Netherlands \\
\hline FCS (for ES cell culture) & Hyclone, Logan, Utah, USA \\
\hline Ganciclovir & Sigma, Taufkirchen \\
\hline G418 sulfate & Invitrogen, Groningen, The Netherlands \\
\hline LIF (ESGRO) & Chemicon, Temecula, California, USA \\
\hline $\begin{array}{l}\text { MEM-non essential amino } \\
\text { acids }\end{array}$ & Invitrogen, Groningen, The Netherlands \\
\hline Mineral oil & Sigma, Taufkirchen \\
\hline Mitomycin C & Sigma, Taufkirchen \\
\hline N-Lauroylsarcosine & Sigma, Taufkirchen \\
\hline Penicillin/Streptomycin & Invitrogen, Groningen, The Netherlands \\
\hline Sodium bicarbonate & Invitrogen, Groningen, The Netherlands \\
\hline Trypsin/EDTA & Invitrogen, Groningen, The Netherlands \\
\hline
\end{tabular}

\subsubsection{Consumables}

\begin{tabular}{ll}
\hline Blotting paper & Schleicher \& Schuell, Dassel; Whatman, Maidstone, UK \\
Cell culture plastic equipment & Corning, Acton, Massachusetts, USA \\
Cellophane sheets & BioRad, Hercules, California, USA \\
Dialysis membranes & Spectrum, Rancho Dominguez, California, USA \\
ECL X-ray films & Amersham Pharmacia Biotech, Little Chalfont, UK \\
Electroporation cuvettes & BioRad, Hercules, California, USA \\
Falcon tubes (14 ml) & Becton Dickinson, Franklin Lakes, New Jersey, USA \\
Filters & $\begin{array}{l}\text { Corning, Acton, Massachusetts, USA; Sartorius, Göttingen; Schleicher } \\
\text { \& Schuell, Dassel }\end{array}$ \\
Glass coverslips & Menzel-Gläser, Braunschweig \\
Glass slides & Menzel-Gläser, Braunschweig \\
Hybond-N nylon membranes & Amersham Pharmacia Biotech, Little Chalfont, UK \\
Microcentrifuge tubes & Corning, Acton, Massachusetts, USA \\
Needles & HSW, Tuttlingen \\
Nitrocellulose membranes & Whatman Biometra, Göttingen \\
\hline
\end{tabular}




\begin{tabular}{|c|c|}
\hline Pasteur pipettes & Brand, Wertheim/Main; Rofa-Mavi, Beverwijk, The Netherlands \\
\hline $\begin{array}{l}\text { Pipettes ( } 1 \mathrm{ml}, 5 \mathrm{ml}, 10 \mathrm{ml} \text {, } \\
25 \mathrm{ml} \text { ) }\end{array}$ & Corning, Acton, Massachusetts, USA \\
\hline Pipette tips & Brand, Wertheim/Main \\
\hline $\begin{array}{l}\text { Pipette tips, aerosol resistant } \\
\text { (for PCR) }\end{array}$ & Brand, Wertheim/Main \\
\hline $\begin{array}{l}\text { Plastic tubes for bacterial } \\
\text { centrifugations }\end{array}$ & Kendro, Asheville, North Carolina, USA \\
\hline $\begin{array}{l}\text { Plastic tubes, sterile }(15 \mathrm{ml} \text {, } \\
50 \mathrm{ml})\end{array}$ & Corning, Acton, Massachusetts, USA \\
\hline Plates, for bacterial culture & Greiner, Nürtingen \\
\hline PCR tubes & Sarstedt, Nümbrecht \\
\hline $\begin{array}{l}\text { Safe-lock microcentrifuge } \\
\text { tubes }\end{array}$ & Eppendorf, Hamburg \\
\hline SDS-PAGE gel loading tips & Corning, Acton, Massachusetts, USA \\
\hline Spectrophotometry cuvettes & Brand, Wertheim/Main \\
\hline Syringes & HSW, Tuttlingen \\
\hline Ultracentrifuge tubes & Kendro, Asheville, North Carolina, USA \\
\hline X-ray films & Kodak, Rochester, New York, USA \\
\hline
\end{tabular}

\subsubsection{Kits for molecular biology}

$\begin{array}{ll}\begin{array}{l}\text { Expand Long Template PCR } \\ \text { System }\end{array} & \text { Roche, Manheim, Germany } \\ \text { High Fidelity PCR } & \text { Roche, Mannheim, Germany } \\ \text { NucleoSpin Plasmid Miniprep Kit } & \text { Macherey-Nagel, Düren, Germany } \\ \text { Plasmid Maxi Kit } & \text { Qiagen, Hilden, Germany } \\ \begin{array}{l}\text { Qiaex II Agarose Gel Extraction } \\ \text { Kit }\end{array} & \text { Qiagen, Hilden, Germany } \\ \text { QIAprep Spin Miniprep Kit } & \text { Qiagen, Hilden, Germany }\end{array}$

\subsubsection{Primary antibodies}

CASK, mouse

Flag, mouse
Chemicon, Temecula, California, USA

Chemicon, Temecula, California, USA 


\begin{tabular}{ll}
\hline $\begin{array}{l}\text { GFP, rabbit } \\
\text { Heat shock protein 70, } \\
\text { mouse }\end{array}$ & Chemicon, Temecula, California, USA \\
HRP, rabbit affinity purified & Kindly provided by Dr. Astrid Rohlmann \\
Mint1 (P932), rabbit & Kindly provided by Dr. TC Südhof, UTSW, Dallas, Texas, USA \\
Myc (9E109), mouse & Santa Cruz, Heidelberg, Germany \\
Neurexin (A473), rabbit & Kindly provided by Dr. TC Südhof, UTSW, Dallas, Texas, USA \\
Neuroligin 1 (4C12), mouse & Kindly provided by Professor Nils Brose, MPI, Göttingen \\
RIM1 $\alpha$ (Q703), rabbit & Kindly provided by Dr. TC Südhof, UTSW, Dallas, Texas, USA \\
RIM1 $\alpha$, mouse & BD Biosciences, Heidelberg, Germany \\
Tubulin $\beta$, mouse & Santa Cruz, Heidelberg, Germany \\
\hline
\end{tabular}

\subsubsection{Secondary antibodies}

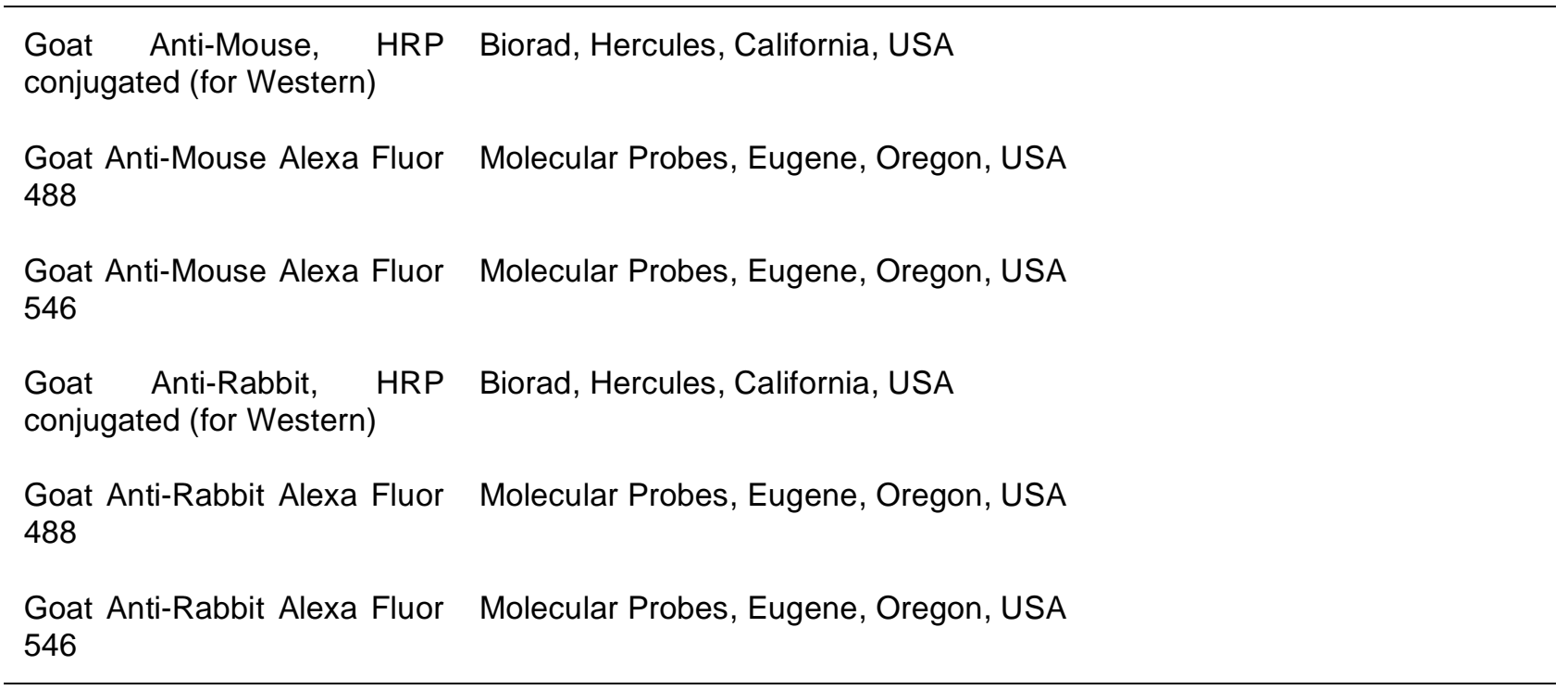

\subsection{METHODS}

\subsubsection{Molecular biology methods}

\subsubsection{Restriction enzyme digestion of DNA}

Restriction endonucleases cut double stranded DNA at specific palindromic recognition sites. This can be used to check the composition of DNA (analytical digest) and for cloning purpose (preparative digest). Analytical digests were carried out in $15 \mu 1$ reaction volume for 2-3 
hours. Preparative digests were carried out overnight in $60 \mu \mathrm{l}$ reaction volume. The temperature for all the digestions was $37^{\circ} \mathrm{C}$ unless otherwise stated by the manufaturer. The buffers to be used were determined by the compatibility table provided by manufacturer.

\subsubsection{Agarose gel electrophoresis}

DNA fragments can be separated according to their size by agarose gel electrophoresis. The larger the fragment is, the slower it migrates. Agarose was dissolved in $100 \mathrm{ml}$ or $300 \mathrm{ml} 1 \mathrm{x}$ TAE buffer in a microwave. The solution was cooled for 15 minutes by stirring and ethidium bromide was added (to a final concentration of $1 \mu \mathrm{g} / \mu \mathrm{l}$ ). The solution was poured into a gel chamber with a well seperator and allowed to cool at room temperature. The concentration of gel varied from $0.8-1.2 \%$, depending on the DNA size where the best seperation was required. Smaller fragments separate better in high concentration gels and larger fragments seperate better in low concentration gels. The bands were made visible and photographed under UV light. The size of the fragments was estimated by comparing it to the size of the bands of a DNA molecular weight marker.

\subsubsection{Purification of DNA from preparative digestion}

Vector DNA was purified from the preparative digest directly without running it on the gel. After adjusting the volume of reaction to $100 \mu \mathrm{l}, 100 \mu \mathrm{l}$ of phenol-chloroform-isoamyl alcohol (25:24:1) was added followed by brief mixing and centrifugation at $16000 \mathrm{~g}$ for 10 minutes. The supernatant was collected and $100 \mu \mathrm{l}$ of chloroform was added followed by brief mixing and centrifugation for 10 minutes. The supernatant was removed and $10 \mu 1$ sodium acetate $(3.3 \mathrm{M})$ and $250 \mu 1100 \%$ ethanol was added and the mixture kept at $-20^{\circ} \mathrm{C}$ for 30 minutes. The DNA was centrifuged down as a pellet by spinning at $16000 \mathrm{~g}$ for 15 minutes. The supernatant was removed and the pellet was washed with $70 \%$ ethanol. This was followed by centrifugation for 5 minutes. The supernatant was removed and the pellet was allowed to dry in air. The pellet was then dissolved in $10 \mu \mathrm{l}$ water and stored at $-20^{\circ} \mathrm{C}$. For isolating the fragment DNA from the preparative digest, the digest was run on $0.8 \%$ agarose gel. The desired fragment was cut from the gel and the DNA extracted using QIAEX II Agarose Gel Extraction Kit. 


\subsubsection{Dephosphorylation of $5^{\prime}$ DNA ends}

To prevent vector re-ligation during cloning procedures in which vector has been cut with only one enzyme or blunt ended, 5' phosphate groups were removed by treating digested vector DNA with $1 \mu \mathrm{l}$ of alkaline phosphatase at $37^{\circ} \mathrm{C}$ for $30 \mathrm{~min}$.

\subsubsection{Ligation}

The fragment was ligated into the vector by incubation with T4 DNA-ligase at $12{ }^{\circ} \mathrm{Co} / \mathrm{n}$. The ligation mixture contained the vector and the fragment in the ratio of about 1:10 in terms of molecular quantities. The following reaction mixture was used:

\begin{tabular}{cl}
\hline $12 \mu \mathrm{l}$ & $\mathrm{dH}_{2} \mathrm{O}$ \\
$1 \mu \mathrm{l}$ & Vector DNA \\
$10 \mu \mathrm{l}$ & Insert DNA \\
$1 \mu \mathrm{l}$ & Ligation buffer 10x \\
$1 \mu \mathrm{l}$ & T4 DNA Ligase 400 units/ $\mu \mathrm{l}$ \\
\hline
\end{tabular}

\subsubsection{Blunt-end cloning}

Blunt-end cloning is required when no compatible restriction sites are present. It involves the elongation of the DNA strands at their 3' ends to eliminate the overhangs created by stickyend endonucleases. DNA (linearised vector as well as the fragments) from the preparative

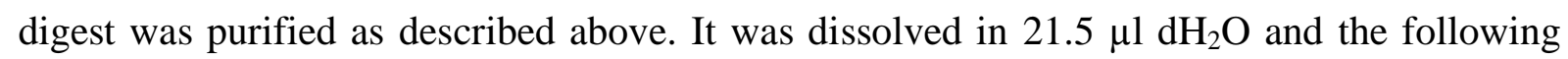
reaction mixture was set up:

\begin{tabular}{ll}
\hline $21.5 \mu \mathrm{l}$ & DNA \\
$2.5 \mu \mathrm{l}$ & Buffer A 10x \\
$0.5 \mu \mathrm{l}$ & dNTPs 10 mM \\
$0.5 \mu \mathrm{l}$ & Klenow polymerase $2 \mathrm{U} / \mu \mathrm{l}$ \\
\hline
\end{tabular}

The reaction was carried out at $37^{\circ} \mathrm{C}$ for $30 \mathrm{~min}$. The vector was again purified by phenolchloroform extraction and ethanol precipitation. The fragments were run on an agarose gel, and the desired fragment extracted as described above. The blunt ended vector and fragment were then taken to set the ligation reaction.

\subsubsection{Electro-transformation of bacteria with plasmid DNA}

In order to amplify plasmid DNA, transformation of bacteria (E.coli, strain XL1-Blue MRF') was done by electroporation. $4 \mu \mathrm{l}$ of plasmid DNA (ligation mixture diluted 1:4 with TE for mini-prep, or mini-prep DNA diluted 1:300 with TE for maxi-prep) was mixed with $40 \mu 1$ of 
electro-competent bacteria (thawed on ice) and kept on ice for 1-5 min. The mixture was transferred to an ice-cold electroporation cuvette $(0.2 \mathrm{~cm}$, BioRad $)$ and pulsed at $2.5 \mathrm{kV}$ in a pulser (E.coli Pulser, BioRad). The bacteria were then put in $1 \mathrm{ml} \mathrm{LB}$ medium and incubated at $37^{\circ} \mathrm{C}$ for $1 \mathrm{~h}$, shaking at $250 \mathrm{rpm}$. For mini-prep DNA preparation, bacteria were then plated on $94 \mathrm{~mm}$ x $16 \mathrm{~mm}$ LB agar plates containing appropriate antibiotic (ampicillin or kanamycin) and grown o/n at $37^{\circ} \mathrm{C}$. For maxi-prep DNA preparation, $4 \mathrm{ml}$ of LB medium was added to each tube along with appropriate antibiotic $(50 \mu \mathrm{g} / \mathrm{ml}$ final concentration) and incubated for further $4 \mathrm{~h} .1 \mathrm{ml}$ of the culture was then added to $500 \mathrm{ml} \mathrm{LB}$ medium containing appropriate antibiotic $\left(50 \mu \mathrm{g} / \mathrm{ml}\right.$ final concentration) and incubated $\mathrm{o} / \mathrm{n}$ at $37^{\circ} \mathrm{C}$.

\subsubsection{DNA mini-prep}

Tubes containing $5 \mathrm{ml} \mathrm{LB}$ medium with appropriate antibiotic $(50 \mu \mathrm{g} / \mathrm{ml}$ final concentration) were inoculated with single colonies from LB agar plates and grown o/n. DNA was extracted and purified using the QIAprep Spin Miniprep Kit and stored in Buffer EB (10 mM Tris-Cl, $\mathrm{pH}$ 8.5) at $4^{\circ} \mathrm{C}$. Purification of plasmid DNA with this kit is based on alkaline lysis of bacterial cell wall and precipitation of genomic DNA and proteins followed by adsorption of plasmid DNA onto a silica-gel membrane. Purified DNA was analysed with restriction digestion.

\subsubsection{DNA maxi-prep}

Maxi-prep procedure was done to obtain higher and better purified amount of DNA. $500 \mathrm{ml}$ LB medium inoculated $\mathrm{o} / \mathrm{n}$ with transformed bacteria was taken and the plasmid DNA extracted using QIAGEN Plasmid Maxi Kit. DNA was stored in TE buffer at $4^{\circ} \mathrm{C}$. Purification of plasmid DNA with this kit is based on alkaline lysis procedure followed by binding of plasmid DNA to an anion-exchange resin.

\subsubsection{DNA adaptor synthesis}

DNA adaptors were synthesised by annealing two oligonucleotides in ligation buffer (1:10) using the PCR machine. First the concentration of each oligonucleotide was measured by spectrophotometer. The concentration of single stranded DNA can be calculated according to the following formula:

$$
1 \mathrm{OD}_{260} \text { unit }=33 \mu \mathrm{g} / \mathrm{ml}
$$


$5 \mu \mathrm{g}$ of each oligonucleotide was taken and the reaction mixture was set in $15 \mu \mathrm{l}$ volume. The mixture was put in a PCR tube and the oligos annealing programme of the PCR machine was applied. This programme consists of the following:

\begin{tabular}{ll}
\hline $95^{\circ} \mathrm{C}$ & $\begin{array}{l}10 \mathrm{~min}, \\
\text { followed by slow decrease to } 50^{\circ} \mathrm{C}\end{array}$ \\
$50^{\circ} \mathrm{C}$ & $10 \mathrm{~min}$ \\
$40^{\circ} \mathrm{C}$ & $1 \mathrm{~min}$ \\
$30^{\circ} \mathrm{C}$ & $1 \mathrm{~min}$ \\
$22^{\circ} \mathrm{C}$ & hold \\
\hline
\end{tabular}

The whole amount of annealed product was then used for ligation directly.

\subsubsection{Colony hybridization}

Colony hybridisation was done to identify colonies with the desired plasmid, when repeated random sampling did not yield any positive clones. Hybond-N nylon membranes were used to lift the colonies from LB agar plates and several assymetric holes were made as markers. Bacterial colonies on membranes were lysed with $10 \%$ SDS for $5 \mathrm{~min}$, denatured for 5 min and neutralized for 5 min by putting the membrane on pieces of Whatman paper which were wet with the respective solutions. The membranes were then incubated in 2x SSPE for 10 min, crosslinked under UV light and washed with 2x SSC, 1\% SDS for 30 minutes. Radioactively labelled probe was synthesized using $\left[\alpha-{ }^{32} \mathrm{P}\right] \mathrm{dCTP}$. The following reaction mixture was used:

\begin{tabular}{lll}
\hline $9 \mu \mathrm{l}$ & DNA fragment & $25 \mathrm{ng}$, denatured at $100^{\circ} \mathrm{C}$ for $5 \mathrm{~min}$ \\
$2 \mu \mathrm{l}$ & Hexanucleotide mix & $62.5 \mathrm{OD}_{260}$ units $/ \mu \mathrm{l}$ \\
$3 \mu \mathrm{l}$ & $\mathrm{dATP}$, dGTP, dTTP & $1 \mu \mathrm{l} \mathrm{each,} 0.5 \mathrm{mM}$ \\
$1 \mu \mathrm{l}$ & Klenow polymerase & $2 \mathrm{U} / \mu \mathrm{l}$ \\
$5 \mu \mathrm{l}$ & {$\left[\alpha-{ }^{32} \mathrm{P}\right] \mathrm{dCTP}$} & $0.37 \mathrm{MBq} / \mu \mathrm{l}, 3.3 \mu \mathrm{M}$ \\
\hline
\end{tabular}

The reaction was done at $37^{\circ} \mathrm{C}$ for $40 \mathrm{~min}$. The reaction mixture was then passed through Quick spin columns to purify the probe. The probe was denatured at $100^{\circ} \mathrm{C}$ for $10 \mathrm{~min}$ before use. Membranes were pre-hybridized in 50\% Hybe buffer with denatured salmon sperm DNA at $42^{\circ} \mathrm{C}$ for 3 hours. These were then incubated with denatured, radiolabelled probe in $50 \%$ Hybe buffer at $42^{\circ} \mathrm{C}$ o/n. Membranes were washed with 0.1x SSC and 0.5\% SDS solution for $10 \mathrm{~min}$ at room temperature and then for $30 \mathrm{~min}$ at $65^{\circ} \mathrm{C}$. X-ray films were autoradiographically exposed to the membranes for $1-2 \mathrm{~h}$ at room temperature. 


\subsubsection{Polymerase chain reaction (PCR) for cloning}

Polymerase chain reaction is an in-vitro method to amplify a specific segment of DNA. This requires a DNA polymerase, the template DNA from which the segment is to be amplified, two oligonucleotide primers that hybridize at the two ends of the sequence to be amplified, deoxyribonucleotides (dNTPs) and buffer. The Expand High Fidelity PCR System (Roche) was used for amplifying DNA fragments for cloning purposes. This system is based on the use of two enzymes: Taq DNA polymerase that amplifies DNA, and Pfu DNA polymerase that corrects any introduced mutations by its $3^{\prime} \rightarrow 5^{\prime}$ exonuclease proofreading activity. The following reaction mix was used:

\begin{tabular}{lll}
\hline $13 \mu \mathrm{l}$ & $\mathrm{dH}_{2} \mathrm{O}$ & \\
$1 \mu \mathrm{l}$ & Plasmid DNA & $\sim 2 \mathrm{ng} / \mu \mathrm{l}$ \\
$1 \mu \mathrm{l}$ & $\mathrm{dNTP}$ & $10 \mathrm{mM}$ \\
$1 \mu \mathrm{l}$ & Forward primer & $5 \mathrm{OD}_{260}$ units \\
$1 \mu \mathrm{l}$ & Reverse primer & $5 \mathrm{OD}_{260}$ units \\
$2 \mu \mathrm{l}$ & PCR buffer & $10 \mathrm{x}$ \\
$1 \mu \mathrm{l}$ & Enzyme mix & \\
\hline
\end{tabular}

The following PCR program was applied:

\begin{tabular}{ccl}
\hline $96^{\circ} \mathrm{C}$ & $2 \mathrm{~min}$ & Initial denaturation \\
$96^{\circ} \mathrm{C}$ & $30 \mathrm{sec}$ & Denaturation \\
$52-62^{\circ} \mathrm{C}$ & $30 \mathrm{sec}$ & Annealing \\
$72^{\circ} \mathrm{C}$ & $2 \mathrm{~min}$ & Extension \\
$72^{\circ} \mathrm{C}$ & $5 \mathrm{~min}$ & Final extension \\
$4^{\circ} \mathrm{C}$ & end & Store \\
\hline
\end{tabular}

The annealing temperature was set differently for different primer combinations (melting temperature minus $5^{\circ} \mathrm{C}$ ). The PCR products were run on an agarose gel and the appropriate fragment was purified. The DNA was cut by appropriate restriction enzymes, purified and cloned into the vector. 


\subsubsection{Preparation of mouse tail DNA for PCR}

For genotyping of mice, DNA was obtained from tails. The tail pieces were added to $3 \mathrm{ml}$ SNET buffer with $0.25 \mathrm{mg} / \mathrm{ml}$ proteinase $\mathrm{K}$ and incubation was carried out at $55^{\circ} \mathrm{C} \mathrm{o} / \mathrm{n} .500$ $\mu l$ of tail lysate was transferred into an Eppendorf tube, mixed with the same amount of phenol-chloroform-isoamyl alcohol and centrifuged at $16000 \mathrm{~g}$ for $10 \mathrm{~min}$. The supernatant was transferred to a new tube and $300 \mu \mathrm{l}$ of isopropanol was addded. The tube was put on ice for $5 \mathrm{~min}$. followed by centrifugation at $1600 \mathrm{rpm}$ for $10 \mathrm{~min}$. The supernatant was removed carefully and the pellet was dried in air. The pellet was resuspended in $500 \mu \mathrm{l}$ TE buffer.

\subsubsection{Polymerase chain reaction (PCR) for genotyping}

PCR was used for regular genotyping of mice as well as for the selection and confirmation of homologous recombinant ES cell clones. Expand Long Template PCR kit (Roche) was used for PCR on ES cell DNA as well as for genotyping from mouse tails at critical steps. This kit has a mixture of two polymerases, thermostable Taq DNA polymerase and Tgo DNA polymerase and is especially optimized to amplify large segments of genomic DNA. DNA was prepared from ES cells and tails as given above and the following reaction mixture was made:

\begin{tabular}{cll}
\hline $33.25 \mu \mathrm{l}$ & $\mathrm{dH}_{2} \mathrm{O}$ & \\
$1 \mu \mathrm{l}$ & Genomic DNA & $10-100 \mathrm{ng} / \mu \mathrm{l}$ \\
$1.75 \mu \mathrm{l}$ & $\mathrm{dATP}, \mathrm{dCTP}, \mathrm{dGTP}, \mathrm{dTTP}$ & $10 \mathrm{mM}$ \\
$1 \mu \mathrm{l}$ & Forward primer & $5 \mathrm{OD}_{260}$ units \\
$1 \mu \mathrm{l}$ & Reverse primer & $5 \mathrm{OD}_{260}$ units \\
$5 \mu \mathrm{l}$ & PCR buffer & $10 \mathrm{x}$ \\
$0.75 \mu \mathrm{l}$ & Enzyme mix & 5 units $/ \mu \mathrm{l}$ \\
\hline
\end{tabular}

The following program was used to amplify DNA:

\begin{tabular}{clll}
\hline $92^{\circ} \mathrm{C}$ & $2 \mathrm{~min}$ & $1 \mathrm{X}$ & Initial denaturation \\
\hline $92^{\circ} \mathrm{C}$ & $10 \mathrm{sec}$ & & Denaturation \\
$50-60^{\circ} \mathrm{C}$ & $30 \mathrm{sec}$ & $10 \mathrm{X}$ & Annealing \\
$68^{\circ} \mathrm{C}$ & $2 \mathrm{~min}$ & & Elongation \\
\hline $92^{\circ} \mathrm{C}$ & $15 \mathrm{sec}$ & & Denaturation \\
$50-60^{\circ} \mathrm{C}$ & $30 \mathrm{sec}$ & $25 \mathrm{X}$ & Annealing \\
$68^{\circ} \mathrm{C}$ & $2 \mathrm{~min}+20 \mathrm{sec} /$ cycle & & Elongation \\
\hline $68^{\circ} \mathrm{C}$ & $7 \mathrm{~min}$ & $1 \mathrm{X}$ & Final elongation \\
\hline $4^{\circ} \mathrm{C}$ & pause & & Storage \\
\hline
\end{tabular}


For regular genotyping from mouse tails, a different PCR strategy was designed which involved amplification of smaller fragments of DNA. The following reaction mixture was used which included less expensive Red Taq polymerase (Sigma).

\begin{tabular}{rll}
\hline $13.35 \mu \mathrm{l}$ & $\mathrm{dH}_{2} \mathrm{O}$ & \\
$1 \mu \mathrm{l}$ & $\mathrm{dNTPs}$ & $25 \mathrm{mM}$ \\
$2.5 \mu \mathrm{l}$ & DMSO & \\
$0.2 \mu \mathrm{l}$ & $\mathrm{BSA}$ & $10 \mathrm{mg} / \mathrm{ml}$ \\
$0.1 \mu \mathrm{l}$ & Forward primer & $5 \mathrm{OD}_{260}$ units \\
$0.1 \mu \mathrm{l}$ & Reverse primer & $5 \mathrm{OD}_{260}$ units \\
$5 \mu \mathrm{l}$ & PCR buffer & $5 \mathrm{x}$ \\
$0.75 \mu \mathrm{l}$ & Red Taq DNA polymerase & 5 units $/ \mu \mathrm{l}$ \\
$2 \mu \mathrm{l}$ & Genomic DNA & $\sim 100 \mathrm{ng}$ \\
\hline
\end{tabular}

The following PCR program was used:

\begin{tabular}{ccl}
\hline $93^{\circ} \mathrm{C}$ & $10 \mathrm{~min}$ & Initial denaturation \\
$93^{\circ} \mathrm{C}$ & $30 \mathrm{sec}$ & Denaturation \\
$52-62^{\circ} \mathrm{C}$ & $45 \mathrm{sec}$ & Annealing \\
$65^{\circ} \mathrm{C}$ & $2 \mathrm{~min}$ & Extension \\
$65^{\circ} \mathrm{C}$ & $10 \mathrm{~min}$ & Final extension \\
$4^{\circ} \mathrm{C}$ & end & Store \\
\hline
\end{tabular}

\subsubsection{DNA sequencing}

For sequencing DNA cloned into a vector, primers that anneal near the multicloning site of the vector were used. In some cases, primers that anneal to an internal sequence of the insert were designed and used for sequencing. Primer synthesis and sequencing was done by Fritz Benseler and Ivonne Thanhäuser at the Department of Molecular Neurobiology, Max Planck Institute for Experimental Medicine, Göttingen using the Oligo synthesizer, ABI 5000 DNA/RNA Synthesizer, and the Applied Biosystems 373 DNA sequencer (modified from Sanger et. al., 1977). Sequences were analyzed on a Macintosh computer, using Lasergene software (DNASTAR, Madison, Wisconsin, USA).

\subsubsection{Southern Blot}

Southern hybridization is a standard method to screen for homologous recombinant ES cell clones as well as for genotyping from mouse tails. This method estimates the size of fragments generated after digestion of the genomic DNA with specific restriction endonucleases and thus helps in mapping the target DNA within the context of restriction 
sites. It is utilized for screening homologous recombination events by designing the targeting vector in such a way that its homologous recombination into the genome changes the size of fragments produced by particular restriction enzymes (e.g. by introduction or deletion of a restriction site or the insertion of exogenous elements like selection marker cassettes). These fragments can then be analysed using appropriate radioactive probes. Southern blotting of DNA derived from ES cell colonies was done in the following steps.

\section{DNA transfer from agarose gels}

Digested genomic DNA from 196 ES cell clones was run on two 0.8\% agarose gels (20x10 $\mathrm{cm})$ at $30 \mathrm{~V} \mathrm{o} / \mathrm{n}$. The gels were prestained with ethidium bromide and photographs were taken afterwards for documentation. The gels were incubated in denaturing buffer for $30 \mathrm{~min}$. at room temperature with gentle shaking. They were then rinsed in water and incubated in neutralization buffer for $30 \mathrm{~min}$. After brief rinsing with water, the gels were assembled in a Southern transfer apparatus and blotted onto Hybond-N nylon membranes with 20x SSC o/n. Within the Southern transfer apparatus, the agarose gel was placed upside down over 2 pieces of Whatman paper whose ends were dipping into 20x SSC buffer. Hybond-N membrane was soaked in water for $15 \mathrm{~min}$ and placed over the gel. Then a wet and a dry piece of Whatman paper were kept over the membrane folowed by a stack of paper towels. Finally a weight of around $1 \mathrm{~kg}$ was placed over the assembled apparatus. The next morning, the apparatus was disassembled and the membrane was washed in 2x SSC buffer for 2 min and exposed to UV light $\left(0.12 \mathrm{~J} / \mathrm{cm}^{2}\right)$ for crosslinking DNA to the membrane. This was followed by washing the membrane with $2 \mathrm{x}$ SSC, $1.5 \%$ SDS for $30 \mathrm{~min}$ at room temperature. The membrane was then pre-hybridized in $50 \%$ Hybe buffer with denatured salmon sperm DNA at $42^{\circ} \mathrm{C} \mathrm{o} / \mathrm{n}$.

\section{Radioactive labeling of DNA probes}

Radioactively labelled probe was synthesized using random primers. The following reaction mixture was used for a $1 \mathrm{x}$ probe.

\begin{tabular}{lll}
\hline $9 \mu \mathrm{l}$ & DNA fragment & $25 \mathrm{ng}$, denatured at $100^{\circ} \mathrm{C}$ for $5 \mathrm{~min}$ \\
$2 \mu \mathrm{l}$ & Hexanucleotide mix & $62.5 \mathrm{OD}_{260}$ units $/ \mu \mathrm{l}$ \\
$3 \mu \mathrm{l}$ & $\mathrm{dATP}$, dGTP, dTTP & $1 \mu \mathrm{l}$ each, $0.5 \mathrm{mM}$ \\
$1 \mu \mathrm{l}$ & Klenow polymerase & $2 \mathrm{U} / \mu \mathrm{l}$ \\
$5 \mu \mathrm{l}$ & {$\left[\alpha^{32} \mathrm{P}\right] \mathrm{dCTP}$} & $0.37 \mathrm{MBq} / \mu \mathrm{l}, 3.3 \mathrm{mM}$ \\
\hline
\end{tabular}


The reaction was carried out at $37^{\circ} \mathrm{C}$ for $40 \mathrm{~min}$. The probe was purified from nucleotides using Quick spin column with centrifugation at $1100 \mathrm{~g}$ for $4 \mathrm{~min}$. The purified radioactive probe was denatured at $100^{\circ} \mathrm{C}$ for 5 min before adding it to the membrane.

\section{Hybridization}

Membrane that was already pre-hybridized was placed in 50\% Hybe buffer and the radioactive probe was added. The incubation was carried out at $42^{\circ} \mathrm{C} \mathrm{o} / \mathrm{n}$. The next day membrane was washed with an $0.1 \mathrm{x}$ SSC, $0.1 \%$ SDS solution for $10 \mathrm{~min}$ at room temperature and then for $30 \mathrm{~min}$ at $65^{\circ} \mathrm{C}$. The membranes were exposed to phosphoimager films for 2 hours and then to X-ray films $\mathrm{O} / \mathrm{N}$ at $-80^{\circ} \mathrm{C}$.

\subsubsection{DNA database search}

DNA databases were searched at National Center for Biotechnology Information website (http://www.ncbi.nlm.nih.gov). GenBank database was accessed to obtain annotated sequences. The alignment of sequences were performed using Basic Local Alignment Search Tool (BLAST) at the website.

\subsubsection{Biochemistry methods}

\subsubsection{SDS-polyacrylamide gel electrophoresis (SDS-PAGE)}

SDS-PAGE is a common biochemical technique for separation of protein samples for further analysis. The proteins are seperated according to their molecular weight when they migrate through the gel in response to an electric field. Protein sample before being subjected to electrophoresis are mixed with a buffer that contains SDS as well as $\beta$-mercaptoethanol. SDS denatures the proteins and provide them with negative charge, irrespective of their isolelectric point. $\beta$-mercaptoethanol breaks disulphide bonds and therefore seperates multisubunit proteins into their monomers.

A gel casting apparatus (Biorad) was used to prepare gels. The glass walls were cleaned with soap and water and arranged as a cassette in the casting apparatus. The seperation gel was poured first and the surface was covered with water-saturated butanol. The concentration of seperation gel varied from $7.5-10 \%$ depending on the protein size where the best separation was required. Low molecular weight proteins separate better in high concentration gels and 
high molecular weight proteins seperate better in low concentration gels. After the gel polymerized (in 30-40 minutes), butanol was removed and the surface of the gel was washed several times with water. The stacking gel was then poured over the seperation gel, and a comb was inserted. After polymerization of the gel (in 10-15 minutes), the cassette was placed into the electrophoresis chamber and filled with running buffer. The protein samples were mixed with an equal volume of $2 \mathrm{x}$ protein sample buffer and heated at $100^{\circ} \mathrm{C}$ for 2 minutes. $20 \mu \mathrm{l}$ of the mixture was loaded into the wells after removing the comb. The electrophoresis was done at $80 \mathrm{~V}$ till the samples got stacked at the lower border of the stacking gel, and then at $120 \mathrm{~V}$ for 1-2 hrs. The gel was immediately used for western blotting or coomassie staining.

\begin{tabular}{cccc}
\hline & Seperation gel 7.5\% & Seperation gel 10\% & Stacking gel 3.75\% \\
\hline $\mathrm{dH}_{2} \mathrm{O}$ & $2.5 \mathrm{ml}$ & $2.5 \mathrm{ml}$ & $1.25 \mathrm{ml}$ \\
Tris buffer $^{*}$ & $1.25 \mathrm{ml}$ & $1.5 \mathrm{ml}$ & $0.5 \mathrm{ml}$ \\
AMBA & $1.25 \mathrm{ml}$ & $2.0 \mathrm{ml}$ & $0.25 \mathrm{ml}$ \\
$10 \%$ APS & $15 \mu \mathrm{l}$ & $17 \mu \mathrm{l}$ & $12 \mu \mathrm{l}$ \\
TEMED & $7 \mu \mathrm{l}$ & $8 \mu \mathrm{l}$ & $5 \mu \mathrm{l}$ \\
\hline
\end{tabular}

* Tris buffer, pH 6.8 (upper tris) was used for preparing stacking gel and Tris buffer, pH 8.8 (lower tris) was used to prepare separation gel.

\subsubsection{Western blotting}

Western blotting or immunoblotting is a technique used for specific detection of a protein in a sample using antibodies. The protein samples seperated by SDS-PAGE are transferred electrophoretically to a nitrocellullose membrane, where they are accessible for interaction with antibodies.

\section{Transfer of proteins from gel to a nitrocellulose membrane}

After undergoing SDS-PAGE, the separation gel was placed along with the nitrocellulose membrane in a transfer cassette. A piece of blotting paper and a sponge are kept on either side of them. The transfer cassette is then placed in a chamber having ice-cold transfer buffer. Proteins were transferred by electrophoresis at $250 \mathrm{~mA}$ for $2 \mathrm{hrs}$. The cassette was disassembled and the membrane removed. It was stained with Ponceau-S stain for 1-2 min, and the background was destained with water. This was done to rapidly check protein transfer. The membrane was photographed under white light for documentation. It was then destained completely by washing for few minutes in PBS-Tween20. 


\section{Immunodetection}

To reduce non-specific binding of antibodies to the proteins, the membrane was first incubated with blocking solution for $1 \mathrm{~h}$. The membrane was then incubated with primary antibody in appropriate dilution in the blocking solution overnight at $4^{\circ} \mathrm{C}$. Primary antibody recognises a specific epitope in the protein of interest. The membrane was washed with PBSTween several times. It was then incubated with secondary antibody in 1:5000 dilution in the blocking solution for $1 \mathrm{~h}$ at room temperature followed by extensive washing at room temperature with PBS-Tween. Horseradish peroxidase (HRP)-labelled secondary antibodies were used which bind to the heavy chain of the primary antibody. Enzymatic chemiluminesence (ECL) system was used to detect the secondary antibody. The ECL system consists of luminol and $\mathrm{H}_{2} \mathrm{O}_{2}$. HRP coupled to secondary antibody reduces the hydrogen peroxide and the resulting oxygen oxidizes the luminol which releases light. The presence of enhancers amplifies this light which is then detected on photographic films. The ECL reaction was done according to manufacturer's protocol. Briefly the Reagents 1 and 2 were mixed 1:1 and the mixture was placed over the membrane for $1 \mathrm{~min}$ at room temperature. The mixture was then discarded and films were placed over the membrane for variable durations in dark. The films were developed and fixed and aligned with the membrane after drying for marking of the protein molecular weight standard.

\subsubsection{Expression of GST-fusion Proteins}

Proteins fused to Glutathione-S-Transferase (GST-fusion proteins) are used to study proteinprotein interactions. The GST-fusion proteins are expressed in bacteria and purified by attaching to glutathione-agarose beads. These beads could then be used to test for binding to known or novel interaction partners of the protein which is fused to GST. The pET vectors or pGEX-KG vectors were used for the expression of GST-fusion proteins in E.coli strain BL21 (DE3). These vectors are meant for protein expression in bacteria as they have a useful property that they are transcriptionally silent until they are induced.

\section{Chemical transformation}

$1 \mu \mathrm{l}$ of plasmid DNA $(0.2 \mu \mathrm{g} / \mu \mathrm{l})$ was added to $10 \mu \mathrm{l}$ of thawed E.coli strain BL21 (DE3) cells and kept on ice for $5 \mathrm{~min}$. The mixture was heated for exactly $30 \mathrm{~s}$ at $42^{\circ} \mathrm{C}$ and the tubes were kept on ice for $2 \mathrm{~min} .80 \mu \mathrm{l}$ of SOC medium was added at room temperature and the mixture was incubated at $37^{\circ} \mathrm{C}$ for $1 \mathrm{~h} .30 \mu \mathrm{l}$ of the mixture was plated on LB-agar plates (containing appropriate antibiotics) and incubated overnight at $37^{\circ} \mathrm{C}$. One colony was picked the next day 
and grown in $50 \mathrm{ml} \mathrm{LB}$ medium (with appropriate antibiotics) for $5-6 \mathrm{~h}$ at $37^{\circ} \mathrm{C}$ shaking till OD $_{600}$ reached 0.4-0.6 units. $900 \mu \mathrm{l}$ of LB culture was then mixed on ice with $100 \mu \mathrm{l}$ of $80 \%$ glycerol in a cryogenic vial, and stored immediately at $-80^{\circ} \mathrm{C}$.

\section{Protein expression and purification}

A small amount of frozen culture was used to inoculate $50 \mathrm{ml}$ of LB culture (containing appropriate antibiotic) and shaken at $37^{\circ} \mathrm{C}$ overnight. $20 \mathrm{ml}$ of this culture was used to inoculate 1 litre of LB culture (containing appropriate antibiotic) and bacteria allowed to grow till $\mathrm{OD}_{600}$ reached 0.5-0.6 units. Protein expression was then induced by addition of $0.1 \mathrm{mM}$ IPTG and further incubation at $37^{\circ} \mathrm{C}$ for $2-3 \mathrm{~h}$. The culture was centrifuged at $6000 \mathrm{~g}$ for 15 min at $4^{\circ} \mathrm{C}$. Pellet was resuspended in $20 \mathrm{ml}$ binding buffer and then $0.1 \mathrm{~g}$ lysozyme was added. The mixture was kept on ice for $45 \mathrm{~min}$ and transferred to $2 \mathrm{x} 15 \mathrm{ml}$ tubes. Sonication was done at power 45 , cycle $45 \%$ for 2 x $30 \mathrm{~s}$. This was followed by centrifugation at $6000 \mathrm{~g}$ for $20 \mathrm{~min}$ at $4^{\circ} \mathrm{C}$. The supernatant was recovered and added to $1 \mathrm{ml}$ of $50 \%$ slurry of glutathione-agarose beads (pre-equilibriated). The incubation was carried on for 40 min rotating at room temperature. The beads were collected by centrifugation at $1000 \mathrm{~g}$. The beads were then washed in $14 \mathrm{ml}$ wash buffer for 5-10 $\mathrm{min}$ followed by collection of beads by spinning at $1000 \mathrm{~g}$ for $1 \mathrm{~min}$. This step was repeated 3 times. In the end the beads were resuspended in $500 \mu \mathrm{l}$ of binding buffer and kept at $4^{\circ} \mathrm{C}$.

\begin{tabular}{cl}
\hline \multicolumn{2}{c}{ Binding buffer } \\
\hline $50 \mathrm{mM}$ & Imidazole, pH 6.6 \\
$100 \mathrm{mM}$ & $\mathrm{NaCl}$ \\
$2 \mathrm{mM}$ & EDTA \\
$1 \mathrm{mM}$ & DTT \\
$1 \mathrm{x}$ & $\begin{array}{l}\text { Protease inhibitor cocktail } \\
\text { (Complete, Roche) }\end{array}$ \\
\hline & \\
\hline & Wash buffer \\
\hline $50 \mathrm{mM}$ & Imidazole, pH 6.6 \\
$2 \mathrm{mM}$ & NaCl \\
$1 \mathrm{mM}$ & EDTA \\
$1 \mathrm{x}$ & DTT \\
& Protease inhibitor cocktail \\
\hline
\end{tabular}




\subsubsection{Expression of proteins in HEK cells}

Recombinant proteins expressed in heterologous cell culture system can be used to study direct protein-protein interactions, without interference of other neuronal proteins. tsA201 strain of human embryonic kidney cells were taken for this purpose. tsA201 cells are SV40 transformed HEK cells and express transiently transfected proteins at high levels. tsA201 cells were maintained at $37^{\circ} \mathrm{C}, 5 \% \mathrm{CO}_{2}$ in Dulbecco's modified Eagle's medium (DMEM) supplemented with $10 \%$ fetal bovine serum and penicillin-streptomycin. The cells were grown to $80 \%$ confluence, split with trypsin-EDTA and plated onto $100 \mathrm{~mm}$ dishes one day before transfection. Immediately before transfection, cells were provided with fresh medium and transfection was done using standard calcium phosphate protocol. 8-10 $\mu \mathrm{g}$ of cDNA was used for transfection of each $100 \mathrm{~mm}$ dish. DNA was mixed with $490 \mu 1$ of $250 \mathrm{mM} \mathrm{CaCl}_{2}$ and added to $500 \mu \mathrm{l}$ of $2 \mathrm{x}$ Hepes buffer. The mixture was allowed to stand at room temperature for 15-20 min. and then pippetted over cells in $100 \mathrm{~mm}$ dishes. After 12 hours, the cells were provided with fresh medium and maintained at $37^{\circ} \mathrm{C}$ till 48 hours after transfection.

\subsubsection{HEK cell lysate preparation}

The cells grown in $100 \mathrm{~mm}$ dishes were harvested $48 \mathrm{~h}$ after transfection. The dish was first washed with D-PBS and the cells were scraped in $1 \mathrm{ml}$ of lysis buffer. This was followed by rotation at $4{ }^{\circ} \mathrm{C}$ for $30 \mathrm{~min}$ and centifugation at $7,000 \mathrm{~g}$ at $4^{\circ} \mathrm{C}$ for $10 \mathrm{~min}$. The supernatant was collected and used for western blotting or GST pulldown experiments.

\begin{tabular}{cl}
\hline & HEK cell lysis buffer \\
\hline $20 \mathrm{mM}$ & Imidazole, $\mathrm{pH} 6.8$ \\
$100 \mathrm{mM}$ & $\mathrm{NaCl}$ \\
$2 \mathrm{mM}$ & EDTA \\
$1 \mathrm{mM}$ & DTT \\
$1 \mathrm{x}$ & Protease inhibitor cocktail \\
$0.1 \%$ & CHAPS \\
\hline
\end{tabular}

\subsubsection{Membrane protein extraction from rodent brain}

Since most of the proteins that were studied in this project were known to be associated with membrane fraction of the brain, a protocol for extraction of membrane proteins was used. Rats were subjected to $\mathrm{CO}_{2}$ anaesthesia and killed by decapitation. Mice were killed by cervical dislocation. The brain was quickly dissected out and parts of hind brain removed. The brain was cut into several pieces and put into homogenisation buffer $(2 \mathrm{ml}$ for each mouse brain and $4 \mathrm{ml}$ for rat brain). Glass-teflon homogenizer was used to homogenize the brain and 
the homogenate was centifuged at $1000 \mathrm{~g}$ at $4^{\circ} \mathrm{C}$ for $5 \mathrm{~min}$. to remove cellular debris, nuclei and blood cells. The supernatant was recovered and centrifuged at 100,000g for $30 \mathrm{~min}$. at $4^{\circ} \mathrm{C}$. The supernatant $\left(\mathrm{S}_{2}\right.$ fraction, mainly containing cytosol) was discarded. The pellet $\left(\mathrm{P}_{2}\right.$ fraction, consisting of the membranes) was resuspended in low volume of binding buffer . The detergent was then added to desired concentration (as indicated), and the mixture was incubated rotating at $4^{\circ} \mathrm{C}$ for $2 \mathrm{~h}$. This was followed by centrifugation at $100,000 \mathrm{~g}$ for $15 \mathrm{~min}$. at $4{ }^{\circ} \mathrm{C}$ to pellet insoluble material. The supernatant was recovered and immediately used for western blotting or GST-pulldown experiments. Alternatively it was shock frozen in liquid nitrogen and stored at $-80^{\circ} \mathrm{C}$.

\begin{tabular}{cl}
\hline \multicolumn{2}{c}{ Homogenization buffer } \\
\hline $320 \mathrm{mM}$ & Sucrose \\
$1 \mathrm{x}$ & Protease inhibitor cocktail \\
\hline & \\
\hline & Binding buffer \\
\hline $100 \mathrm{mM}$ & Imidazole, $\mathrm{pH} \mathrm{6.8}$ \\
$2 \mathrm{mM}$ & $\mathrm{NaCl}$ \\
$1 \mathrm{mM}$ & EDTA \\
$1 \mathrm{x}$ & DTT \\
\hline
\end{tabular}

\subsubsection{GST fusion protein pulldown experiments}

$1 \mathrm{ml}$ of brain membrane fraction (in binding buffer) was mixed with $100 \mu \mathrm{l}$ of glutathioneagarose beads (50\% slurry) coupled to GST-fusion protein. For $1 \mathrm{ml}$ of HEK cell lysate, $15 \mu \mathrm{l}$ of beads were used. The mixture was incubated rotating at $4{ }^{\circ} \mathrm{C}$ for $2 \mathrm{~h}$. Pulldown was done by centrifuging the beads at $1000 \mathrm{~g}$ for $1 \mathrm{~min}$. The beads were then washed in $1.4 \mathrm{ml}$ binding buffer for 5-10 min followed by collection of beads by spinning at $1000 \mathrm{~g}$ for $1 \mathrm{~min}$. This step was repeated 3 times. In the end $80 \mu 1$ of $2 x$ protein sample buffer was added to the beads and boiled for $3 \mathrm{~min}$. This was followed by centrifugation at $16000 \mathrm{~g}$ for $30 \mathrm{~s}$. The supernatant was collected and stored at $-20^{\circ} \mathrm{C}$.

\begin{tabular}{cl}
\hline \multicolumn{2}{c}{ Wash buffer } \\
\hline $20 \mathrm{mM}$ & Imidazole, pH 6.8 \\
$100 \mathrm{mM}$ & $\mathrm{NaCl}$ \\
$2 \mathrm{mM}$ & EDTA \\
$1 \mathrm{mM}$ & DTT \\
$1 \mathrm{x}$ & Protease inhibitor cocktail \\
$0.1 \%$ or $0.4 \%$ * & Detergent \\
\hline
\end{tabular}


*For pulldown of brain proteins, wash buffer included $0.4 \%$ detergent while for pulldown from HEK cell lysate, wash buffer included $0.1 \%$ CHAPS.

\subsubsection{Dialysis}

When sodium cholate or sodium deoxycholate was used for extraction of membrane proteins from the brain, protein samples were dialyzed against a detergent-less buffer to reduce the concentration of the detergent. The dialysis membranes with molecular weight cut-off size (MWCO) of 12-14 kDa were used. The extracted protein sample was diluted 1:5 times and introduced into the dialysis tubing. The dialysis tubing was put into $2 \mathrm{~L}$ of dialysis buffer (same as wash buffer in 2.2.2.6 minus protease inhibitors and detergent) and kept rotating at $4^{\circ} \mathrm{C}$ overnight. The dialysis buffer was changed next morning and dialysis continued for further 5 hours. The dialysed sample from the tubing was then taken out and mixed with 100 $\mu \mathrm{l}$ of glutathione-agarose beads to perform GST-fusion pulldown experiment as described in section 2.2.2.6.

\subsubsection{Cell culture}

\subsubsection{Embryonic stem cell culture}

Embryonic stem cell culture was carried out to create neurexin $1 \alpha$ knock-in recombinant ES cells, to be used for the generation of neurexin $1 \alpha$ knock-in mice. Embryonic stem cells can be cultured in-vitro and split a few times. However they have to be maintained with care and cultured under special conditions to prevent them from differentiation. The preservation of undifferentiated state is critical for the generation of germ-line mouse chimeras. ES cell line (E14.1) from SV129 inbred mouse strain (made by Klaus Rajewski, Cologne) was used.

\subsection{Preparation of feeder layer}

ES cells were cultured on a feeder layer of mouse embryonic fibroblasts (MEF). The function of feeder cells is to secrete factors that are required for the optimal growth of ES cells and help in suppressing diffrentiation. MEF cells are derived from fibroblast rich tissues of 12.513.5 days old mouse embryos resistant to geneticin. The MEF cells that we used were obtained from Genome Systems and were available at passage 3, stored in liquid nitrogen. 
The MEF cells from one thawed vial were cultured in $75 \mathrm{~cm}^{2}$ flask in regular ES cell medium at $37{ }^{\circ} \mathrm{C}, 5 \% \mathrm{CO}_{2}$. When the cells reached confluency, they were split 1:4 into more $75 \mathrm{~cm}^{2}$ flasks. After confluency was reached, MEF cells were mitotically inactivated by incubating with $10 \mu \mathrm{g} / \mathrm{ml}$ mitomycin $\mathrm{C}$ in medium for $2 \mathrm{~h}$ in the incubator. Cells were washed with PBS, seperated by enzymatic digestion and distributed into $25 \mathrm{~cm}^{2}$ flasks or $100 \mathrm{~cm}$ dishes, depending on the application (see following sections). All flasks and dishes were gelatincoated by incubating with $0.1 \%$ gelatin in PBS for $30-60 \mathrm{~min}$.

\subsection{Culture of ES cells over feeder layer}

A vial of ES cells was thawed in a $37^{\circ} \mathrm{C}$ water bath and the cells were transferred to a $15 \mathrm{ml}$ tube with $7 \mathrm{ml}$ of ES cell medium. The cells were pelleted down at $1000 \mathrm{~g}$ for 5 minutes and resuspended in $1 \mathrm{ml}$ of medium. The cells were then transferred to a $25 \mathrm{~cm}^{2}$ flask, containing inactivated MEF cells in $5 \mathrm{ml}$ of medium. The medium was changed every day, always leaving $1 \mathrm{ml}$ of conditioned medium behind. The ES cells were continuously monitored for signs of diffrentiation. Diffrentiated cells flatten out and take the form of epithelial cells. We did not observe any significant diffrentiation at any stage of cell culture. The ES cells were cultured to subconfluency and were then split 1:4 into more $25 \mathrm{~cm}^{2}$ flasks. When the cells were again subconfluent, they were ready to be used for electroporation.

\subsection{Preparation of DNA for electroporation}

60-100 $\mu \mathrm{g}$ of targeting vector DNA were linearized by restriction digestion with ClaI. DNA was extracted twice with phenol/chloroform, twice with chloroform and precipitated with sodium acetate and ethanol. DNA was washed twice with $70 \%$ ethanol and resuspended in $500 \mu \mathrm{l}$ of sterile D-PBS.

\subsection{Preparation of cells for electroporation}

ES cells from one $25 \mathrm{~cm}^{2}$ flask were used for one electroporation. On the day of electroporation, the cells were washed with D-PBS and made into a single cell suspension. The cells were transferred to a $15 \mathrm{ml}$ tube and centrifuged at $1000 \mathrm{~g}$ for 5 minutes. The cell pellet was washed twice with D-PBS by resuspending and centrifuging. After the last wash the cells were resuspended in $500 \mu \mathrm{l}$ of D-PBS.

\subsection{Electroporation procedure}


The ES cell suspension and linearized DNA were mixed and quickly transferred to a cold electroporation cuvette. The cells were electroporated by a pulse at $500 \mu \mathrm{F}$ capacitance, $230 \mathrm{~V}$ voltage (GenePulserII, Biorad). They were then transferred immediately to $29 \mathrm{ml}$ of medium and distributed into 2x $100 \mathrm{~mm}$ dishes with inactivated MEF cells.

\subsection{Selection of clones}

The next day, medium was changed and the cells were cultured for 11 days with regular changing of the medium (once or twice a day, depending on the confluency). The ES cells were selected for drug resistance starting $24 \mathrm{~h}$ after electroporation. Positive selection was carried out using Geneticin G418 at a final concentration of the active compound of 190 $\mu \mathrm{g} / \mathrm{ml}$. In the presence of Geneticin which is an analogue of neomycin, only cells with an integration of neomycin-resistance gene survive. This leads to a selection of recombinant clones (both homologous and non-homologous). $48 \mathrm{~h}$ after selection started, there was massive cell death. The dying cells were cleared by regular change of medium. In order to enhance selection for homologous recombinant clones, negative selection was applied from third to fifth day, using ganciclovir at a final concentration of $0.25 \mu \mathrm{M}$. Ganciclovir acts as a substrate of thymidine kinase (TK) resulting in a toxic product. A 2x TK sequence had been cloned in the targeting vector, close to the targeting sequence. Homologous recombinant clones do not integrate this sequence and therefore survive. However non-homologous recombinant clones contain the $2 \mathrm{x}$ TK sequence and therefore die in the presence of ganciclovir. However, negative selection is not very efficient and many non-homologous recombinant clones survive. Drug resistant ES cell colonies started appearing 7 days after the electroporation. The colonies were continuously monitored for signs of diffrentiation. Only few colonies showed any signs of differentiation at their periphery.

\subsection{Collection of resistant clones}

11 days after electroporation colonies were ready to be picked. One day before collection, cells were fed with medium without any selective agent to allow the clones to recover. ES cell colonies were picked under a microscope using $100 \mu \mathrm{l}$ pipette and yellow tips. The medium of the $100 \mathrm{~mm}$ dish containing the colonies was saved in $50 \mathrm{ml}$ tubes. The cells were washed with D-PBS and kept in D-PBS during the picking procedure. Undifferentiated colonies of different sizes which were well seperated were picked and placed in the wells of a 96-well plate containing $50 \mu \mathrm{l}$ of trypsin-EDTA. 16-32 colonies were picked in one round lasting not more than 25 minutes. Then the 96 -well plate was incubated at $37^{\circ} \mathrm{C}$ for 5 minutes for 
dissociation. $50 \mu \mathrm{l}$ of medium was added per well to stop trypsinization and the cells were triturated with the multi-channel pipette 10-15x. The cell suspension was split into two 96well dishes with feeder cells in $150 \mu \mathrm{l}$ of medium. After picking colonies from the first 100 $\mathrm{mm}$ dish for 25 minutes, medium was replaced and the cells allowed to recover in the incubator. In the meantime the second dish was used for picking the colonies. A total of 196 colonies were picked.

The cells were cultured for further 4 days when they became subconfluent. At this point of time, cells from one of the 96-well plates (masterplate) were trypsinized, mixed with $2 \mathrm{x}$ freezing medium and overlayed with mineral oil. The plate was sealed with Parafilm, put in a Styroform box (to allow a slow decrease of temperature) and frozen at $-80^{\circ} \mathrm{C}$.

The other 96-well dish was used for DNA preparation. The cells were split 1:2 into 96-well plates (without feeder layer) and cultured till they were confluent. Cells were lysed with lysis buffer at $60^{\circ} \mathrm{C}$ o/n and DNA was precipitated with ethanol and $\mathrm{NaCl}$ within the wells. DNA was then subjected to restriction enzyme digestion at $37^{\circ} \mathrm{C} \mathrm{o} / \mathrm{n} .1$ set of plates were digested with NdeI and the other set with EcoRI and the digested DNA was used for Southern Blot analysis.

\subsection{Preparation of ES cells for injection}

The ES cell clones that were identified by Southern Blot needed to be thawed. The 96-well plates were taken out of the freezer and kept at $37^{\circ} \mathrm{C}$ for 10 minutes. The selected clones were identified and the entire content of each well was transferred into a well of a 12-well plate with feeder cells. The medium was changed the next day to remove DMSO and oil. The cells were grown till they were subconfluent and then split 1:2 into 2x 12-well plates, one of which was coated with MEF cells (cell plate) and the other only with gelatin (DNA plate). The ES cells in each well of the cell plate were grown till they were subconfluent. The cells were then trypsinized, mixed with $2 x$ freezing medium and distributed into 3 cryogenic vials. The cryogenic vials were kept at $-80^{\circ} \mathrm{C} \mathrm{o} / \mathrm{n}$ and then transferred to liquid nitrogen. The cells in DNA plate were used for the preparation of DNA. The cells in each well were lysed with lysis buffer $\mathrm{o} / \mathrm{n}$ at $60^{\circ} \mathrm{C}$. The solution was taken out in an Eppendorf tube and subjected to phenol-chloroform extraction and ethanol precipitation. The identity of the clones was retested using Southern Blot and long range PCR on this DNA. 
2 days before injection, a vial of cells was thawed (one each for the three positive clones). The cells were plated in 12-well plates over MEF cells and maintained in culture for 2 days. The cells were then washed $3 x$ with D-PBS, trypsinized and triturated gently 5-10x. The cells were transferred to a $15 \mathrm{ml}$ tube and centrifuged at $1000 \mathrm{~g}$ for 5 minutes. The cell pellet was washed twice with medium by resuspending and centrifuging. After the last wash the cells were resuspended in $1 \mathrm{ml}$ of medium. The cells were kept on ice and immediately taken for injection.

\subsection{Microinjection of positive ES cell clones}

ES cells from positive clones were microinjected into blastocysts from C57Black6/N mice by the technicians at the Animal Facility of MPI Experimental Medicine, Göttingen. These chimeric blastocysts were implanted to pseudopregnant mice. The microinjection dates were 22/24/25 September 2003.

\subsubsection{Cell culture and transfection of HEK293_Ca $\mathrm{a}_{\mathrm{v}} \mathbf{2 . 2}$}

HEK293 cells stably transfected with $\mathrm{Ca}_{\mathrm{v}} 2.2$ calcium channel subunits (HA-tagged rabbit $\alpha 1 \mathrm{~B}$, rabbit $\beta 3$ and rat $\alpha 2 \delta$ ) were grown at $37^{\circ} \mathrm{C}, 5 \% \mathrm{CO}_{2}$ in Dulbecco's modified Eagle's medium (DMEM) supplemented with 10\% fetal bovine serum, $2 \mathrm{mM}$ L-Glutamine, 100 $\mu \mathrm{g} / \mathrm{ml}$ hygromycin B and penicillin-streptomycin. The cells were grown to $80 \%$ confluence, split with trypsin-EDTA and plated onto $60 \mathrm{~mm}$ dishes for transfection. The next day, cells were transfected using calcium phosphate method (MBS mammalian transfection kit, Stratagene) with $4 \mu \mathrm{g}$ of each plasmid as appropriate (pCMV-Neurexin 1 $\alpha$-IRES-GFP, pCMV-CASK and pCMV-Mint 1). After 24 hours, the cells were briefly trypsinized and plated onto $16 \mathrm{~mm}$ glass coverslips. Patch-clamp experiments were done on the second and third day after plating.

\subsubsection{Cell culture and transfection of tsA201 cells}

tsA201 cells were maintained at $37^{\circ} \mathrm{C}, 5 \% \mathrm{CO}_{2}$ in Dulbecco's modified Eagle's medium (DMEM) supplemented with $10 \%$ fetal bovine serum and penicillin-streptomycin. The cells were grown to $80 \%$ confluence, split with trypsin-EDTA and plated onto $16 \mathrm{~mm}$ coverslips (kept in $60 \mathrm{~mm}$ dishes) one day before transfection. Immediately before transfection, cells were provided with fresh medium and transfection was done using standard calcium phosphate protocol. $3 \mu \mathrm{g}$ of cDNA encoding for each calcium channel subunit (rat $\alpha 1 \mathrm{~B}, \beta 1 \mathrm{~b}$ 
and $\alpha 2 \delta$ ) were used along with $0.3 \mu \mathrm{g}$ of cDNA for green fluorescent protein (pEGFP-C1, Clontech) and $3 \mu \mathrm{g}$ of cDNA for neurexin $1 \alpha$ (pCMV-Neurexin $1 \alpha$ ) or control vector (pCMV5). After 12 hours, the cells were provided with fresh medium and maintained at $37^{\circ} \mathrm{C}$ for further 12 hours. The cells were then moved to $30{ }^{\circ} \mathrm{C}$ in $5 \% \mathrm{CO}_{2}$ and maintained for upto 6 days. Patch-clamp experiments were done on the fourth to sixth day after transfection.

\subsubsection{Electrophysiological recordings}

\subsubsection{Whole-cell patch-clamp on HEK293_Ca 2.2 cells}

The coverslips were transferred to a custom made chamber with external bath solution containing (in mM) $140 \mathrm{NaCl}, 10 \mathrm{BaCl}_{2}, 1 \mathrm{MgCl}_{2}, 10$ Hepes, 10 Glucose $(7.4 \mathrm{pH}, 312$ $\mathrm{mOsm} / \mathrm{kg}$ osmolarity) at room temperature. Patch pipettes (Borosilicate glass, $1.8 \mathrm{~mm}$ outer diameter, Hilgenberg, Malsfeld, Germany) were pulled using a two-stage electrode puller (Narishige, Tokyo, Japan), fire polished, and showed resistances of 3-5 megaohms. The internal pipette solution contained (in $\mathrm{mM}$ ) 125 Cesium methane sulphonate, 20 TEA-Cl, 5 EGTA, $2 \mathrm{MgCl}_{2}$, 10 Hepes, $4 \mathrm{Na}$-ATP, $0.5 \mathrm{Na}-\mathrm{GTP}$ (7.4 pH, $280 \mathrm{mosm} / \mathrm{kg}$ osmolarity). Aliquots of pipette solution were stored at $-80{ }^{\circ} \mathrm{C}$ and kept on ice after thawing. Whole-cell patch-clamp recordings were performed using an EPC7 patch-clamp amplifier (List, Darmstadt, Germany). The signals were filtered with a built-in Bessel filter at $3 \mathrm{kHz}$, digitized at $10 \mathrm{kHz}$ by a custom built $\mathrm{A} / \mathrm{D}$ convertor and stored on a hard disc of a computer using a custom acquisition and evaluation program written in C. Cells were held at $-80 \mathrm{mV}$ in the whole-cell configuration. Leak currents and whole-cell membrane capacitance were determined by applying $50 \mathrm{~ms}$ pulses to $-100 \mathrm{mV}$. Here the whole-cell capacitance $\left(\mathrm{C}_{\mathrm{mem}}\right)$ was calculated by integrating the area under the whole-cell capacitance transient current (charge transfer, Q) divided by voltage pulse $(\mathrm{V})$, i.e., $\mathrm{C}_{\mathrm{mem}}=\mathrm{Q} / \mathrm{V}$. Leak currents were substracted offline. Current-voltage (I-V) relationships were obtained by $20 \mathrm{~ms}$ voltage pulses from a holding potential of $-80 \mathrm{mV}$ to $+50 \mathrm{mV}$ in $10 \mathrm{mV}$ increments. Currents were measured $15 \mathrm{~ms}$ after the onset of the test pulse as an average over $5 \mathrm{~ms}$. I-V traces from individual cells were fit with a modified Boltzmann equation as follows:

$$
\mathrm{I}=\mathrm{G}_{\max }\left(\mathrm{V}-\mathrm{V}_{\text {rev }}\right) /\left(1+\exp \left(-\left(\mathrm{V}-\mathrm{V}_{1 / 2 \text { act }}\right) / \mathrm{k}_{\mathrm{act}}\right)\right)
$$


where $G_{\max }$ is the maximum slope conductance, $V_{\text {rev }}$ is the reversal potential, $V_{1 / 2}$ act is the half-activation potential and $\mathrm{k}_{\mathrm{act}}$ is the slope factor. Current density was calculated as current amplitude normalized to whole-cell capacitance. Steady-state inactivation properties were obtained by measuring currents in response to a test pulse to $+10 \mathrm{mV}$ (20 ms duration) after a prepulse ( $2 \mathrm{~s}$ duration) that changed from $-120 \mathrm{mV}$ to $+10 \mathrm{mV}$ in $10 \mathrm{mV}$ increments. Amplitudes of currents evoked by the test pulses to $10 \mathrm{mV}$ were normalized to the maximum current elicited and plotted against the prepulse potential. The data from individual cells was fit with a Boltzmann equation as follows:

$$
\mathrm{I}_{\text {norm }}=\mathrm{A} 1+(\mathrm{A} 2-\mathrm{A} 1) /\left(1+\exp \left(\left(\mathrm{V}-\mathrm{V}_{1 / 2 \text { inact }}\right) / \mathrm{k}_{\text {inact }}\right)\right)
$$

where $\mathrm{A} 1$ and $\mathrm{A} 2$ are the non-inactivating and inactivating fraction respectively, $\mathrm{V}_{1 / 2}$ inact is the half-inactivation potential and $\mathrm{k}_{\text {inact }}$ is the slope factor. Initial analysis (measuring current, leak resistance and whole-cell capacitance) was done under LINUX using a custom program written in C. Plotting and fitting of the data as well as statistical analysis were done in Prism (GraphPad Software, San Diego, CA, USA). Statistical significance was evaluated using an unpaired t-test and one-way ANOVA as appropriate.

\subsubsection{Whole-cell patch-clamp on tsA201 cells}

The coverslips were transferred to a custom made chamber with external bath solution containing (in mM) $65 \mathrm{CsCl}, 40 \mathrm{TEA}-\mathrm{Cl}, 20 \mathrm{BaCl}_{2}$ or $10 \mathrm{CaCl}_{2}$ (as indicated), $1 \mathrm{MgCl}_{2}, 10$ Hepes, 10 Glucose, $\mathrm{pH} 7.2$ at room temperature. The internal pipette solution contained (in mM) 108 Cesium methane sulphonate, $4 \mathrm{MgCl}_{2}, 9$ EGTA, 9 Hepes. The rest of the experimental conditions were the same as with HEK293_Ca 2.2 cells except for the protocol for eliciting current-voltage (I-V) relationships, which were obtained by $150 \mathrm{~ms}$ voltage pulses from $-40 \mathrm{mV}$ to $+50 \mathrm{mV}$ in $10 \mathrm{mV}$ increments.

\subsubsection{Extracellular field potential recordings in acute hippocampal slices}

\section{Slice preparation}

Acute hippocampal slices were prepared from 6-14 weeks old littermate mice. Mice were deeply anesthetized with diethyl ether before decapitation. The brain was quickly removed and immersed for 2-3 minutes in ice-cold artificial cerebrospinal fluid (ACSF, for 
composition see below). Transverse slices of $400 \mu \mathrm{m}$ thickness were cut in ice-cold ACSF with a vibroslicer (Campden Instruments, 752M Vibroslice). The slices were then transferred to an interface recording chamber of the Oslo type and were allowed to recover for 90 minutes. The recording chamber was continuously aerated with $95 \% \mathrm{O}_{2}-5 \% \mathrm{CO}_{2}$ and perfused with oxygenated ACSF (3-4 ml/min). The temperature was kept at $33{ }^{\circ} \mathrm{C}$. For recordings in the presence of bicuculline, a cut was between CA3 and CA1 region of the hippocampal slice to prevent recurrent activity.

\section{Solutions and drugs}

The ACSF had the following composition (in $\mathrm{mM}$ ): $130 \mathrm{NaCl}, 3.5 \mathrm{KCl}, 1.2 \mathrm{CaCl}_{2}, 1.2$ $\mathrm{MgSO}_{4}, 1.25 \mathrm{NaH}_{2} \mathrm{PO}_{4}, 24 \mathrm{NaHCO} 3,10$ Dextrose. The ACSF was constantly aerated with 95\% $\mathrm{O}_{2}-5 \% \mathrm{CO}_{2}$. DL-APV (DL-2-amino-5-phosphonovaleric acid; Sigma-Aldrich) was dissolved in water to make $10 \mathrm{mM}$ stock solution and stored at $-20^{\circ} \mathrm{C}$. It was used at $100 \mu \mathrm{M}$ concentration in ACSF. Bicuculline methiodide (Sigma-Aldrich) was dissolved in water to make $10 \mathrm{mM}$ stock solution and stored at $-20^{\circ} \mathrm{C}$. It was used at $10 \mu \mathrm{M}$ concentration in ACSF.

\section{Extracellular recordings}

The recording electrodes were pulled from thin-walled borosilicate glass capillaries (GC150TF-10, Harvard Apparatus) using a horizontal puller (Flaming Brown, P-80/PC). They were filled with ACSF. Monopolar stimulation electrodes made from bare stainless steel microwire (50 $\mu \mathrm{m}$ diameter, AM-Systems) were used for stimulation. The stimuli were generated by photoelectric stimulus isolation units (Grass PSIU6) triggered by a stimulator (Grass S88). Extracellular field potential recordings were done using a custom-built DC amplifier. Data were digitized by a TL-1/Lab Master acquisition system at a sampling rate of $20 \mathrm{kHz}$ and stored on a PC using the Axiotape V2 software (Axon Instruments, USA). Initial analysis of the data was done in Clampfit 8.0 (Axon Instruments, USA). Plotting of the data as well as statistical analysis were done in Prism (GraphPad Software, USA). Statistical significance was evaluated using one-way ANOVA when three experimental groups were present. 2 groups were compared using unpaired t-test.

To evoke field excitatory postsynaptic potentials (fEPSPs) the stimulation electrode was placed in stratum radiatum for the activation of Schaffer collaterals. The recording electrode was placed in the stratum radiatum of CA1 region. The magnitude of fEPSPs was measured 
as the slope between $20-80 \%$ level of the rising phase. For input-output relationship, fEPSPs were evoked with $0.1 \mathrm{~ms}$ stimuli at $0.25 \mathrm{~Hz}$ and an average of four consecutive responses was taken. fEPSP slopes were plotted against stimulus intensity (10 to $150 \mu \mathrm{A})$. Paired-pulse facilitation (PPF) was measured at different inter-stimulus intervals $(15,25,50,75,100,125$ and $150 \mathrm{~ms}$ ) as the ratio of the second fEPSP to the first fEPSP slope. Here also the paired stimuli were given at $0.25 \mathrm{~Hz}$ and an average of four consecutive responses was taken. To study frequency-induced plasticity, a baseline response was measured at $0.1 \mathrm{~Hz}$ for 1 minute and frequency-induced plasticity was then evoked by a $14 \mathrm{~Hz}$ train for 300 stimuli. For studying post-tetanic potentiation (PTP), slices were perfused with ACSF containing $100 \mu \mathrm{M}$ DL-APV (NMDA receptor antagonist) for atleast 25 minutes before recordings were started. Since PTP in $1.2 \mathrm{mM} \mathrm{Ca}^{2+}$ is very brief lasting less than $15 \mathrm{~s}$, we used a $1 \mathrm{~Hz}$ train to elicit responses. After a baseline stimulation for 1 minute at $1 \mathrm{~Hz}$, a single train at $100 \mathrm{~Hz}$ for $1 \mathrm{~s}$ was used to induce PTP. The post-tetanic responses were then measured by giving stimuli at 1 $\mathrm{Hz}$ for 2 minutes. To measure long-term potentiation (LTP), baseline responses were evoked every $30 \mathrm{~s}$ for 10 minutes and LTP was induced by 4 trains separated by $20 \mathrm{~s}$, each train consisting of $100 \mathrm{~Hz}$ stimuli for $1 \mathrm{~s}$. The post-train responses were then measured every $30 \mathrm{~s}$ for 60 minutes. The magnitude of LTP was measured as the average between 55-60 minutes of responses after induction. The modification of LTP protocol in the presence of various drugs is described in the results section. 


\subsection{The effect of $\alpha$-neurexins on calcium channels}

Mammalian cell lines provide a heterologous expression system to study the interaction between two or more proteins. We used the HEK293 cell line to investigate a potential influence of $\alpha$-neurexins on the functional properties of high-voltage activated calcium channels. In our lab a HEK293 cell line with stable expression of $\alpha 1 \mathrm{~B}$ (pore forming subunit of $\left.\mathrm{Ca}_{\mathrm{v}} 2.2\right), \alpha 2 \delta 1$ and $\beta 3$ subunits of voltage-gated calcium channels (HEK_Ca 2.2 cells) had been created. We started with the electrophysiological characterization of this cell line.

\subsubsection{Basic characterization of HEK293 cells stably transfected with $\mathrm{Ca}_{\mathrm{v}} 2.2$ calcium channel subunits}

The whole-cell patch-clamp technique was used to measure $\mathrm{Ca}^{2+}$ channel currents from HEK_Ca 2.2 cells. The recordings were done under conditions (see Materials and Methods) that prevent contamination by other currents, e.g., potassium channel currents. Inward $\mathrm{Ca}^{2+}$ channel currents were obtained by applying depolarizing voltage pulses from a holding potential of $-80 \mathrm{mV}$ (Fig. 3.1A). The currents were characterized by an initial peak, the activation time of which decreased with higher depolarizing voltage steps. This was followed by partial inactivation of currents, characteristic of $\mathrm{N}$-type $\left(\mathrm{Ca}_{\mathrm{v}} 2.2\right)$ and $\mathrm{P} / \mathrm{Q}$-type $\left(\mathrm{Ca}_{\mathrm{v}} 2.1\right)$ calcium channels. The inward currents were activated at potentials higher than $-20 \mathrm{mV}$ (Figure 3.1B) indicating that they were high-voltage activated currents. The currents were larger and activated at more negative potentials in the presence of $\mathrm{Ba}^{2+}$ (as compared to $\mathrm{Ca}^{2+}$ ) in accordance with known properties of these channels (Figure 3.1B). Since the currents were larger with $\mathrm{Ba}^{2+}$ and do not suffer with $\mathrm{Ca}^{2+}$-dependent inactivation, $\mathrm{Ba}^{2+}$ was used as charge carrier in rest of the experiments with HEK_Ca 2.2 cells. To confirm that the inward currents were mediated by $\mathrm{N}$-type $\left(\mathrm{Ca}_{\mathrm{v}} 2.2\right)$ calcium channels, we applied $\omega$-CTX GVIA, a specific blocker of N-type calcium channels. The currents rapidly decayed in response to $1 \mu \mathrm{M} \omega$-CTX GVIA (Fig. 3.1C and 3.1D). 

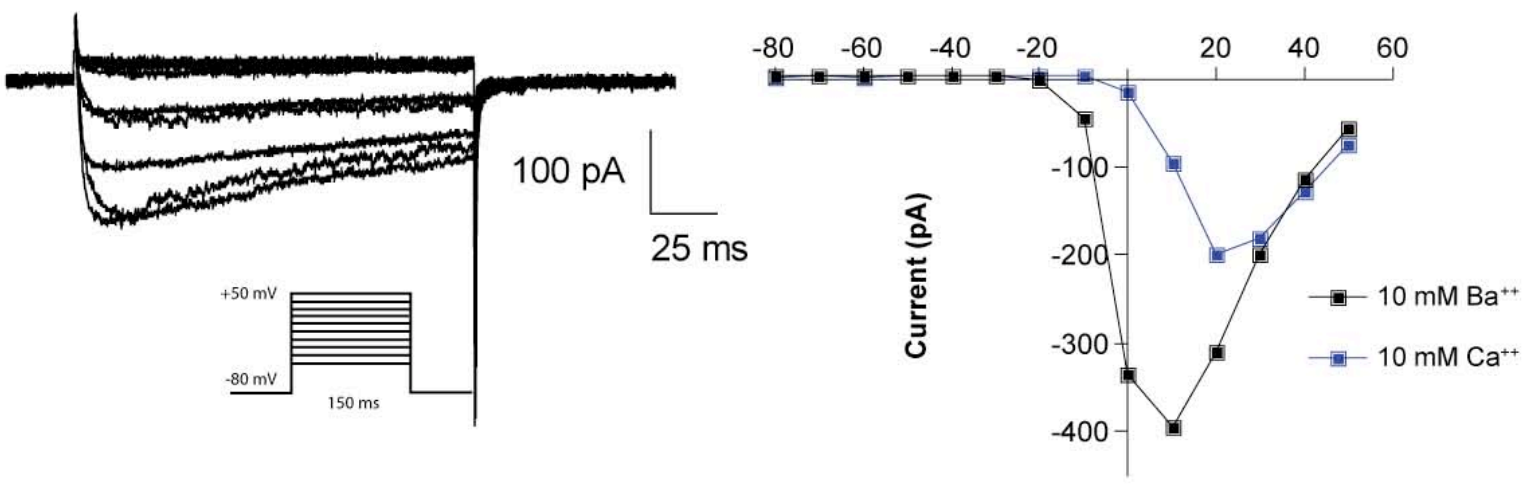

C

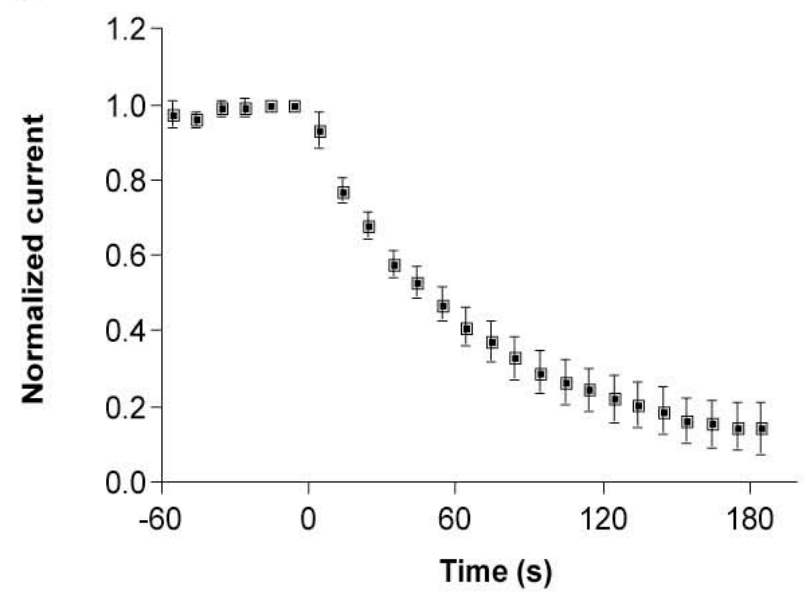

D

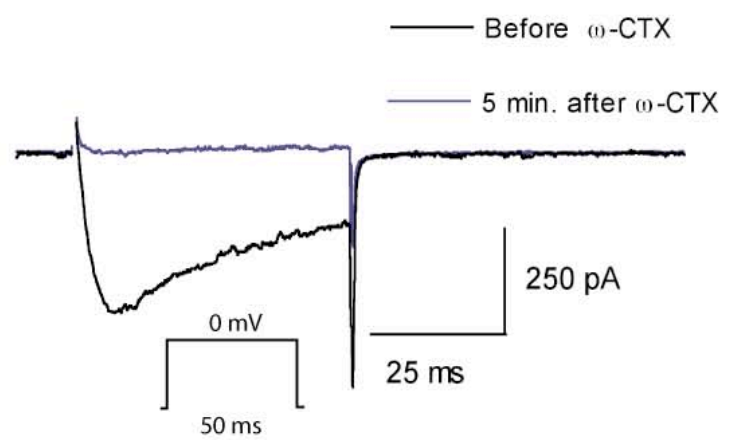

Figure 3.1 Characterization of HEK293 cells stably transfected with $\mathrm{Ca}_{\mathrm{v}} 2.2$ calcium channels ( $\alpha 1 \mathrm{~B}, \boldsymbol{\beta} 3$ and $\alpha \mathbf{2 \delta}$ subunits). (A) Representative current traces induced by 150 $\mathrm{ms}$ voltage pulses from $-40 \mathrm{mV}$ to $+50 \mathrm{mV}$ in $10 \mathrm{mV}$ increments. (B) Representative currentvoltage (I-V) relationship from a HEK293_Ca 2.2 cell with $\mathrm{Ba}^{2+}$ (black trace) or $\mathrm{Ca}^{2+}$ (blue trace) as charge carrier. The currents are activated at voltages higher than $-20 \mathrm{mV}$ (high voltage-activated calcium channel currents). The current is larger and shifted in the hyperpolarized direction in the presence of $\mathrm{Ba}^{2+}$ as compared to $\mathrm{Ca}^{2+}$. (C) Inward currents are specifically mediated by $\mathrm{Ca}_{v} 2.2\left(\mathrm{~N}\right.$-type) $\mathrm{Ca}^{2+}$ channels. Time course of action of $1 \mu \mathrm{M} \omega$ CTX GVIA (start $t=0$ ) obtained by applying $50 \mathrm{~ms}$ voltage pulses to $0 \mathrm{mV}$ every $10 \mathrm{~s}$. The current rapidly decays in response to the specific blocker of $\mathrm{Ca}_{\mathrm{v}} 2.2$ (N-type) calcium channels, $\omega$-CTX GVIA (D) An example showing the current traces before and 5 minutes after the application of $1 \mu \mathrm{M} \omega$-CTX GVIA. The current disappears completely after $5 \mathrm{~min}$. of the application of $\omega$-CTX GVIA. 


\subsubsection{Investigation of the influence of $\alpha$-neurexins on the functional properties of $\mathrm{N}$-type calcium channels in HEK_Ca 2.2}

Neurexin $1 \alpha$ was expressed in HEK_Ca 2.2 cells under a CMV promoter and the transfected cells were identified on the patch-clamp setup by the co-expression of GFP (Fig. 3.2A and B). More than $95 \%$ cells that appeared green also expressed neurexin $1 \alpha$. Two representative cells are shown (Fig. 3.2C). $\mathrm{Ca}^{2+}$ channel currents were measured from GFP expressing cells, and compared to cells that were not fluorescent (control).

A

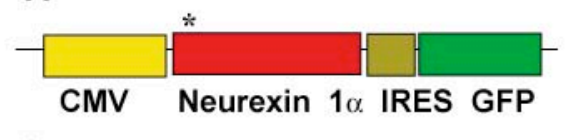

B

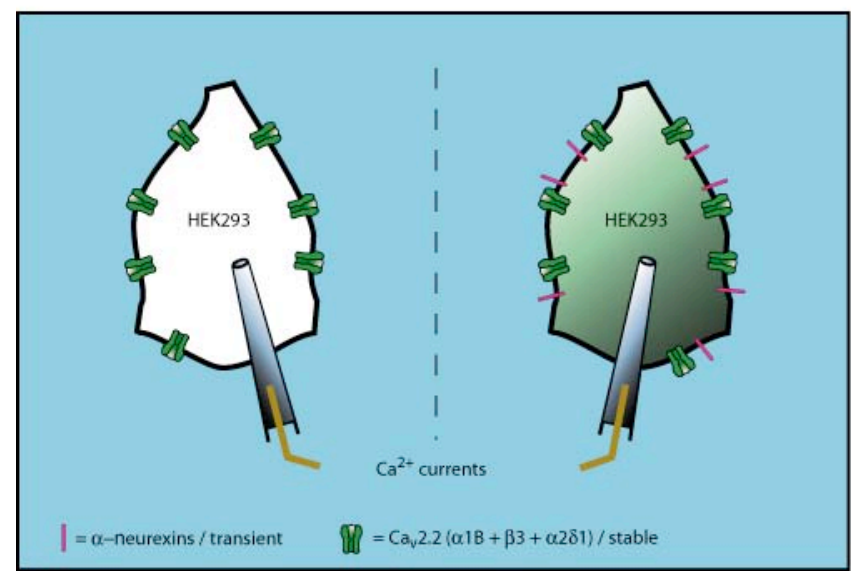

C
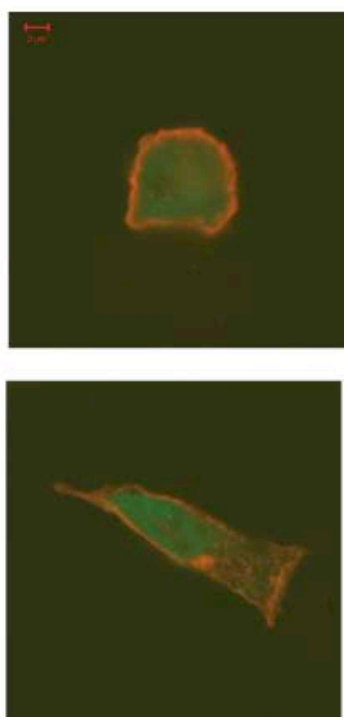

Figure 3.2 HEK293 cells stably transfected with $\mathrm{Ca}_{\mathrm{v}} 2.2$ calcium channels used to study the interaction with $\alpha$-neurexins. (A) Schematic showing the Flag-neurexin $1 \alpha$-IRES-GFP construct used for transfecting HEK_Ca 2.2 cells. Neurexin $1 \alpha$ is expressed under the CMV promoter and IRES directs the translation of GFP from the same transcript. This bicistronic vector ensured good co-expression of neurexin $1 \alpha$ and GFP. (B) Strategy for patch-clamp experiments on HEK_Ca 2.2 cells. Cells expressing neurexin $1 \alpha$ appeared green because of co-expression of GFP. $\mathrm{Ca}^{2+}$ channel currents were measured from cells that appeared green under blue light on patch-clamp setup, and compared to cells that were not fluorescent (control) (C) The cells transfected with Flag-Neurexin 1 $\alpha$-GFP showing co-expression of membranous neurexin $1 \alpha$ (anti-Flag antibody) and cytoplasmic EGFP (green). 
$\mathrm{Ca}^{2+}$ channel currents were elicited by $20 \mathrm{~ms}$ voltage pulses from a holding potential of -80 $\mathrm{mV}$ to $+50 \mathrm{mV}$ in $10 \mathrm{mV}$ increments. The measured curents were divided by whole-cell capacitance to get current density. The current density was not significantly different in cells transfected with neurexin $1 \alpha$ as compared to controls (Fig. 3.3A). We then decided to transfect two other molecules, CASK and Mint1 along with neurexin $1 \alpha$ into HEK_Ca 2.2 cells. CASK and Mint1 are MAGUK proteins that interact with the c-terminus of neurexins and have also been shown to bind to $\alpha 1 \mathrm{~B}$ subunit of $\mathrm{N}$-type $\mathrm{Ca}^{2+}$ channels. So CASK and Mint 1 could potentially link neurexin $1 \alpha$ with $\mathrm{N}$-type $\mathrm{Ca}^{2+}$ channels. Co-expression of CASK and Mint1 along with neurexin $1 \alpha$ did not significantly alter the current density in HEK_Ca 2.2 cells as compared to controls (Fig. 3.3A-C). At $10 \mathrm{mV}$ test potential, the current density in control cells was $-24.8 \pm 2.2 \mathrm{pA} / \mathrm{pF}$ while it was $-28.8 \pm 2.6 \mathrm{pA} / \mathrm{pF}$ in cells transfected with neurexin $1 \alpha$ alone and $-29.7 \pm 3.8 \mathrm{pA} / \mathrm{pF}$ in cells transfected with neurexin $1 \alpha$, CASK and Mint1. To investigate the activation properties of $\mathrm{Ca}^{2+}$ channel currents, I-V traces from individual cells were fit with modified Boltzmann equation (see section 2.2.4.1). 4 activation parameters were obtained: $\mathrm{V}_{1 / 2}$ act (half-activation potential), $\mathrm{k}_{\mathrm{act}}$ (slope factor), $\mathrm{G}_{\max }$ (maximum slope conductance), $\mathrm{V}_{\text {rev }}$ (reversal potential). None of the activation parameters were altered significantly with neurexin $1 \alpha$ alone or with CASK and Mint1, as compared to control cells (Table 1A).

To investigate the inactivation properties of $\mathrm{Ca}^{2+}$ channel currents, currents were evoked using $20 \mathrm{~ms}$ test pulse to $+10 \mathrm{mV}$ after $2 \mathrm{~s}$ voltage displacement (prepulse) from $-120 \mathrm{mV}$ to $+10 \mathrm{mV}$ in $10 \mathrm{mV}$ increments. Amplitudes of currents evoked by the test pulses were normalized to the maximum currents elicited and plotted against the prepulse potential (Figure 3.3D). The data from individual cells was fit with a Boltzmann equation (see section 2.2.4.1) to get the values of the parameters: $V_{1 / 2}$ inact (half-inactivation potential) and $k_{\text {inact }}$ (slope factor). The inactivation parameters were also not altered by the expression of neurexin $1 \alpha$ alone or with CASK and Mint1 (Table 1A). 
Figure 3.3 The effect of neurexin $1 \alpha$ on the current density as well as activation and inactivation profile of $\mathrm{Ca}^{2+}$ channel currents in $\mathrm{HEK} \mathrm{Ca}_{\mathrm{v}} 2.2$ cells. (A) Averaged current density-voltage relationships for control cells and cells expressing neurexin $1 \alpha$ alone or with CASK and Mint1. Current density at all test potentials is not significantly different in control cells from that in cells transfected with neurexin $1 \alpha$ or transfected with neurexin $1 \alpha+$ CASK + Mint1. The voltage-dependency of activation is also not changed as indicated by a non-shift of I-V curve in either direction. (B) Example current traces $\left(\mathrm{V}_{\mathrm{t}}=10 \mathrm{mV}, 20 \mathrm{~ms}\right)$ from a control cell (black) and a cell transfected with neurexin $1 \alpha+$ CASK + Mint1 (blue). (C) Bar graph showing current density at $10 \mathrm{mV}$ test potential. Current density in control cells $\left(\mathrm{V}_{\mathrm{t}}=10 \mathrm{mV}, \mathrm{I}\right.$ density $=-24.8 \pm 2.2 \mathrm{pA} / \mathrm{pF})$ is not significantly different from that in cells transfected with neurexin $1 \alpha\left(\mathrm{V}_{\mathrm{t}}=10 \mathrm{mV}, \mathrm{I}\right.$ density $\left.=-28.8 \pm 2.6 \mathrm{pA} / \mathrm{pF}\right)$ or transfected with neurexin $1 \alpha+$ CASK + Mint1 $\left(\mathrm{V}_{\mathrm{t}}=10 \mathrm{mV}\right.$, I density $\left.=-29.7 \pm 3.8 \mathrm{pA} / \mathrm{pF}\right)$. (D) Averaged steady-state inactivation curves for control cells and cells expressing neurexin $1 \alpha$ alone or with CASK and Mint1. Curves were generated from currents evoked by $20 \mathrm{~ms}$ test pulse to $+10 \mathrm{mV}$ after $2 \mathrm{~s}$ voltage displacement (prepulse) from $-120 \mathrm{mV}$ to $+10 \mathrm{mV}$ in $10 \mathrm{mV}$ increments. Similar inactivation profile is seen in the three groups of cells. 
A

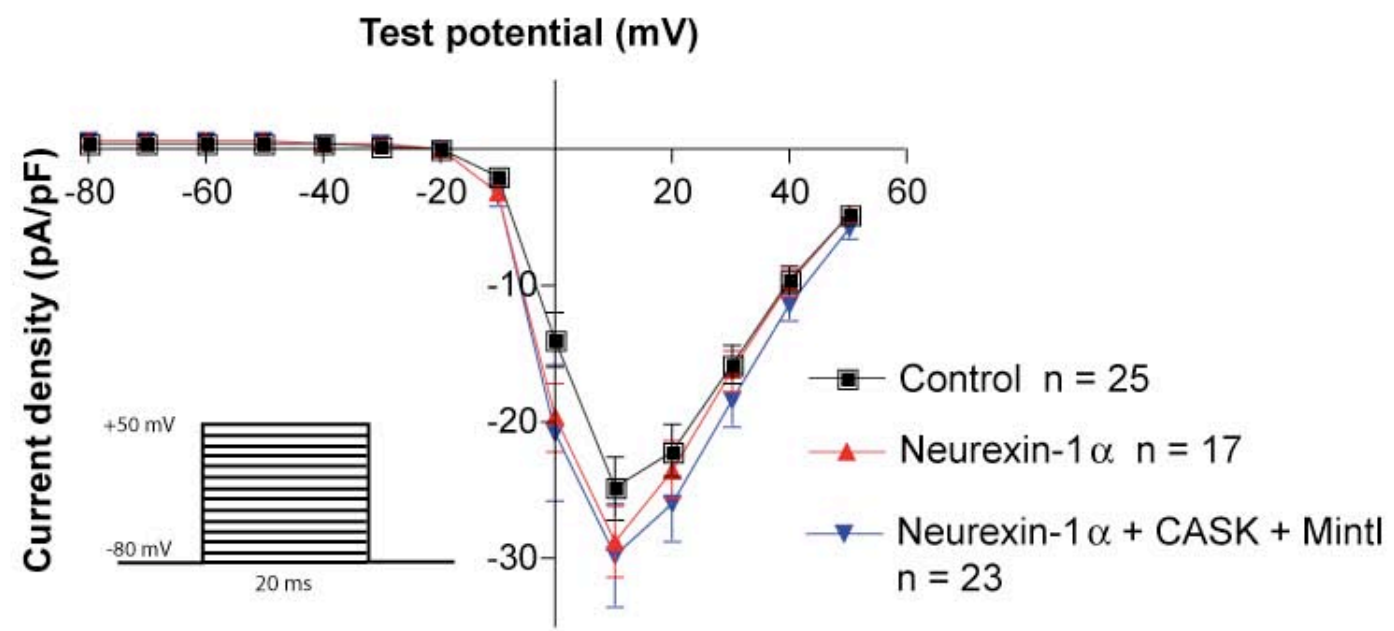

B

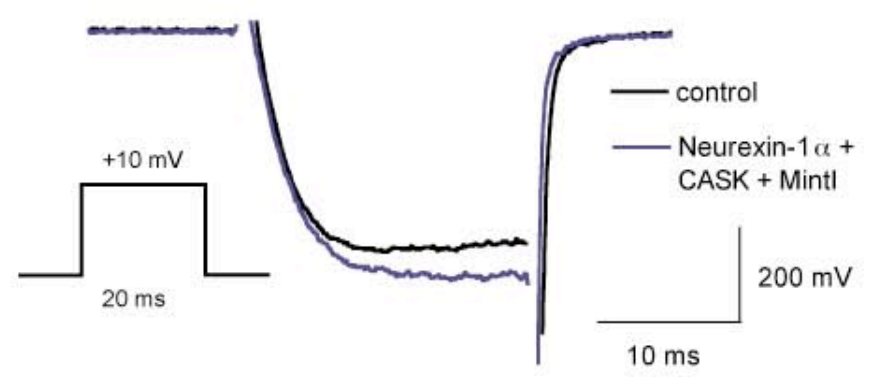

D

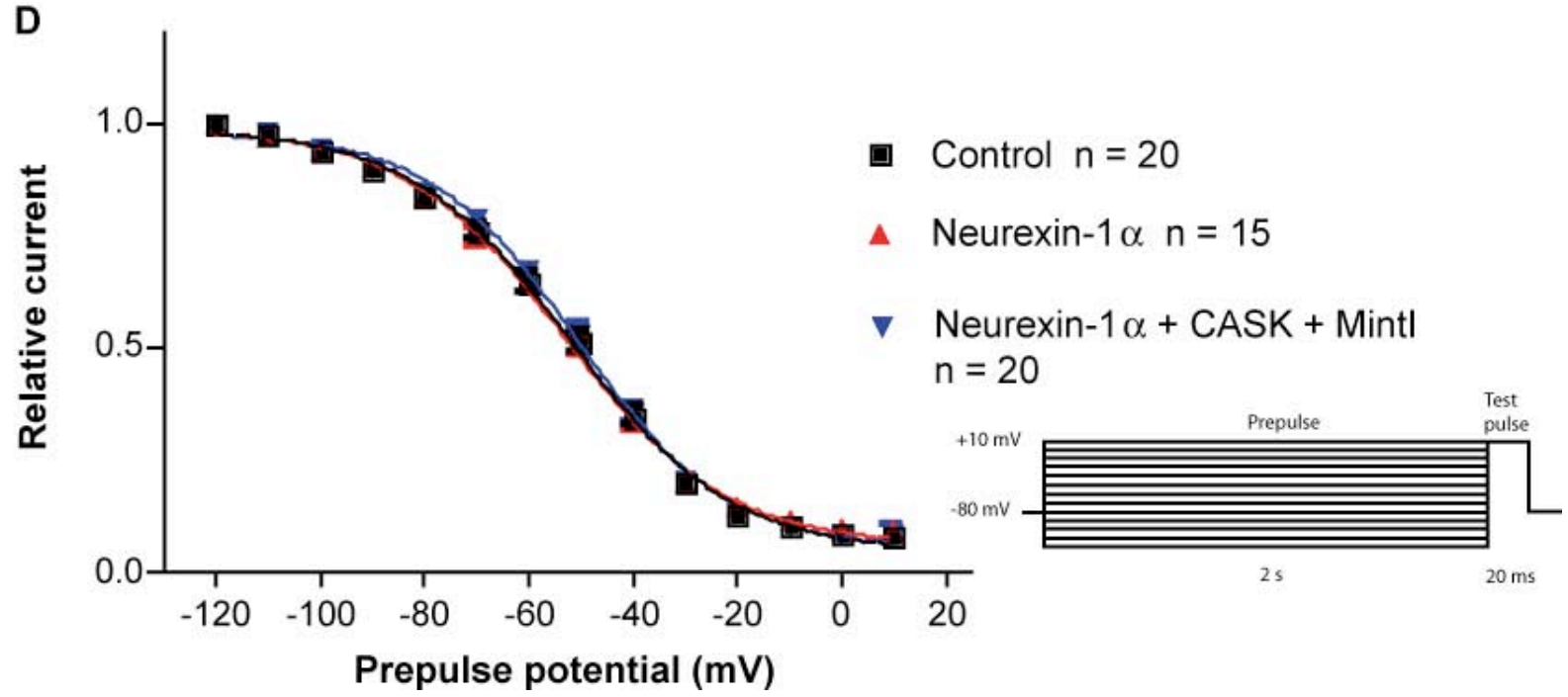

C

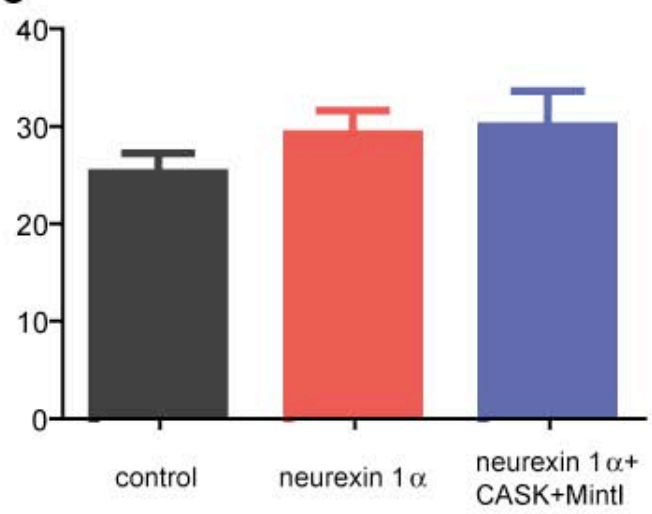




\subsubsection{Investigation of the influence of $\alpha$-neurexins on the functional properties of $\mathrm{N}$-type $\mathrm{Ca}^{2+}$ channels in tsA201 cells}

To rule out that the lack of an effect of neurexin $1 \alpha$ in HEK_Ca 2.2 cells was an artifact of that system, we investigated the same effect on another system, i.e., tsA201 cells transiently transfected with rat $\mathrm{Ca}^{2+}$ channel subunits. tsA201 cells are modified HEK293 cells stably transfected with SV40 large T antigen to increase expression levels of transiently transfected proteins. The $\mathrm{Ca}^{2+}$ channel subunits used were $\alpha 1 \mathrm{~B}, \beta 1 \mathrm{~b}$ and $\alpha 2 \delta 1$, all from rat to insure maximum possible interaction with rat neurexin $1 \alpha$.

Whole-cell patch-clamp measurements with $\mathrm{Ba}^{2+}$ as charge carrier revealed inward $\mathrm{Ca}^{2+}$ channel currents typical of high-voltage activated calcium channels (Fig. 3.4A). The cells were transfected with neurexin $1 \alpha$ and GFP or with GFP alone (control). For measuring curent density and activation parameters, currents were evoked by $150 \mathrm{~ms}$ voltage pulses from $-40 \mathrm{mV}$ to $+50 \mathrm{mV}$ in $10 \mathrm{mV}$ increments. Current density in control cells $\left(\mathrm{V}_{\mathrm{t}}=20 \mathrm{mV}, \mathrm{I}\right.$ density $=-20.97 \pm 3.0 \mathrm{pA} / \mathrm{pF}$ ) was not significantly different (Fig. 3.4C) from that in cells transfected with neurexin $1 \alpha\left(\mathrm{V}_{\mathrm{t}}=20 \mathrm{mV}\right.$, I density $\left.=-20.85 \pm 3.07 \mathrm{pA} / \mathrm{pF}\right) . \mathrm{I}-\mathrm{V}$ traces from individual cells were fit with modified Boltzmann equation to get the activation parameters, none of which was significantly different between the two groups (see Table 1B). For studying inactivation properties of $\mathrm{Ca}^{2+}$ channel currents, currents were evoked using $20 \mathrm{~ms}$ test pulse to $+10 \mathrm{mV}$ after $2 \mathrm{~s}$ voltage displacement (prepulse) from $-120 \mathrm{mV}$ to $+10 \mathrm{mV}$ in $10 \mathrm{mV}$ increments. The inactivation parameters were also not significantly different between the two groups (Fig 3.4D and Table 1B).

Similar experiments as described above were also done in the presence of $\mathrm{Ca}^{2+}$ as charge carrier (Fig. 3.4E and 3.4F). Current density in control cells $\left(\mathrm{V}_{\mathrm{t}}=30 \mathrm{mV}\right.$, I density $=-14.61 \pm$ $2.81 \mathrm{pA} / \mathrm{pF}$ ) was again not significantly different from that in cells transfected with neurexin $1 \alpha\left(\mathrm{V}_{\mathrm{t}}=30 \mathrm{mV}\right.$, I density $\left.=-13.57 \pm 2.89 \mathrm{pA} / \mathrm{pF}\right)$. There was a small but statistically significant shift in the half-activation potential of $\mathrm{Ca}^{2+}$ currents in cells transfected with neurexin $1 \alpha$ as compared to control cells (Table 1B). Other activation and inactivation parameters were not altered significantly with expression of neurexin $1 \alpha$. 
Figure 3.4 ts A201 cells transiently transfected with $\mathrm{Ca}_{\mathrm{v}} 2.2$ calcium channels $(\alpha 1 \mathrm{~B}, \beta 1 \mathrm{~b}$ and $\alpha 2 \delta$ subunits) used to study the interaction with $\alpha$-neurexins. (A) Representative current traces induced by $150 \mathrm{~ms}$ voltage pulses from $-40 \mathrm{mV}$ to $+50 \mathrm{mV}$ in $10 \mathrm{mV}$ increments. (B) Western blot from lysate of tsA201 cells transfected with neurexin $1 \alpha$ and labelled with anti-neurexin antibody. (C) Averaged current density-voltage relationships for control cells and cells expressing neurexin $1 \alpha$ in the presence of $20 \mathrm{mM} \mathrm{Ba}^{2+}$ as charge carrier. Current density in control cells $\left(\mathrm{V}_{t}=20 \mathrm{mV}, \mathrm{I}\right.$ density $\left.=-20.97 \pm 3.0 \mathrm{pA} / \mathrm{pF}\right)$ is not significantly different from that in cells transfected with neurexin $1 \alpha\left(\mathrm{V}_{\mathrm{t}}=20 \mathrm{mV}\right.$, I density $=$ $20.85 \pm 3.07 \mathrm{pA} / \mathrm{pF}$ ). (D) Averaged steady-state inactivation curves for control cells and cells expressing neurexin $1 \alpha$ with $20 \mathrm{mM} \mathrm{Ba}^{2+}$ as charge carrier. Curves were generated from currents evoked by 20 ms test pulse to $+10 \mathrm{mV}$ after $2 \mathrm{~s}$ voltage displacement (prepulse) from $-120 \mathrm{mV}$ to $+10 \mathrm{mV}$ in $10 \mathrm{mV}$ increments. Amplitudes of currents evoked by the test pulses were normalized to the maximum currents elicited. Steady-state inactivation does not differ between control cells and cells transfected with neurexin $1 \alpha$. (E) Similar experiment as in $3.4 \mathrm{C}$ but with $10 \mathrm{mM} \mathrm{Ca}^{2+}$ as charge carrier. Current density in control cells $\left(\mathrm{V}_{\mathrm{t}}=30 \mathrm{mV}, \mathrm{I}\right.$ density $=-14.61 \pm 2.81 \mathrm{pA} / \mathrm{pF}$ ) is not significantly different from that in cells transfected with neurexin $1 \alpha\left(V_{t}=30 \mathrm{mV}\right.$, I density $\left.=-13.57 \pm 2.89 \mathrm{pA} / \mathrm{pF}\right)$. (F) Similar experiment as in 3.4D but with $10 \mathrm{mM} \mathrm{Ca}^{2+}$ as charge carrier. A $30 \mathrm{mV}$ test pulse was used. Steady-state inactivation does not differ between control cells and cells transfected with neurexin $1 \alpha$. 


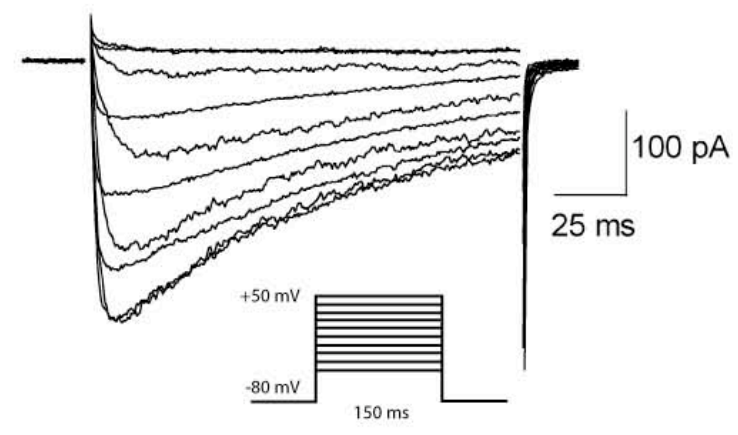

C

$20 \mathrm{mM} \mathrm{Ba}^{2+}$ as charge carrier

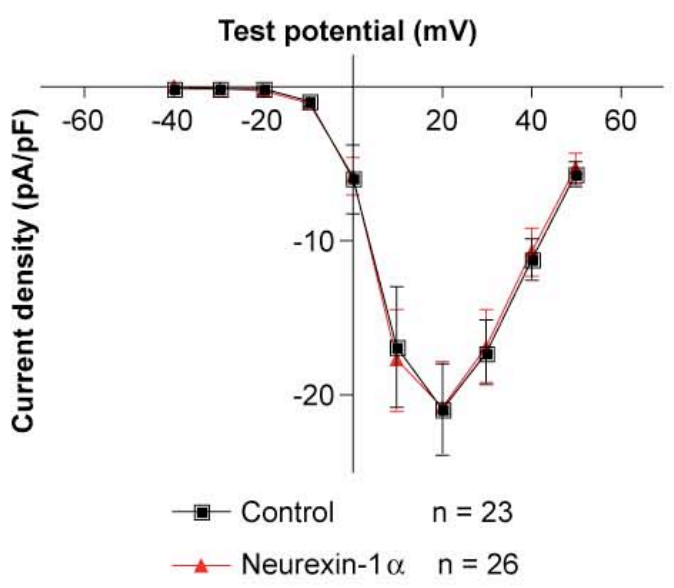

E

$10 \mathrm{mM} \mathrm{Ca}^{2+}$ as charge carrier

Test potential $(\mathrm{mV})$

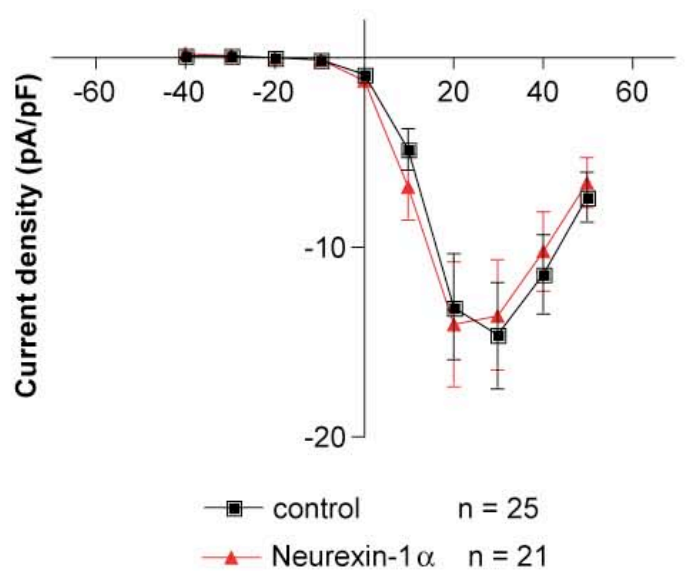

B

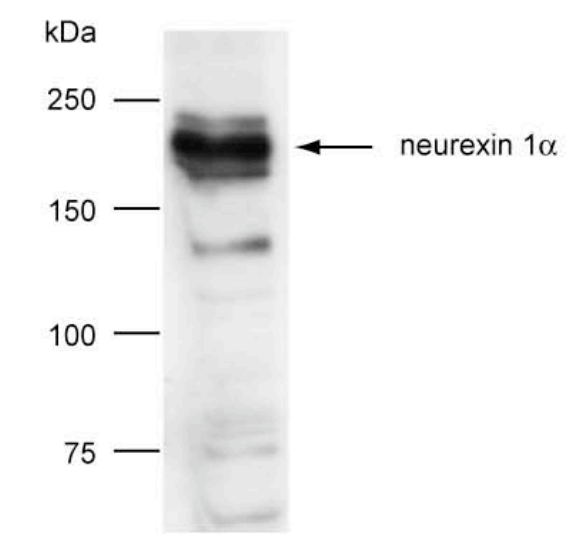

D

\section{$20 \mathrm{mM} \mathrm{Ba}^{2+}$ as charge carrier}

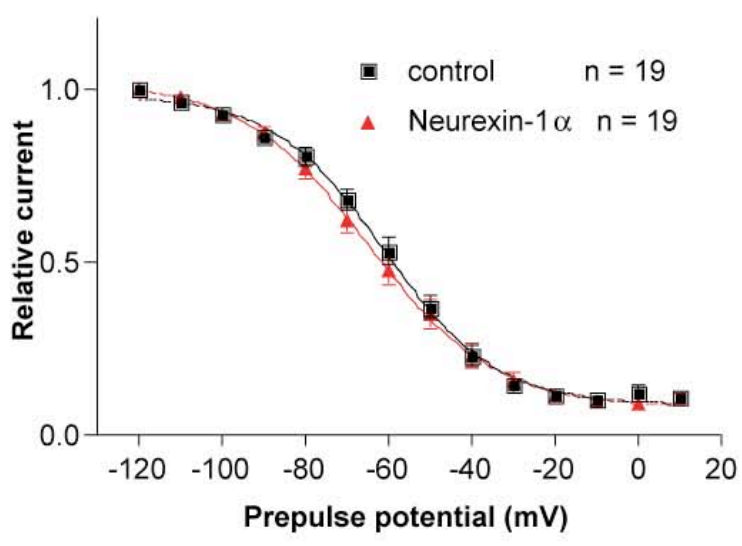

F

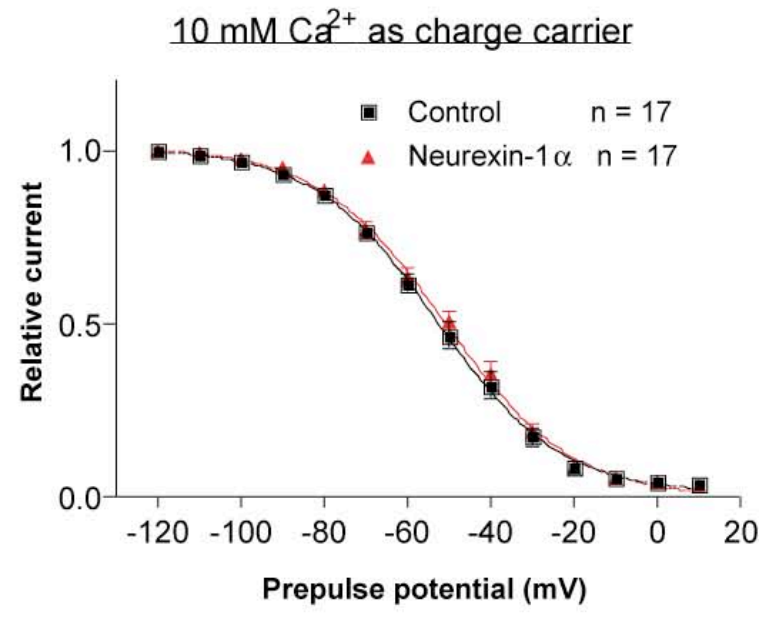


A. Stable HEK293_Cav2.2 cell line transfected with:

\begin{tabular}{|c|c|c|c|c|}
\hline & Control & $\operatorname{Nrxn} 1 \alpha$ & Nrxn $1 \alpha \&$ CASK & \\
\hline & & & Mint1 & $P=$ \\
\hline Activation & $\mathrm{n}=25$ & $\mathrm{n}=17$ & $n=23$ & \\
\hline $\mathrm{V}_{1 / 2}$ act $[\mathrm{mV}]$ & $1.46 \pm 0.69$ & $-0.812 \pm 0.72$ & $1.02 \pm 0.98$ & 0.16 \\
\hline $\mathrm{k}_{\mathrm{act}}[\mathrm{mV}]$ & $3.53 \pm 0.19$ & $3.14 \pm 0.21$ & $3.42 \pm 0.28$ & 0.53 \\
\hline $\mathrm{V}_{\mathrm{rev}}[\mathrm{mV}]$ & $56.12 \pm 0.72$ & $55.88 \pm 0.70$ & $56.37 \pm 1.28$ & 0.94 \\
\hline $\mathrm{G}_{\max }[\mathrm{mV}]$ & $8.04 \pm 0.68$ & $8.47 \pm 0.81$ & $9.37 \pm 1.07$ & 0.52 \\
\hline Inactivation & $\mathrm{n}=20$ & $\mathrm{n}=15$ & $\mathrm{n}=20$ & \\
\hline $\mathrm{V}_{1 / 2}$ inact $[\mathrm{mV}]$ & $-52.65 \pm 1.55$ & $-53.73 \pm 1.48$ & $-50.50 \pm 1.09$ & 0.26 \\
\hline $\mathrm{K}_{\text {inact }}[\mathrm{mV}]$ & $14.86 \pm 0.69$ & $15.07 \pm 0.69$ & $13.72 \pm 0.46$ & 0.25 \\
\hline
\end{tabular}

B. tsA201 cells transiently transfected with Cav2.2 subunits and Nrxn $1 \alpha$ or control:

$$
\text { Control Nrxn } 1 \alpha \quad \text { Control Nrxn } 1 \alpha
$$

\begin{tabular}{|c|c|c|c|c|c|c|}
\hline Charge carrier & \multicolumn{2}{|c|}{$20 \mathrm{mM} \mathrm{Ba}^{2+}$} & $P=$ & \multicolumn{2}{|c|}{$10 \mathrm{mMCa}^{2+}$} & $P=$ \\
\hline Activation & $n=23$ & $n=26$ & & $\mathrm{n}=25$ & $n=21$ & \\
\hline $\mathrm{V}_{1 / 2 \text { act }}[\mathrm{mV}]$ & $10.36 \pm 0.76$ & $9.55 \pm 0.89$ & 0.51 & $18.55 \pm 0.59$ & $15.97 \pm 0.93$ & 0.02 * \\
\hline $\mathrm{k}_{\text {act }}[\mathrm{mV}]$ & $5.08 \pm 0.22$ & $5.07 \pm 0.22$ & 0.98 & $5.17 \pm 0.17$ & $5.11 \pm 0.24$ & 0.83 \\
\hline $\mathrm{V}_{\text {rev }}[\mathrm{mV}]$ & $59.18 \pm 0.92$ & $58.70 \pm 0.93$ & 0.71 & $68.28 \pm 0.78$ & $67.18 \pm 0.71$ & 0.31 \\
\hline $\mathrm{G}_{\max }[\mathrm{mV}]$ & $11.83 \pm 1.69$ & $11.20 \pm 1.38$ & 0.77 & $9.55 \pm 1.57$ & $9.30 \pm 1.86$ & 0.92 \\
\hline Inactivation & $n=19$ & $n=19$ & & $n=17$ & $n=17$ & \\
\hline $\mathrm{V}_{1 / 2 \text { inact }}[\mathrm{mV}]$ & $-60.70 \pm 1.92$ & $-63.62 \pm 2.28$ & 0.33 & $-52.38 \pm 2.09$ & $-51.01 \pm 1.99$ & 0.64 \\
\hline $\mathrm{K}_{\text {inact }}[\mathrm{mV}]$ & $12.26 \pm 0.86$ & $13.49 \pm 0.51$ & 0.23 & $13.75 \pm 0.54$ & $14.24 \pm 0.38$ & 0.47 \\
\hline
\end{tabular}

Data are means \pm SEM; $n=$ number of cells analyzed from at least 3 different transfections. 


\subsection{Synaptic transmission at Schaffer collateral-CA1 synapses in $\alpha$-neurexin knockout mice}

It has been shown in earlier studies that basal properties of synaptic transmission are impaired in double and triple knockouts of $\alpha$-neurexins. However little is known about the role of $\alpha$ neurexins in synaptic plasticity. We therefore decided to investigate whether deletions of $\alpha$ neurexins alter various forms of synaptic plasticity. For this, we performed extracellular recordings of field excitatory postsynaptic potentials (fEPSPs) in acute hippocampal slices derived from $\alpha$-neurexin $\mathrm{KO}$ mice. 6-14 weeks old mice which were neurexin $1 \alpha / 2 \alpha$ double $\mathrm{KO}$ or neurexin $2 \alpha / 3 \alpha$ double $\mathrm{KO}$ were used, and compared with neurexin $2 \alpha$ single $\mathrm{KO}$ mice which acted as littermate controls in all experiments. Neurexin $2 \alpha$ single KO mice have least mortality among $\alpha$-neurexin KOs and show similar synaptic transmission as compared to wildtype mice in acute brainstem slices (Missler et al., 2003). Importantly neurexin $2 \alpha$ single KO (but not wildtype mice) are obtained as littermates of $\alpha$-neurexin double KOs during breeding, and therefore possess the same genetic background as $\alpha$-neurexin double KOs.

\subsubsection{Basal synaptic transmission at Schaffer collateral-CA1 synapses in $\alpha$-neurexin KO mice}

The Schaffer collateral-CA1 synapse in hippocampus is a commonly studied synapse to decipher the properties of synaptic transmission and synaptic plasticity. Due to its well defined circuitry and easy accessibility, it yields itself well to extracellular recordings. We first wanted to see whether deletion of $\alpha$-neurexins reduces basal release at these synapses, similar to what has been found for synapses in neocortical slice cultures and acute brainstem slices (Missler et al., 2003; Zhang et al., 2005). Evoked responses were recorded from stratum radiatum of CA1 region after stimulation of Schaffer collaterals with increasing stimulus strengths (Figure 3.5A,B). Analysis of input-output curves showed that fEPSP slopes initially increased with increasing stimulus strength, and began to plateau at higher stimulus intensities (Figure 3.5D). Average of fEPSP slopes between stimulus intensities 110-150 $\mu \mathrm{A}$ from each slice were grouped according to genotype. Their comparison indicated that synaptic transmission is significantly reduced in neurexin $1 \alpha / 2 \alpha$ double $\mathrm{KO}(-0.88 \pm 0.15 \mathrm{mV} / \mathrm{ms} ; \mathrm{n}=$ 16 slices, 4 mice $)$ and neurexin $2 \alpha / 3 \alpha$ double $\mathrm{KO}(-0.93 \pm 0.10 \mathrm{mV} / \mathrm{ms} ; \mathrm{n}=18$ slices, 4 mice $)$ as compared to contol mice $(-1.54 \pm 0.27 \mathrm{mV} / \mathrm{ms} ; \mathrm{n}=15$ slices, 4 mice $)$. 
A

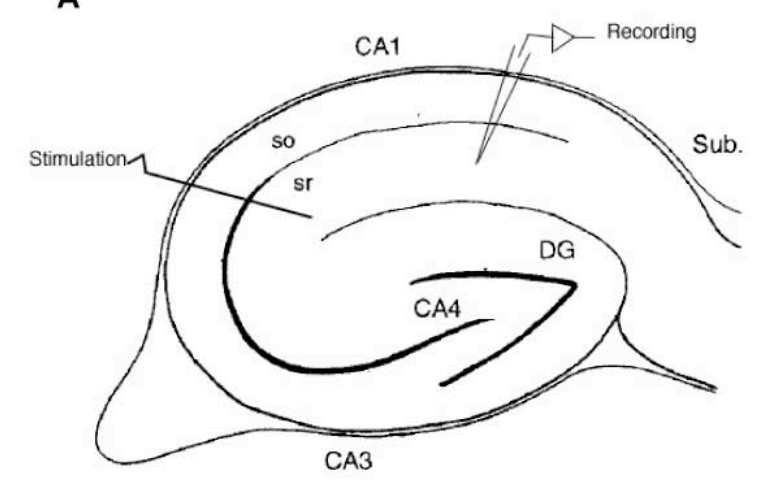

B

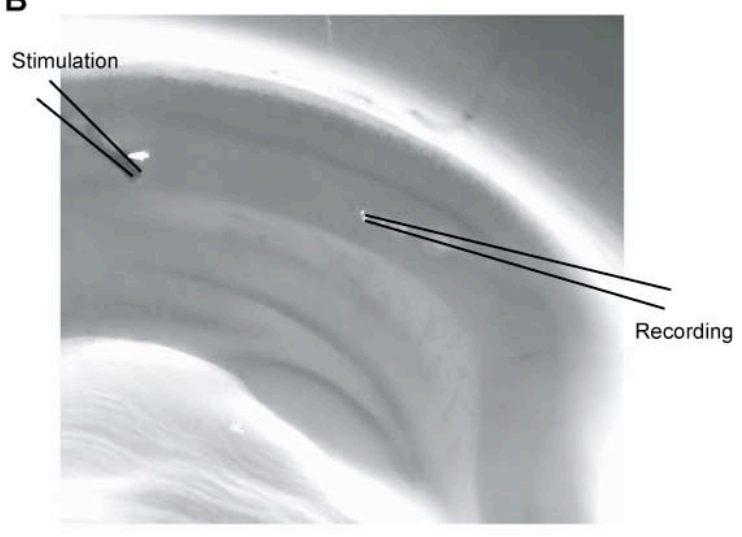

C
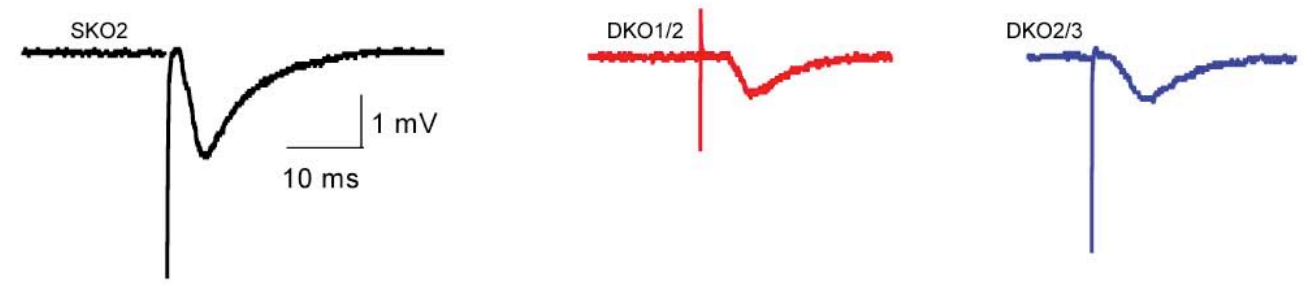

D

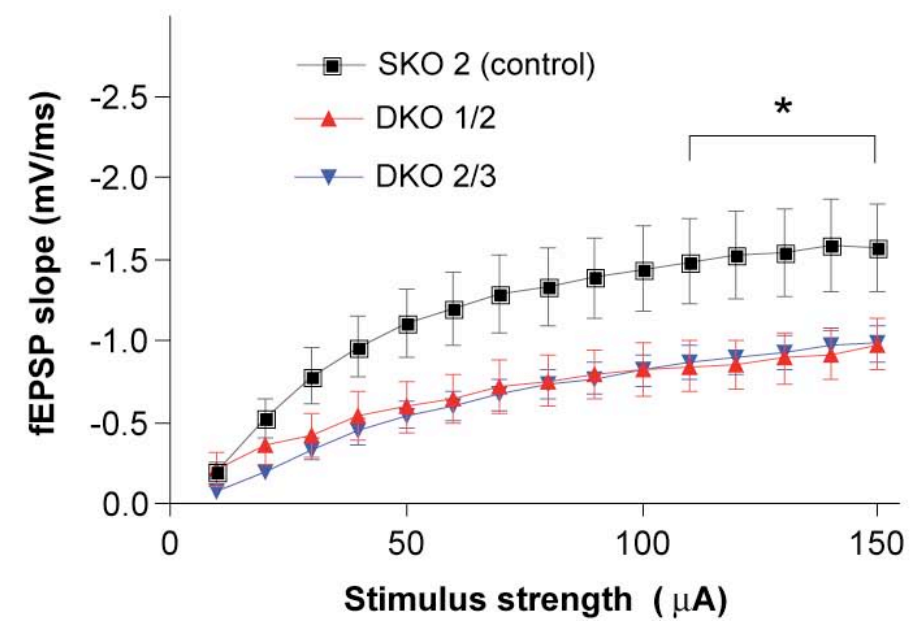

Figure 3.5 Basal synaptic transmission is reduced at Schaffer collateral-CA1 synapses in $\alpha$-neurexin double KO mice. Extracellular field potential recordings done in acute hippocampal slices derived from 6-14 week old mice. (A) A schematic representation of a coronal slice used for recordings (modified from Muller and Somjen, 1999). Schaffer collaterals were stimulated by a unipolar microwire electrode and recordings taken at CA1 stratum radiatum (sr). (B) A photograph of a slice (400 $\mu \mathrm{m}$ thick) used for recording. Electrode positions are indicated. (C) Sample recordings, with an initial large deflection (stimulation artifact) followed by a slowly decaying synaptic potential (fEPSP). Recordings at $50 \%$ of maximum response (average of 4 traces) shown for control (black trace), neurexin $1 \alpha / 2 \alpha \mathrm{KO}$ (red trace) and neurexin $2 \alpha / 3 \alpha \mathrm{KO}$ (blue trace). (D) Input-output curve as a measure of baseline synaptic transmission. fEPSP slope is plotted against the stimulation strength. fEPSP slope was significantly reduced in neurexin $1 \alpha / 2 \alpha(n=16$ slices, 4 mice $)$ and neurexin $2 \alpha / 3 \alpha$ double KOs ( $n=18$ slices, 4 mice) as compared to control mice (neurexin $2 \alpha$ single $\mathrm{KO}$ ) ( $\mathrm{n}=15$ slices, 4 mice). Error bars indicated standard error of mean (SEM). 


\subsubsection{Short-term synaptic plasticity at Schaffer collateral-CA1 synapses in $\alpha$-neurexin KO mice}

The shortest form of plasticity at many synapses is paired-pulse facilitation (PPF) or depression (PPD) (Zucker and Regehr, 2002). Schaffer collateral-CA1 synapses show pairedpulse facilitation. Paired-pulse facilitation was measured at different inter-stimulus intervals $(15,25,50,75,100,125$ and $150 \mathrm{~ms})$ as the ratio of the second fEPSP slope to the first fEPSP slope (paired-pulse ratio). We found that $\alpha$-neurexin double KOs showed significantly enhanced paired-pulse facilitation as compared to controls at short interstimulus intervals (Figure 3.6 and Table 2).

A

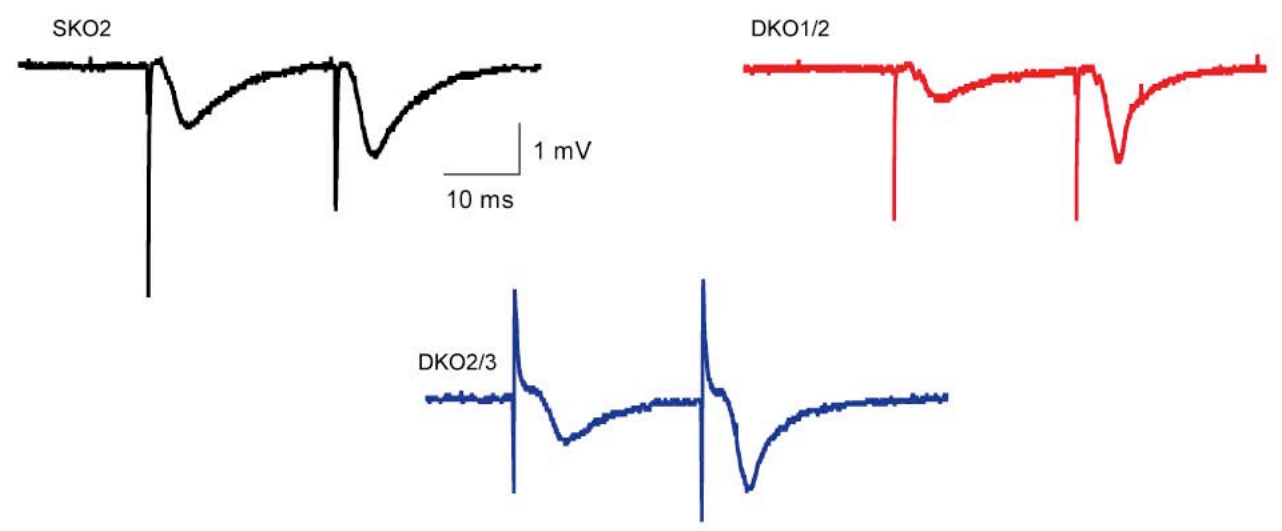

B

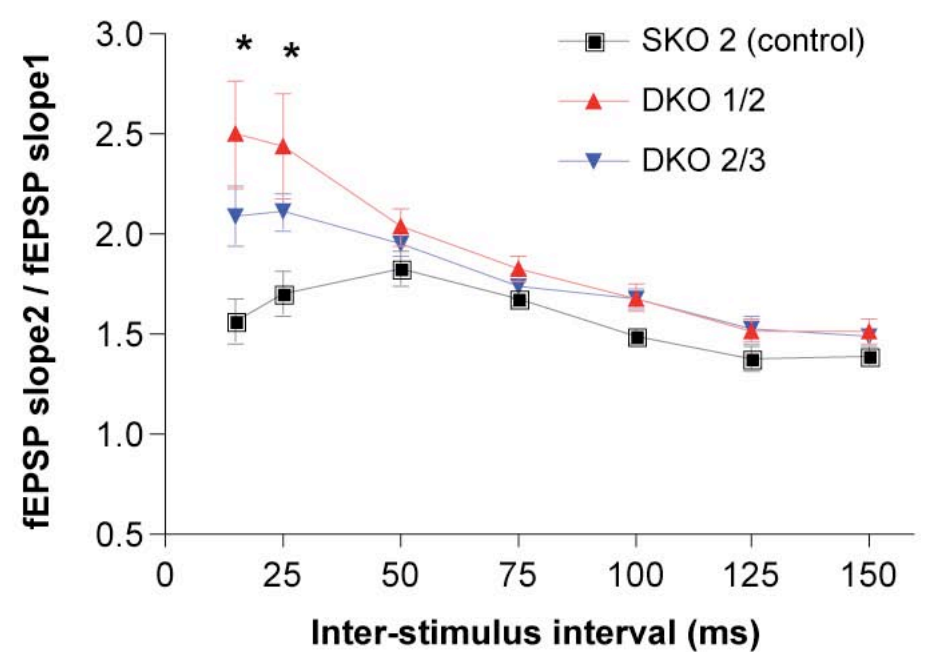

Figure 3.6 Paired-pulse facilitation is enhanced in $\alpha$-neurexin double KO mice. (A) Example traces for neurexin $2 \alpha$ single KO (control, black trace), neurexin $1 \alpha / 2 \alpha$ (red trace) and neurexin $2 \alpha / 3 \alpha$ (blue trace) with $25 \mathrm{~ms}$ interstimulus interval. (B) Paired-pulse ratio (fEPSP slope for 2nd stimulus)/ (fEPSP slope for 1st stimulus) at inter-stimulus interval of 15 and $25 \mathrm{~ms}$ is significantly greater in neurexin $1 \alpha / 2 \alpha(n=18$ slices, 5 mice $)$ and neurexin $2 \alpha / 3 \alpha$ double KOs ( $n=18$ slices, 4 mice) as compared to control mice $(n=12-16$ slices, 4 mice). 
In addition, the maximum facilitation appeared at shorter inter-stimulus intervals in $\alpha$ neurexin double KOs as compared to controls, so the "facilitation curve" was shifted towards the left. In control mice, paired-pulse ratio peaked at $50 \mathrm{~ms}$ interstimulus interval while in neurexin $1 \alpha / 2 \alpha$ double KOs, maximum facilitation was present at $15 \mathrm{~ms}$, which was the shortest inter-stimulus interval tested. In neurexin $2 \alpha / 3 \alpha$ double KOs, peak facilitation was observed at $25 \mathrm{~ms}$ inter-stimulus interval.

TABLE 2: Paired-pulse facilitation at different inter-stimulus intervals in control (SKO 2), neurexin $1 \alpha / 2 \alpha$ double KOs (DKO 1/2) and neurexin $2 \alpha / 3 \alpha$ double KOs (DKO 2/3)

\begin{tabular}{cccc}
\hline \multicolumn{4}{c}{ Paired-pulse ratio } \\
\hline $\begin{array}{c}\text { Inter-stimulus } \\
\text { interval (ms) }\end{array}$ & $\begin{array}{l}\text { SKO } 2 ; n= \\
\text { slices, } 4 \text { mice }\end{array}$ & $\begin{array}{l}\text { DKO } 1 / 2, n=18 \text { slices, } \\
5 \text { mice }\end{array}$ & $\begin{array}{l}\text { DKO } 2 / 3, n=18 \text { slices, } \\
4 \text { mice }\end{array}$ \\
\hline 15 & $1.56 \pm 0.12$ & $2.50 \pm 0.27^{*}$ & $2.09 \pm 0.15^{*}$ \\
25 & $1.71 \pm 0.11$ & $2.44 \pm 0.26^{*}$ & $2.11 \pm 0.10^{*}$ \\
50 & $1.83 \pm 0.08$ & $2.04 \pm 0.10$ & $1.95 \pm 0.06$ \\
75 & $1.68 \pm 0.04$ & $1.8 \pm 0.06$ & $1.74 \pm 0.06$ \\
100 & $1.49 \pm 0.04$ & $1.68 \pm 0.06$ & $1.67 \pm 0.05$ \\
125 & $1.38 \pm 0.06$ & $1.52 \pm 0.06$ & $1.52 \pm 0.07$ \\
150 & $1.39 \pm 0.05$ & $1.51 \pm 0.06$ & $1.49 \pm 0.04$ \\
\hline
\end{tabular}

Data are means \pm SEM. * indicates statistical significance $(p<0.05)$.

We also looked at how synaptic strength is changed in response to a train of stimuli (frequency induced plasticity). When Schaffer collaterals were stimulated with a $14 \mathrm{~Hz}$ train (23 s, 300 stimuli) , $\alpha$-neurexin double KOs showed increased facilitation as compared to controls (Figure 3.7A). In control mice, fEPSP slopes increased for the first 4-5 stimuli in the train and then started decreasing gradually. Neurexin $1 \alpha / 2 \alpha$ and neurexin $2 \alpha / 3 \alpha$ double KOs showed more extended facilitation and fEPSP slopes peaked after the first 10-12 stimuli. So the ratio (fEPSP slope 40th stimulus)/(fEPSP slope 4th stimulus) was significantly greater in neurexin $1 \alpha / 2 \alpha$ double KOs $(1.084 \pm 0.09 ; n=13$ slices, 4 mice $)$ and neurexin $2 \alpha / 3 \alpha$ double KOs $(1.076 \pm 0.07 ; \mathrm{n}=16$ slices, 4 mice $)$ as compared to control mice $(0.824 \pm 0.05 ; \mathrm{n}=12$ slices, 4 mice) (Figure 3.7B). After reaching the peak, fEPSP slopes from double KOs also began to decrease in a parallel course as control mice, indicating that depression was not altered by the deletion of $\alpha$-neurexins (Figure 3.7C). This implies that the increased ratio (fEPSP slope 40th stimulus)/(fEPSP slope 4th stimulus) in $\alpha$-neurexin double KOs is because of enhanced facilitation and not due to reduced depression. This depression was followed by a period of potentiation, which was possibly NMDA-dependent short-term potentiation (Cabin 
et al., 2002). When the train was continued till 300 stimuli, the responses from the three groups returned to similar values, as judged by the ratio (fFEPSP slope 300th stimulus/fFEPSP slope 4th stimulus) (Figure 3.7D). This indicated that the total pool of vesicles or rate of replenishment of releasable vesicle pool is similar between control and $\alpha$ neurexin double $\mathrm{KO}$ mice.

Post-tetanic potentiation (PTP) is another form of short-term synaptic plasticity that is induced by a train of stimuli and persists for a short period of time after the cessation of the train. PTP was studied in the presence of NMDA receptor antagonist, DL-APV to prevent contamination with NMDA receptor-dependent short-term potentiation (STP). We used a 1 $\mathrm{Hz}$ train to elicit responses. After a baseline stimulation for 1 minute at $1 \mathrm{~Hz}$, a single train at $100 \mathrm{~Hz}$ for $1 \mathrm{~s}$ was used to induce PTP. The post-tetanic responses were then recorded by giving stimuli at $1 \mathrm{~Hz}$ for 1 minute (Figure 3.7E). The magnitude of PTP was quantified by measuring the highest point of potentiation of fEPSP after the train. Comparing the responses between genotypes showed that PTP in control mice (1.54 $\pm 0.06 ; \mathrm{n}=7$ slices, 3 mice $)$ was not significantly different from neurexin $1 \alpha / 2 \alpha$ double KOs $(1.73 \pm 0.25 ; \mathrm{n}=9$ slices, 3 mice $)$ and neurexin $2 \alpha / 3 \alpha$ double KOs $(1.42 \pm 0.09 ; \mathrm{n}=9$ slices, 3 mice $)$. There was however a tendency in neurexin $1 \alpha / 2 \alpha$ double KOs to show higher PTP but it did not reach statistical significance. The protocol that we used for PTP is unusual in that the post-tetanic responses were recorded starting $1 \mathrm{~s}$ after the tetanus. This was done because in $1.2 \mathrm{mM} \mathrm{Ca}^{2+}$ (the usual concentration of $\mathrm{Ca}^{2+}$ in ACSF in all of our experiments), PTP is very brief lasting less than 15 s (Schulz and Fitzgibbons, 1997). However at this time the synapses are still recovering from depression induced by the train, and might interfere with PTP measurements. 
A

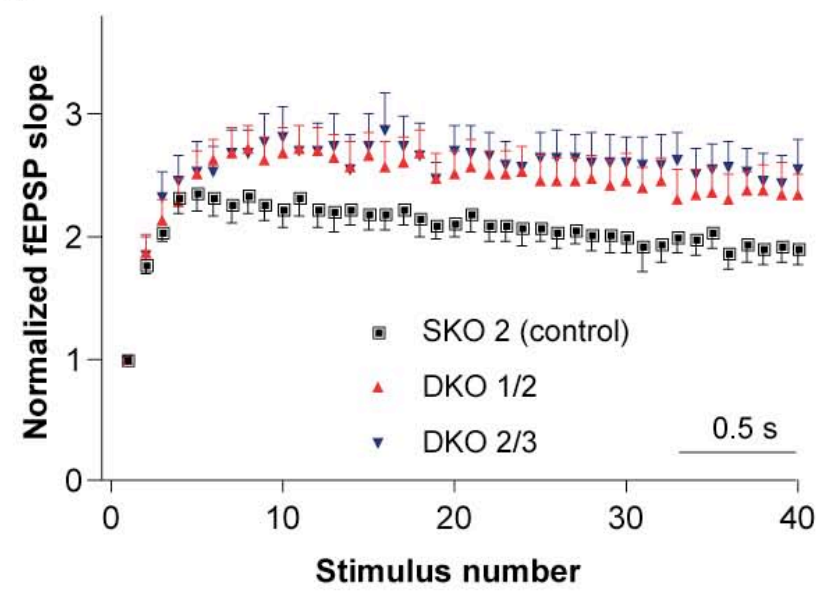

C

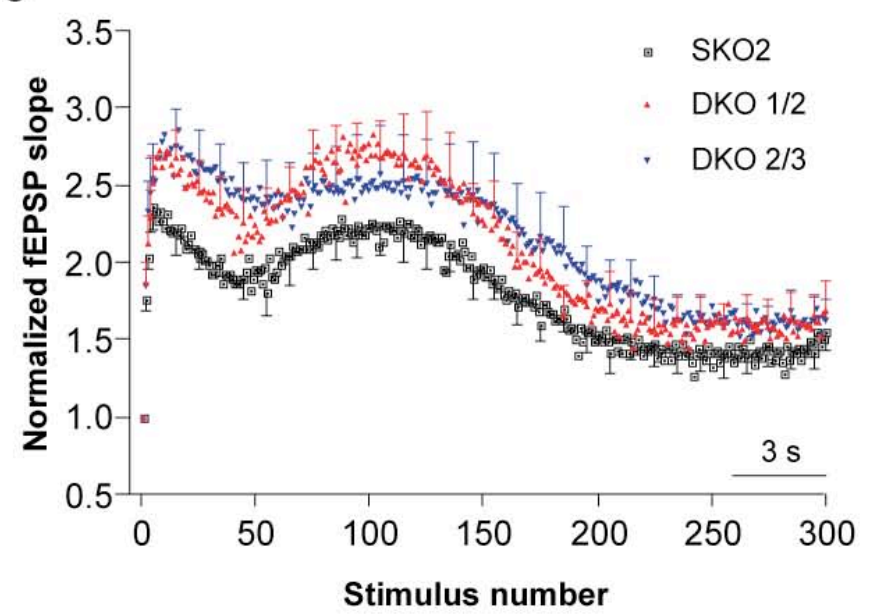

B

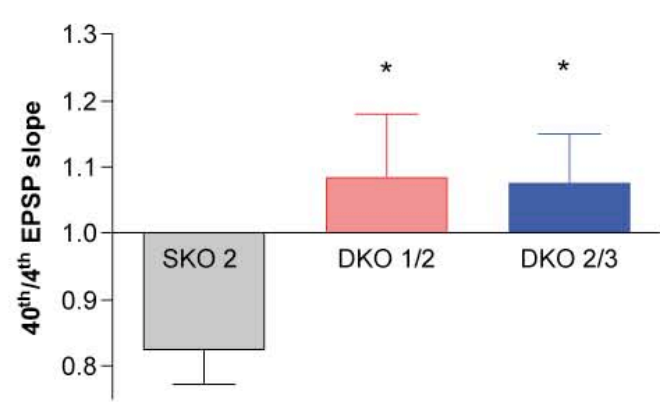

D

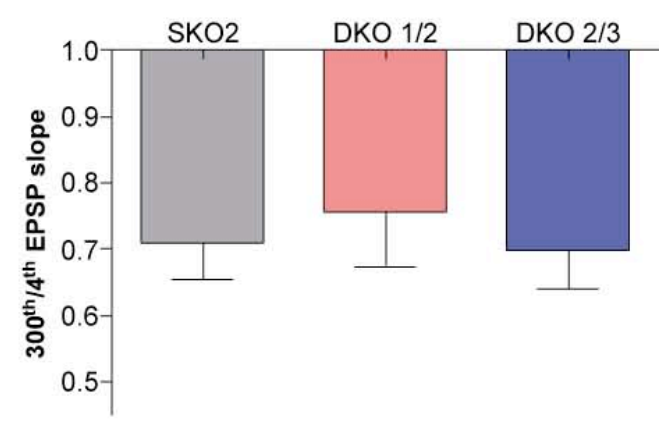

E

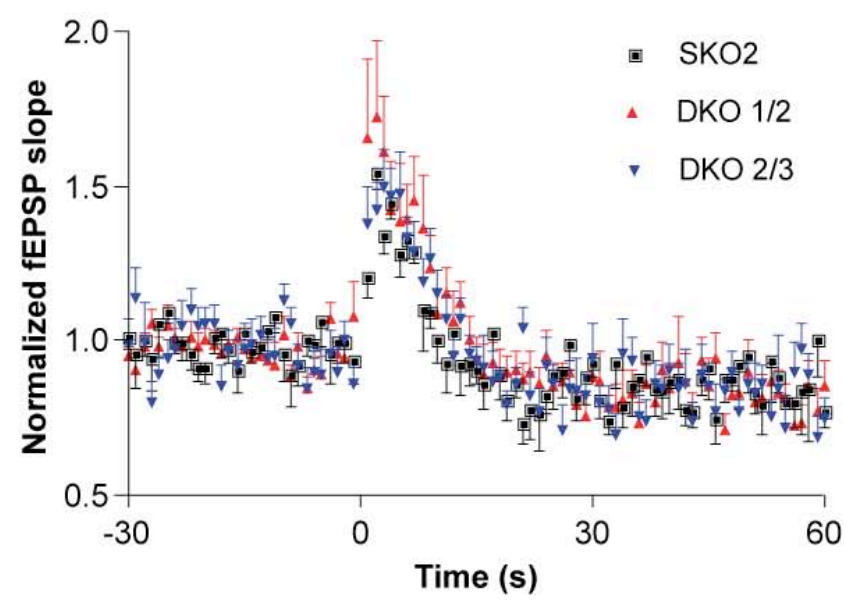




\section{Long-term potentiation (LTP) at Schaffer collateral-CA1 synapses in $\alpha$-neurexin KO mice}

Schaffer collateral-CA1 synapses show long term increase in the efficacy of synaptic transmission in response to tetanic stimulation (Bliss and Collingridge, 1993; Malenka and Nicoll, 1999; Malenka and Bear, 2004). We examined whether deletion of $\alpha$-neurexins leads to any change in long-term potentiation (LTP). To measure LTP, baseline responses were evoked every $30 \mathrm{~s}$ for 10 minutes and LTP was induced by 4 trains separated by $20 \mathrm{~s}$, each train consisting of $100 \mathrm{~Hz}$ stimuli for $1 \mathrm{~s}$. The post-train responses were then measured every $30 \mathrm{~s}$ for 60 minutes. The magnitude of LTP was determined as the average between 50-60 minutes of responses after induction. We found that LTP was significantly higher in neurexin $1 \alpha / 2 \alpha$ double KOs (191.4 $\pm 19.48 \%$ of baseline; $n=11$ slices, 5 mice) as compared to control mice (142.3 $\pm 12.96 \%$ of baseline; $\mathrm{n}=11$ slices, 5 mice) (Figure 3.8). In addition, short-term potentiation defined as the maximum potentiation within 1 minute after the trains was also significantly enhanced in neurexin $1 \alpha / 2 \alpha$ double KOs $(299.0 \pm 28.69 \%$ of baseline; $\mathrm{n}=11$ slices, 5 mice $)$ as compared to control mice $(224.9 \pm 16.41 \%$ of baseline; $\mathrm{n}=11$ slices, 5 mice).

Figure 3.7 (on the facing page) Frequency-dependent synaptic plasticity is altered in $\alpha$-neurexin double KOs. Neurexin $1 \alpha / 2 \alpha$ and neurexin $2 \alpha / 3 \alpha$ double KOs showed enhanced facilitation in response to a $14 \mathrm{~Hz}$ train. (A) fEPSP slopes for each event normalized against baseline response and plotted against stimulus number for the first 40 stimuli. fEPSP sizes increased for the first 4-5 stimuli in the train and then started to decrease gradually in control mice ( $n=12$ slices, 4 mice). Neurexin $1 \alpha / 2 \alpha(n=13$ slices, 4 mice) and neurexin $2 \alpha / 3 \alpha$ double KOs ( $n=16$ slices, 4 mice) showed more extended facilitation. (B) The ratio (fEPSP slope $40^{\text {th }}$ stimulus)/(fEPSP slope $4^{\text {th }}$ stimulus) is significantly higher in double KOs as compared to control. (C) Average responses for 300 stimuli with $14 \mathrm{~Hz}$ train. fEPSP slopes for each event normalized to the baseline response and plotted against stimulus number. Error bars are shown only for every 10th response, for clarity. (D) The responses for all three genotypes returned to similar values after 300 stimuli as indicated by the ratio of fEPSP slope $300^{\text {th }}$ stimulus/fEPSP slope $4^{\text {th }}$ stimulus. (E) Posttetanic potentiation (PTP) was not significantly different between control and double KO mice. Baseline responses were obtained by stimulating at $1 \mathrm{~Hz}$, and PTP was elicited by a single $100 \mathrm{~Hz}$ train for $1 \mathrm{~s}($ at $\mathrm{t}=0)$. Post-tetanic responses were obtained by stimulation at 1 $\mathrm{Hz}$. The experiments were done in the presence of $100 \mu \mathrm{M}$ DL-APV to prevent the induction of NMDA receptor-dependent short term potentiation (STP). 
A

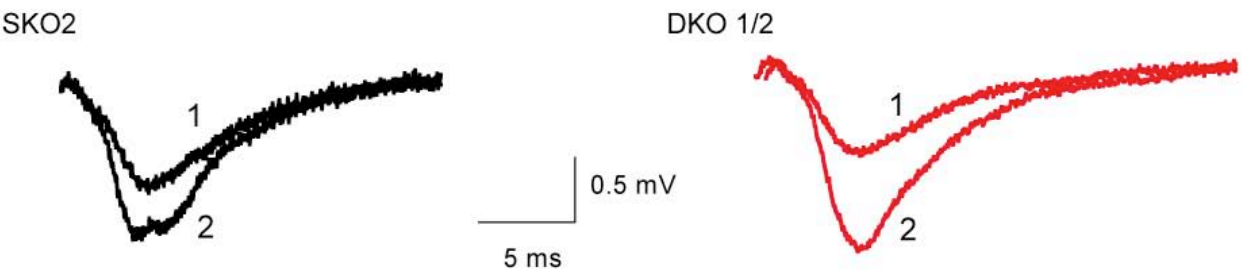

B

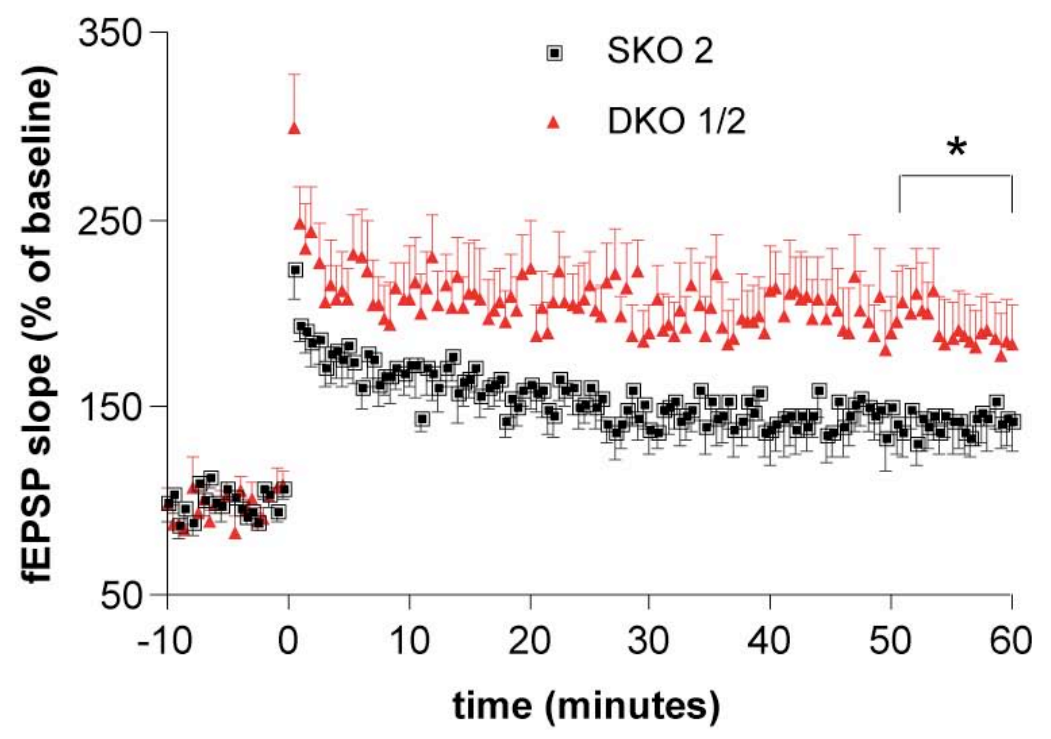

C

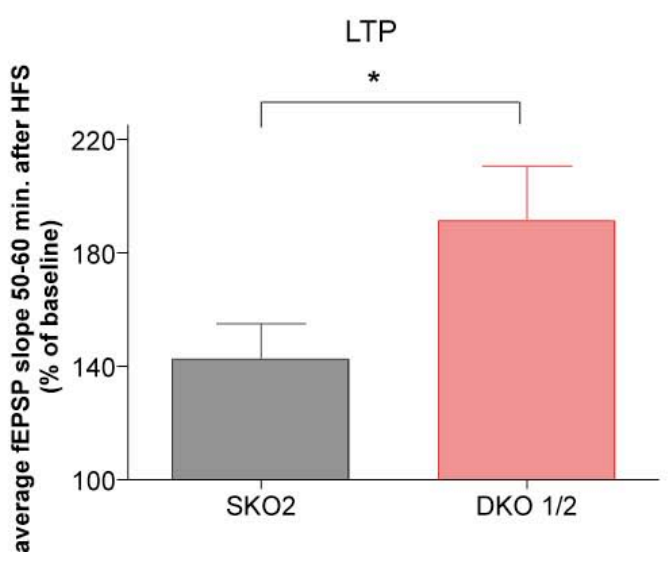

D

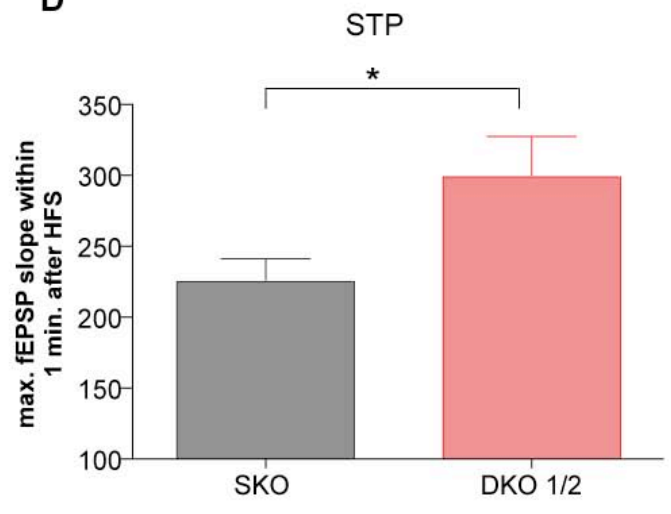

Figure 3.8 Increased LTP at Schaffer collateral-CA1 synapses in neurexin $1 \alpha / 2 \alpha$ double KO mice. (A) Example traces. An average of 10 responses before High Frequency Stimulus-HFS (1) and between 55 and 60 min. after HFS (2). (B) Long-term potentiation elicited by HFS ( $4 \times 100 \mathrm{~Hz}$ for $1 \mathrm{~s}$ each, $20 \mathrm{~s}$ interval). fEPSP slopes were normalized to baseline and plotted against time. Time 0 represents the application of HFS. (C) The magnitude of LTP was determined by averaging responses between 50 and 60 minutes after HFS. Hippocampal slices from neurexin $1 \alpha / 2 \alpha$ double KO ( $n=11$ slices, 5 mice) show significantly enhanced LTP as compared to controls ( $n=11$ slices, 5 mice). (D) Short-term potentiation (STP) measured as the maximum response within 1 minute after HFS is also significantly increased in neurexin $1 \alpha / 2 \alpha$ double KO mice as compared to controls. 
We then investigated the mechanism for enhanced LTP in neurexin $1 \alpha / 2 \alpha$ double KO mice. Induction of LTP at Schaffer collateral-CA1 synapses with the experimental conditions that we used is known to be NMDA-receptor-dependent. We wondered whether the enhanced LTP that we observed in neurexin $1 \alpha / 2 \alpha$ double $\mathrm{KO}$ mice might be due to the appearance of an abnormal NMDA-receptor-independent form of LTP. To check this, experiments were performed in the presence of NMDA receptor antagonist DL-APV $(100 \mu \mathrm{M})$. We found that the slices from neurexin $1 \alpha / 2 \alpha$ double KO mice failed to develop any LTP in the presence of DL-APV (Figure 3.9). This ruled out an abnormal NMDA receptor-independent component of LTP in neurexin $1 \alpha / 2 \alpha$ double KO mice.

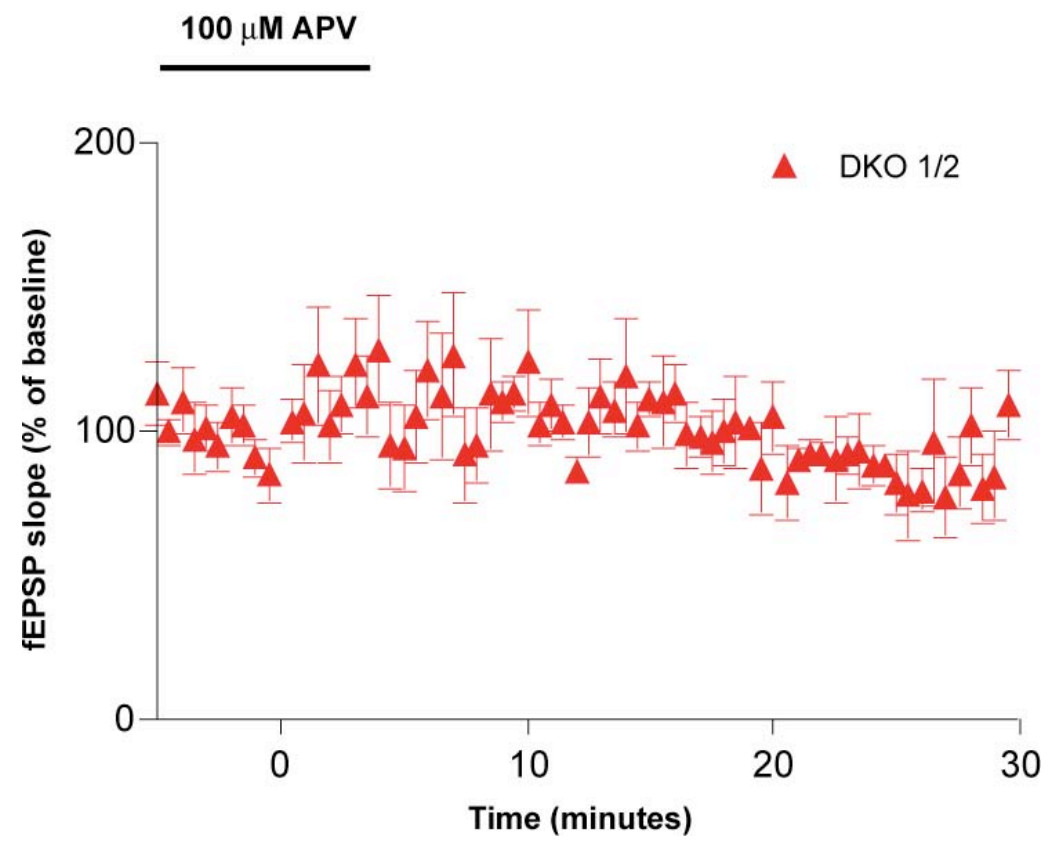

Figure 3.9 Enhanced LTP in neurexin $1 \alpha / 2 \alpha$ double KO is NMDA-dependent. A high frequency stimulus ( $4 \times 100 \mathrm{~Hz}$ for $1 \mathrm{~s}$ each, $20 \mathrm{~s}$ interval) was given in the presence of 100 $\mu M$ DL-APV (NMDA receptor antagonist). Time 0 represents the application of HFS. No LTP could be induced in the presence of $100 \mu \mathrm{M}$ DL-APV in slices from neurexin $1 \alpha / 2 \alpha$ double KOs ( $n=4$ slices, 2 mice). Slices were bathed in $100 \mu \mathrm{M}$ DL-APV for 25 minutes before recordings were started and DL-APV was present till 5 minutes after the HFS.

Another reason that could underlie enhanced LTP in neurexin $1 \alpha / 2 \alpha$ double KO mice is the reduction in inhibitory tone in the CA1 region of hippocampus. To examine this possibility, we performed experiments with control mice and neurexin $1 \alpha / 2 \alpha$ double $\mathrm{KO}$ mice with 10 $\mu \mathrm{M}$ bicuculline methiodide $\left(\mathrm{GABA}_{\mathrm{A}}\right.$ receptor antagonist). This treatment should remove any influence of GABAergic synaptic transmission on the analysis of LTP between the two genotypes. After measuring baseline responses every $30 \mathrm{~s}$ for 10 minutes, LTP was induced 
by 2 trains $(100 \mathrm{~Hz}, 1 \mathrm{~s}$ duration) seperated by 20 s. 2 trains were used in this protocol (instead of 4) because under blockade of GABA-ergic transmission multiple population spikes might appear and contaminate the rising slope of fEPSP. After induction, the higher is the potentiation the earlier the population spikes appear. Using only 2 trains reduces the potentiation and hence reduces the contamination of fEPSP slope with pop spikes. The posttrain responses were then evoked by stimuli every $30 \mathrm{~s}$ for 60 minutes. The magnitude of LTP was determined as the average between 50-60 minutes of responses after induction. We found that in the presence of bicuculline methiodide, there was no difference in the magnitude of LTP between control mice (172.5 $\pm 38.95 \%$ of baseline; $n=6$ slices, 3 mice $)$ and neurexin $1 \alpha / 2 \alpha$ double KO mice (158.9 $\pm 13.07 \%$ of baseline, $\mathrm{n}=5$ slices, 4 mice) (Figure 3.10). This showed that it was the reduction in inhibitory GABAergic synaptic transmission that was responsible for enhanced LTP in neurexin $1 \alpha / 2 \alpha$ double KO mice.

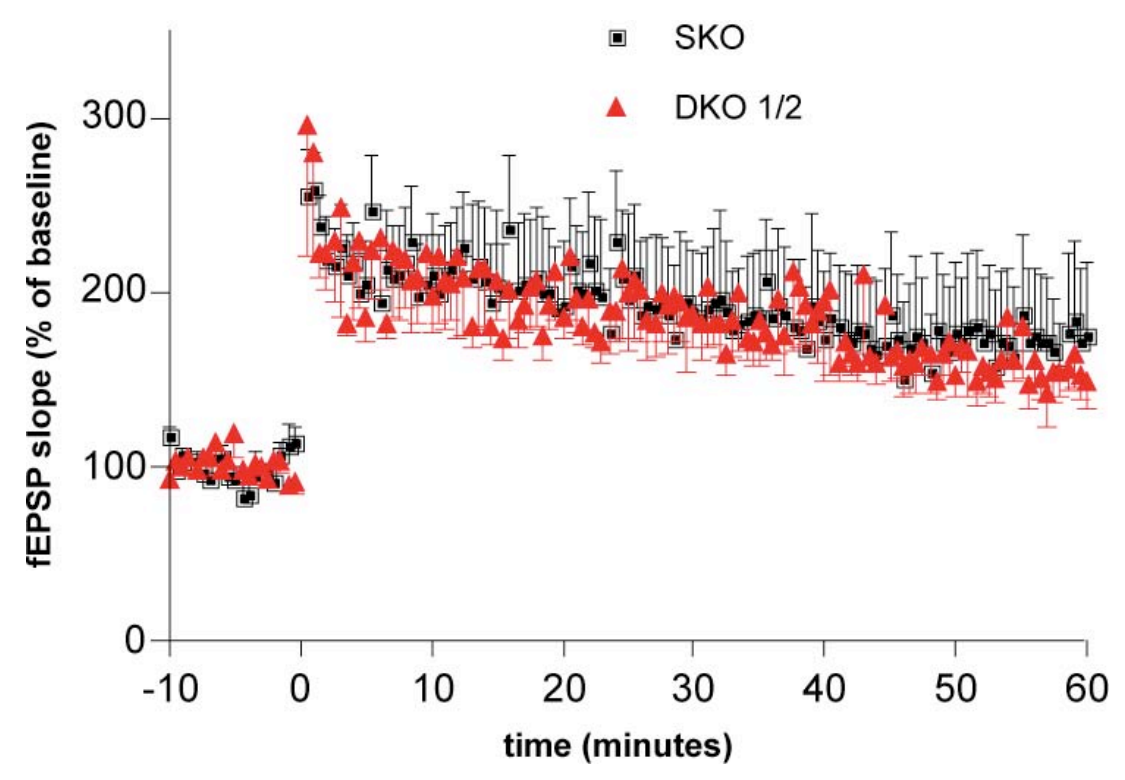

Figure 3.10 Enhanced LTP in neurexin $1 \alpha / 2 \alpha$ double KO depends on a reduced activity of inhibitory GABAergic synapses. LTP was induced in the presence of $10 \mu \mathrm{M}$ bicuculline methiodide (GABA-A receptor antagonist) using an HFS $(2 \times 100 \mathrm{~Hz}$ for $1 \mathrm{~s}$ each, $20 \mathrm{~s}$ interval). Time 0 represents the application of HFS. There was no significant difference in the amount of LTP between control ( $n=6$ slices, 3 mice) and neurexin $1 \alpha / 2 \alpha$ double KO mice (5 slices, 4 mice). Slices were bathed in $10 \mu \mathrm{M}$ bicuculline methiodide for 25 minutes before recordings were started and bicuculline was present throughout the experiment. 


\subsection{Biochemical interaction of neurexins with RIM1 $\alpha$}

The phenotype of $\alpha$-neurexin double knockouts as described in the previous section resembled to some extent the phenotype of RIM1 $\alpha$ knockout (see section 4.5) indicating that RIMs could be interaction partners of neurexins. To test this possibility, modelling studies were performed (by C. Reissner, AG Missler) that predicted an interaction of the C-terminus of neurexin 1 with the PDZ domain of RIM1 $\alpha$ (Figure 3.11).

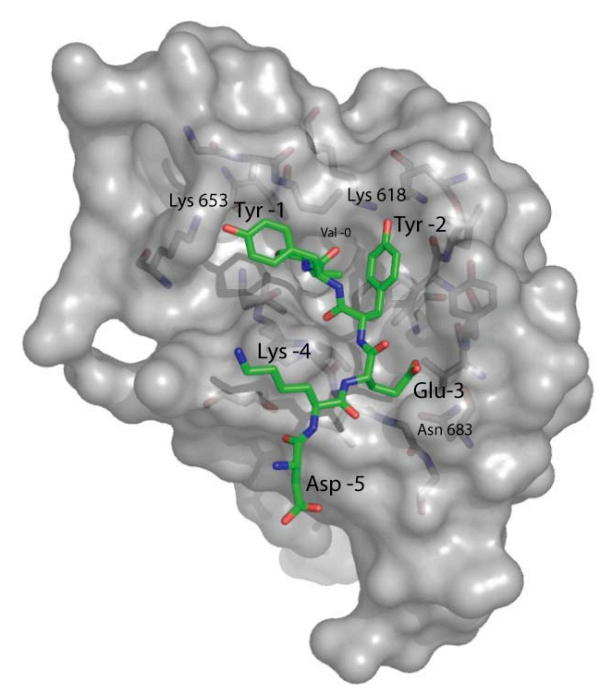

Figure 3.11 Model structure of RIM1 $\alpha$ PDZ domain (surface) interacting with C-terminal peptide of neurexins (sticks) (C. Reissner, AG Missler). Neurexin conserved C-terminal peptide DKEYYV is placed into the binding pocket of RIM1 $\alpha$ using the coordinates of the solution structure of the RIM1 $\alpha$ PDZ domain in complex with an ELKS1b C-terminal peptide EEGIWA (Lu et al., 2005). The side chains at the binding pocket have been energy minimized, while main chains of the binding peptide and the PDZ domains were constrained and remained identical to the solution structure (protein databank entry: 1ZUB. Berman et al., 2000). The side chain residues at the -1 to -3 position of neurexins find corresponding binding partners in Lys653, Lys618, and Asn683, respectively.

To directly test if RIM1 $\alpha$ interacts with neurexins, we performed biochemical experiments using co-sedimentation assays. GST fusion protein of the C-terminus (complete intracellular part) of neurexin 1 (GST-Nrxn1) was expressed in bacteria, immobilized on glutathioneagarose beads and used in pulldown experiments with myc-RIM1 $\alpha$ constructs expressed in tsA201 cells. Myc-RIM1(1-730) is an N-terminal construct of RIM1 $\alpha$ fused at its N-terminus to myc epitope tag and consists of $\mathrm{Zn}^{2+}$ finger (Rab-binding domain) and PDZ domain (Figure 3.12A). It was efficiently pulled down with GST-Nrxn1, but not with GST alone (Figure 3.12B). In contrast Myc-RIM1 $\triangle \mathrm{PDZ}$ construct, a RIM1 $\alpha$ construct that lacks the PDZ domain was not pulled down with GST-Nrxn1. This showed that neurexin 1 does interact biochemically with RIM1 $\alpha$. The interaction is mediated via the C-terminus of neurexin 1 binding to the PDZ domain of RIM1 $\alpha$. 
A

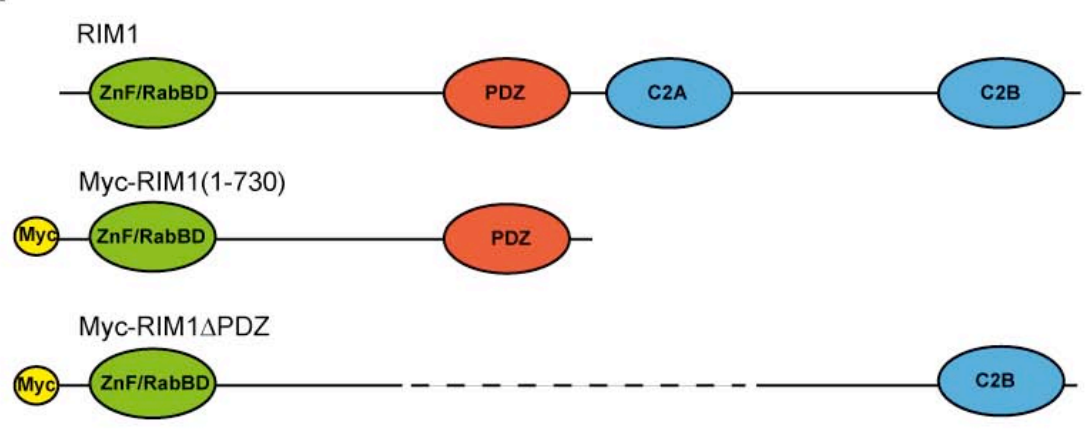

B

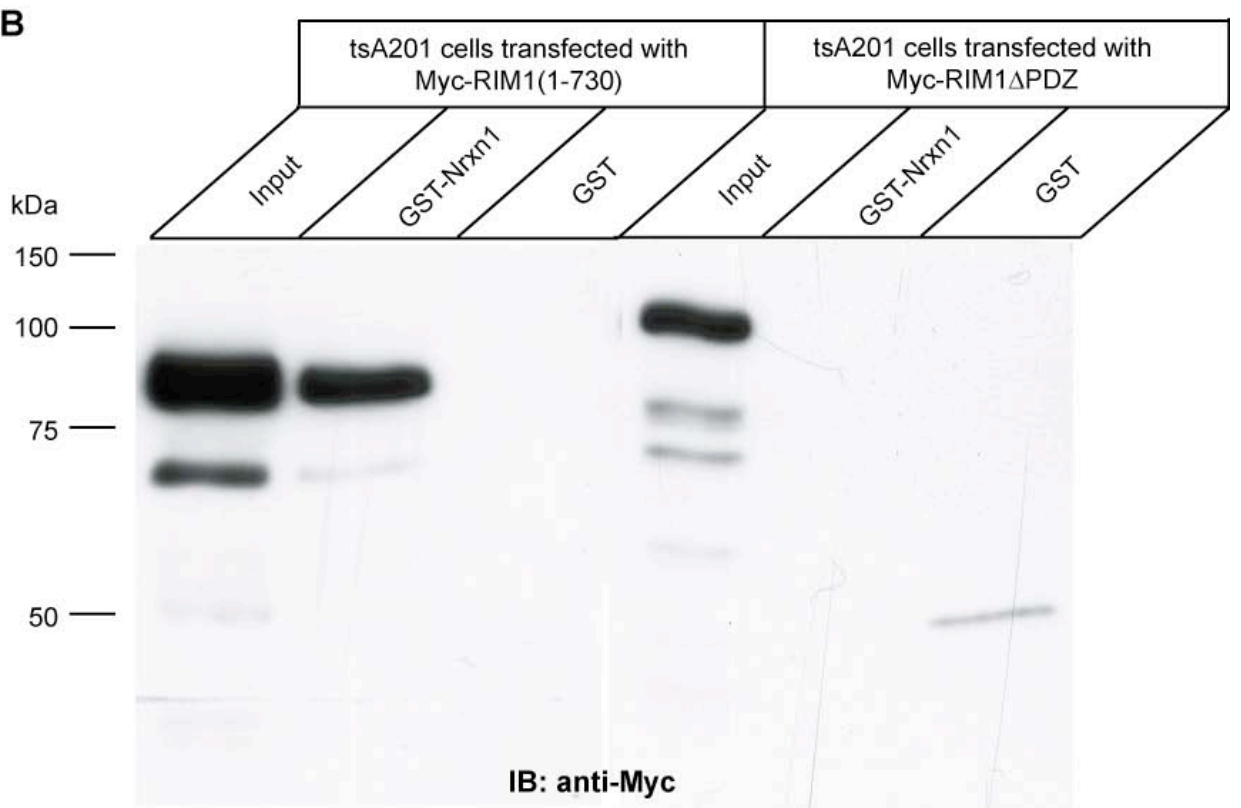

Figure 3.12 Binding of recombinant RIM1 $\alpha$ to immobilized C-terminus of neurexin 1. (A) A schematic diagram depicting the domain structure of full length RIM $1 \alpha$ protein and the myc epitope-tagged constructs expressed in tsA201 cells. (B) A GST fusion protein consisting of C-terminus of neurexin 1 (GST-Nrxn1) was immobilized on glutathione-agarose beads and used in pulldown experiments with recombinant RIM $1 \alpha$ constructs expressed in tsA201 cells. Myc-RIM1(1-730) was pulled down with GST-Nrxn1 but not with GST alone. Myc-RIM1 $\triangle$ PDZ was not pulled down with GST-Nrxn1 or GST. Immuolabelling was done with monoclonal anti-myc antibody. Numbers at the left indicate the positions of molecular weight markers (in $\mathrm{kDa}$ ).

To investigate the biochemical interaction in the 'reverse' direction, we used the GST fusion protein of RIM1 $\alpha$ PDZ domain (GST-RIM1_PDZ) in pulldown experiments with neurexin $1 \alpha$ and neurexin $1 \beta$ expressed in tsA201 cells. The intracellular part of $\alpha$ - and $\beta$ - neurexins is completely identical. Neurexin $1 \beta$ was pulled down with GST-RIM1_PDZ but not by GST alone (Figure 3.13A). Since the anti-neurexin antibody is not very specific, we expressed neurexin $1 \beta$ tagged at its $\mathrm{N}$-terminus to EGFP (N-EGFP-Nrxn1 $\beta$ ) in tsA201 cells. It was efficiently pulled down with GST-RIM1_PDZ as shown by labelling with anti-GFP antibody (Figure 3.13B). Neurexin $1 \alpha$ expressed in tsA201 cells was also pulled down with GST- 
RIM1_PDZ (Figure 3.13C). In contrast, recombinant neuroligin 1 was not pulled down with GST-RIM1_PDZ (Figure 3.13D). These experiments showed that RIM1 $\alpha$ has the capability to bind to neurexin $1 \alpha$ and neurexin $1 \beta$ expressed in heterologous cells.

A

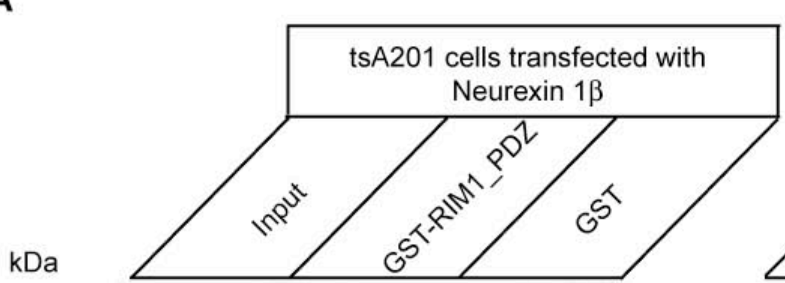

B
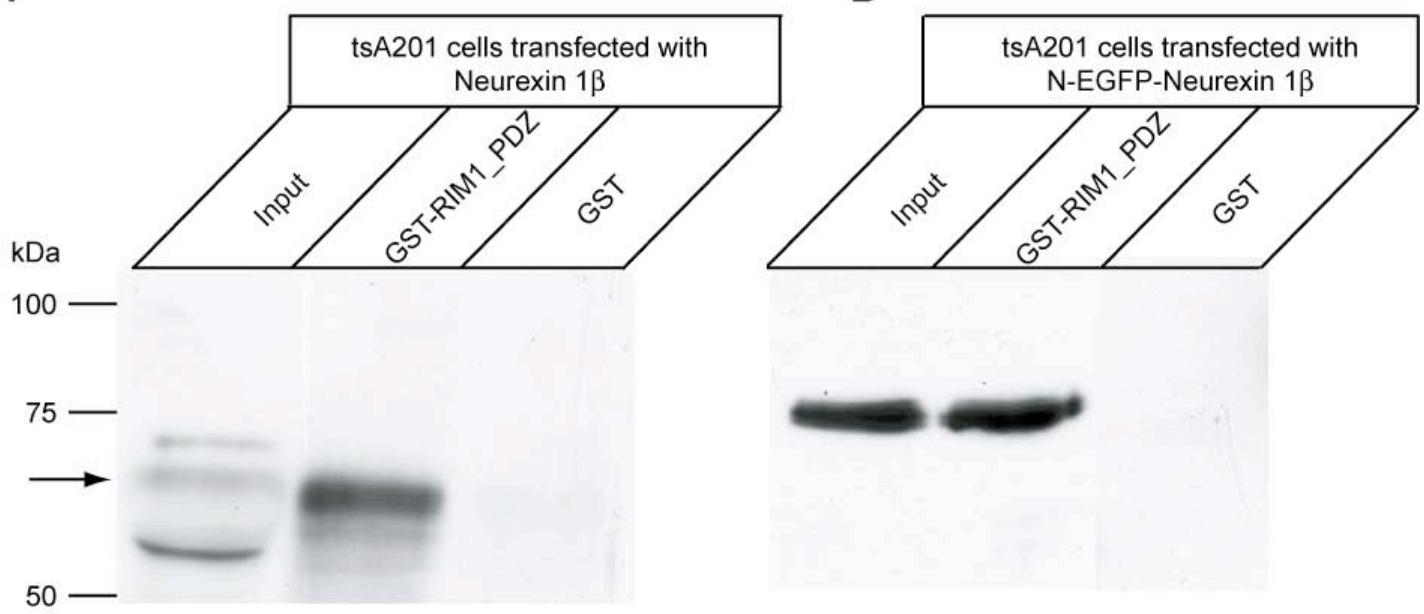

IB: anti-neurexin (A473)

IB: anti-GFP

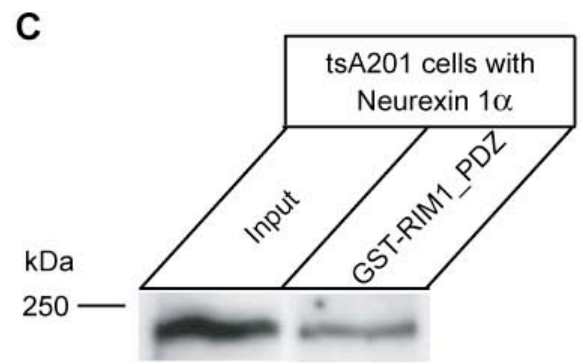

IB: anti-neurexin (A473)

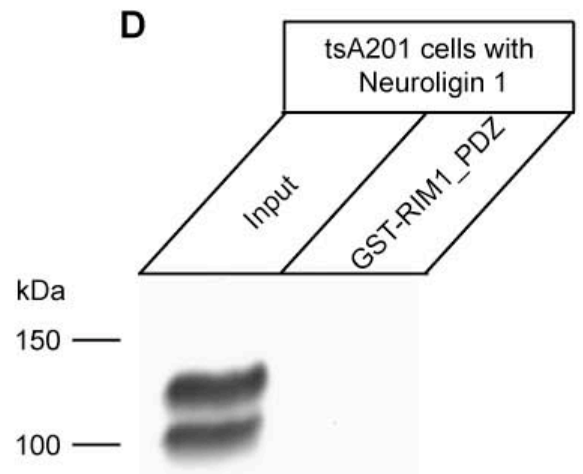

IB: anti-Neuroligin (4C12)

Figure 3.13 Binding of recombinant $\alpha$ - and $\beta$-neurexins to immobilized PDZ domain of RIM1 $\alpha$. GST fusion protein consisting of RIM1 $\alpha$ PDZ domain (GST-RIM1_PDZ) was immobilized on glutathione-agarose beads and used in pulldown experiments with recombinant neurexins expressed in tsA201 cells. (A) Full length Neurexin $1 \beta$ was pulled down with GST-RIM1_PDZ, but not with GST alone. Immunolabelling was done with a panneurexin antibody directed against the C-terminus (A473). The arrow indicates the position of neurexin $1 \beta$. (B) Neurexin $1 \beta$ fused to GFP at its $N$-terminus (N-EGFP-Nrxn1 $\beta$ ) was pulled down with GST-RIM1_PDZ, but not with GST alone. Immunolabelling was done with antiGFP antibody. (C) Full length Neurexin $1 \alpha$ pulled down with GST-RIM1_PDZ. Immunolabelling was done with a pan-neurexin antibody directed against the C-terminus (A473). (D) Neuroligin 1 was not pulled down with GST-RIM1_PDZ, indicating specificity of the pulldown experiments. Immunolabelling was done with a monoclonal antibody (4C12). Note that 4C12 gives two bands with neuroligin 1 expressed in HEK or COS cells (Song et al., 1999; Chubykin et al., 2005). 
We then investigated whether RIM1 $\alpha$ can pulldown native neurexins from brain extracts. Rat brains were used to obtain the membrane fraction (crude P2 synaptosomal preparation), and subjected to pulldown experiments with GST-RIM1_PDZ. Results showed that $\alpha$-neurexins and to some extent $\beta$-neurexins were pulled down (Figure 3.14). This showed that RIM1 $\alpha$ is able to bind to native neurexins from the brain.

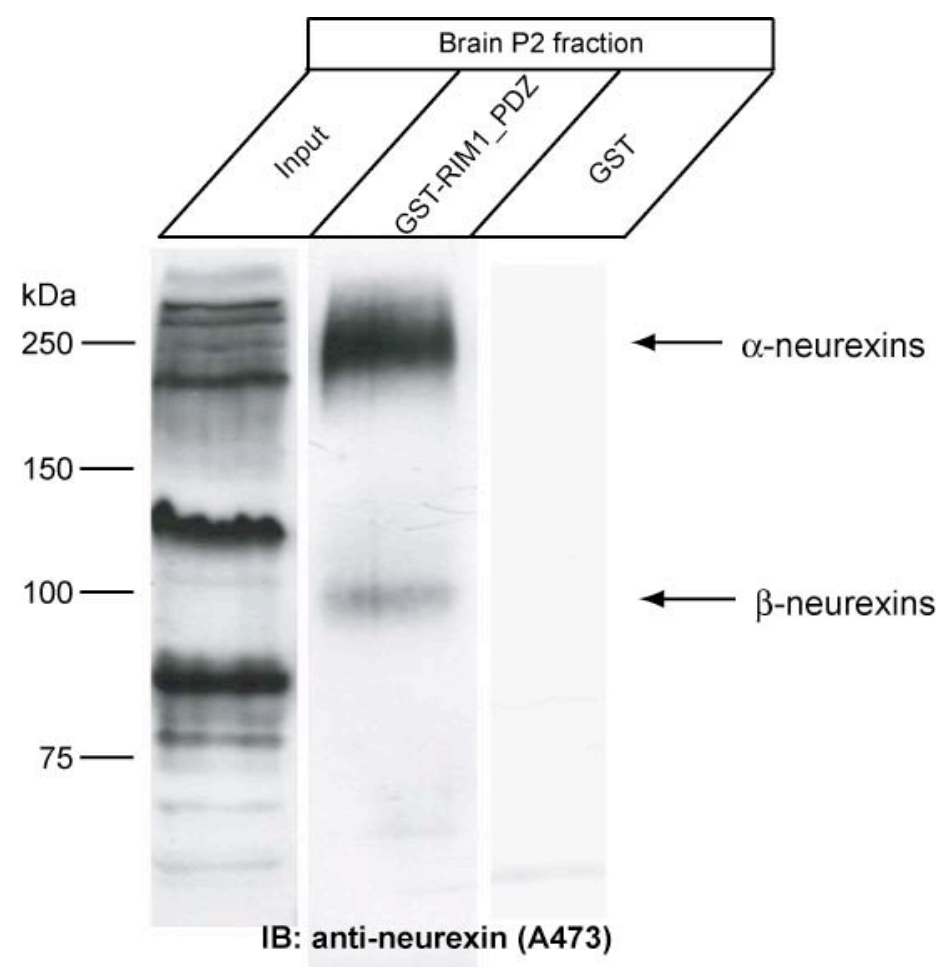

Figure 3.14 Binding of native $\alpha$ - and $\beta$-neurexins to immobilized PDZ domain of RIM1 $\alpha$. Proteins from brain membrane fraction (crude P2 synaptosomal preparation) were extracted using 1\% CHAPS detergent and incubated with GST-RIM1_PDZ or GST immobilized on glutathione-agarose beads for pulldown experiments. Both $\alpha$ - and $\beta$ neurexins were pulled down with GST-RIM1_PDZ, but not with GST. Immunolabelling was done with pan-neurexin antibody (A473).

Next we wanted to examine if GST-Nrxn1 is able to pulldown RIM1 $\alpha$ from the brain, as it does from tsA201 cells. RIMs are difficult to extract from the brain as they are not solubilized with commonly used detergents like CHAPS and TritonX100 (Wang et al., 1997, 2000). We used stronger ionic detergents, sodium deoxycholate or sodium cholate to solubilize them. Proteins from rat brain membrane fraction (crude P2 synaptosomal preparation) were extracted with $1 \%$ sodium cholate and incubated with GST-Nrxn1 immobilized on glutathione-agarose beads. RIMs were not pulled down with GST-Nrxn1 (Figure 3.15A left). It was found that CASK which is a known biochemical interaction partner of neurexins was 
also not pulled down (Figure 3.15A right). This could happen because sodium cholate is a strong detergent which can interfere with the binding reaction. To overcome this problem, we dialysed the extracted brain membrane proteins with a buffer containing no detergent. The dialysed samples were incubated with GST-Nrxn1 immobilized on glutathione-agarose beads. RIMs still could not be pulled down, although CASK was pulled down well under these conditions (Figure 3.15B). This implies that CASK is an efficient interaction partner of neurexins at least biochemically. The inability of the C-terminus of neurexin 1 to pulldown RIMs from the brain might be due to the sensitivity of RIM structure and neurexin-RIM interaction to extraction and binding conditions. In a similar manner, it was reported that RIMs from brain could not be pulled down with ERC1b, although a strong interaction was observed with recombinantly expressed RIM1 $\alpha$ construct (Wang et al., 2002). More effort would be needed in the future to get the right conditions for extraction of native RIMs from the brain, and their binding to neurexins. However the efficient binding of recombinant neurexins and RIMs, and the binding of native neurexins to RIM1 PDZ domain indicates that RIM1 is a novel interaction partner of $\alpha$ - and $\beta$-neurexins.

As part of our effort to find other interaction partners of neurexin-RIM complex, we utilized mass spectrometry to find more proteins binding to RIM1 PDZ domain. We noticed that when extracted proteins from rat or mouse brain were pulled down with GST-RIM1_PDZ immobilized on glutathione-agarose beads, 2 bands $\sim 50 \mathrm{kDa}$ appeared, as seen on Coomassie staining of the SDS-PAGE gel (Figure 3.16A). These bands were sent for mass spectrometric analysis. The samples were processed using matrix-associated laser desorption-ionizationtime-of-flight (MALDI-TOF) mass spectrometry at the Proteomics Group, Max Planck Institute for Experimental Medicine, Goettingen. The identification of proteins was done using peptide mass fingerprinting (PMF) and MS/MS-based peptide fragment fingerprinting (PFF), followed by database searches in NCBI nr protein sequence database (performed by Dr. Olaf Jahn, Proteomics Group, MPI for Experimental Medicine, Goettingen). The best matches for sample S1 were gi 135446, 92930, 4580988, which corresponded to $\beta$-tubulin. The best matches for sample S2 were gi 73996530, 67463743, 54035478, which corresponded to $\alpha$-tubulin. Western blotting with an anti- $\beta$-tubulin antibody confirmed that $\beta$-tubulin was pulled down with GST-RIM1_PDZ (Figure 3.16B). 
A

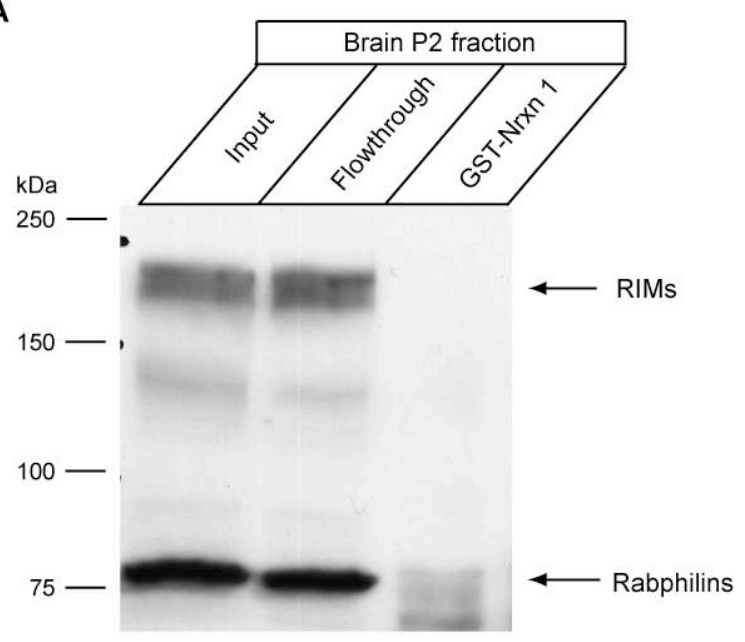

IB: anti-RIM (Q703)

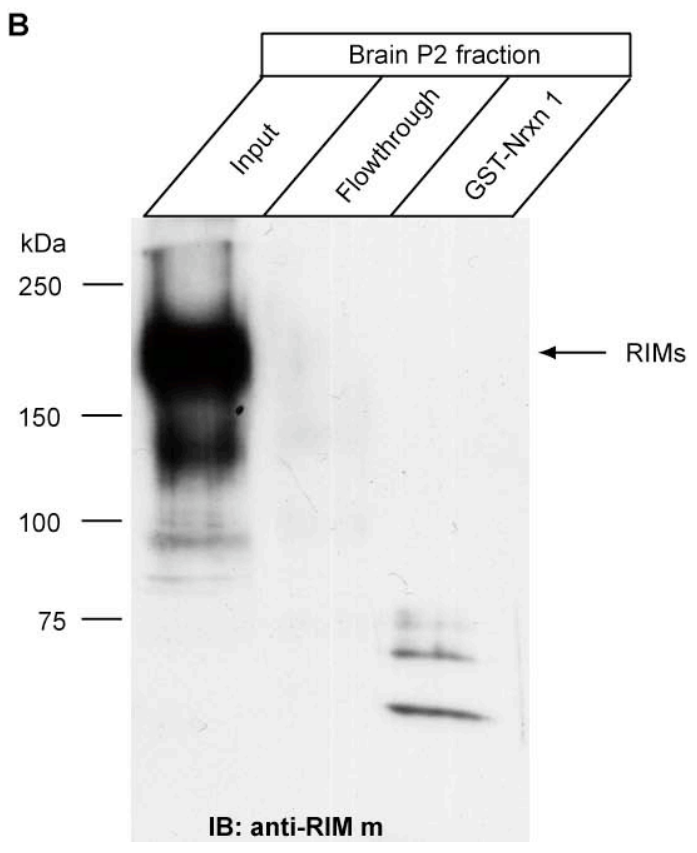

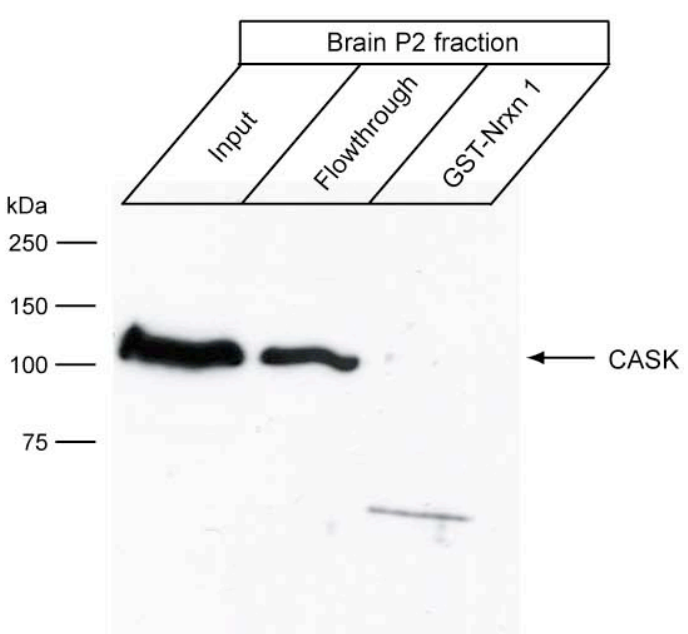

IB: anti-CASK

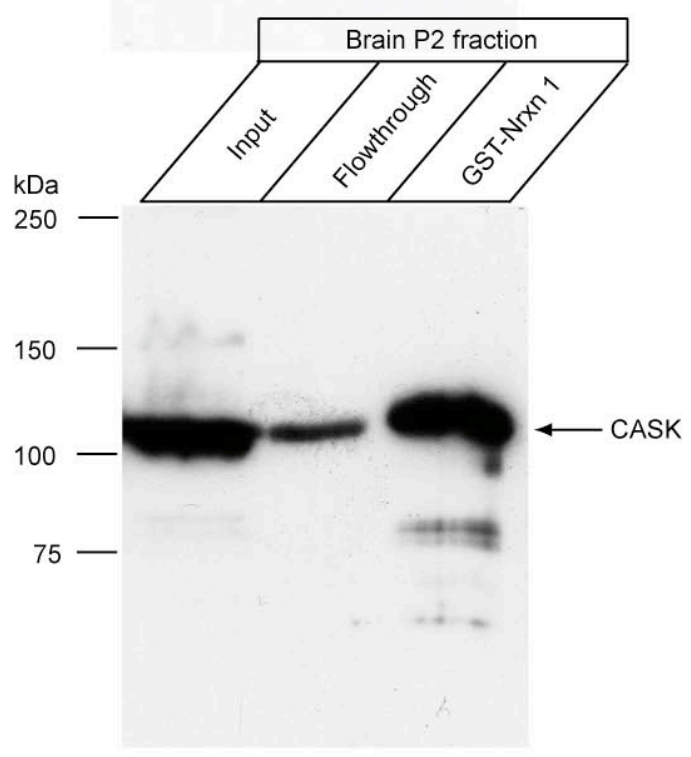

IB: anti-CASK

Figure 3.15 Pulldown of native CASK but not native RIMs with immobilized C-terminus of neurexin 1. (A) Proteins from brain membrane fraction (crude P2 synaptosomal preparation) were extracted with 1\% sodium cholate (Input, Lane 1), and binding reaction with GST-Nrxn1 immobilized on glutathione-agarose beads performed in the presence of $1 \%$ sodium cholate. The supernatant was collected after pulldown (Flowthrough, Lane 2). The proteins pulled down with GST-Nrxn1 are shown in Lane 3 (GST-Nrxn1). Left No pulldown of RIMs was obtained with GST-Nrxn1. Immunolabelling was done with polyclonal anti-RIM antibody (Q703), which shows cross-reactivity with rabphilins (Schoch et al., 2002). Right CASK, a known biochemical interaction partner was also not pulled down with GST-Nrxn1. Immunolabelling was done with monoclonal anti-CASK antibody. (B) Proteins from brain membrane fraction (crude P2 synaptosomal preparation) were extracted with $1 \%$ sodium deoxycholate followed by 1:5 dilution and dialysis with a buffer containing no detergent. The dialysed sample was then incubated with GST-Nrxn1 immobilized on glutathione-agarose beads. Left No pulldown of RIMs was obtained with GST-Nrxn1. Immunolabelling was done with monoclonal anti-RIM antibody. Right CASK was pulled down with GST-Nrxn1. Immunolabelling was done with monoclonal anti-CASK antibody. 
A

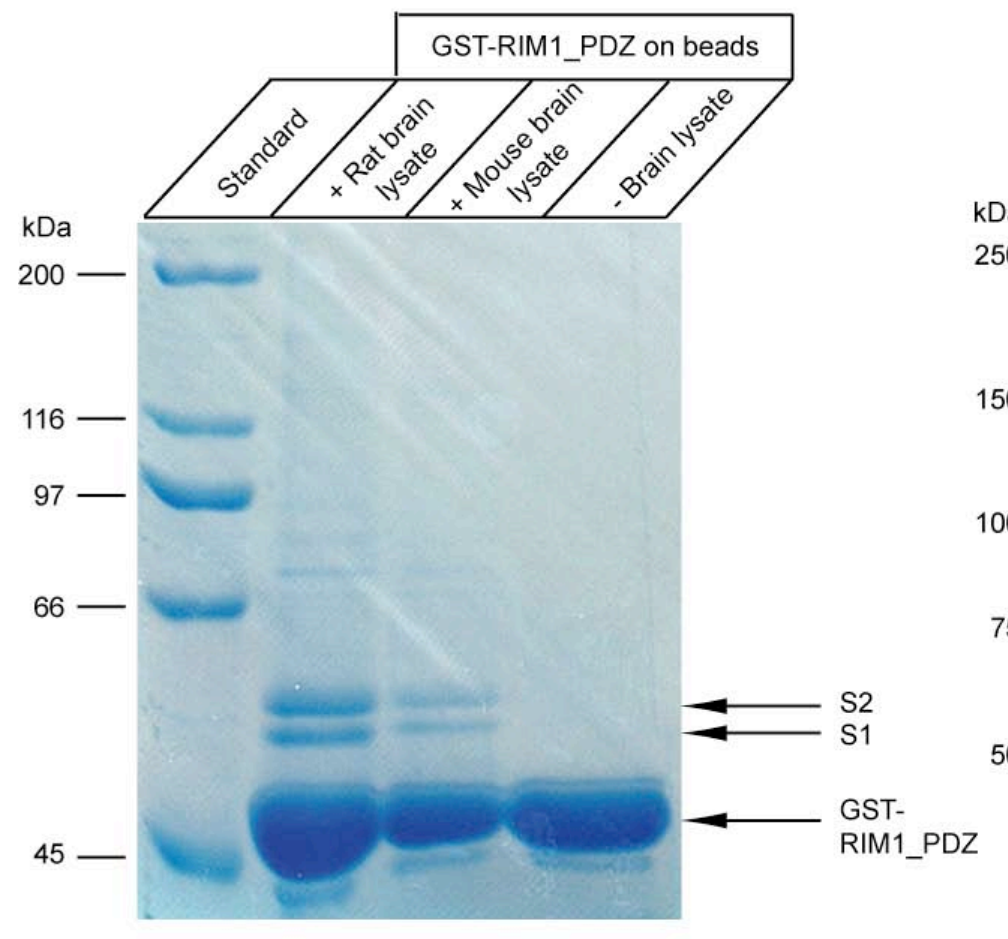

B

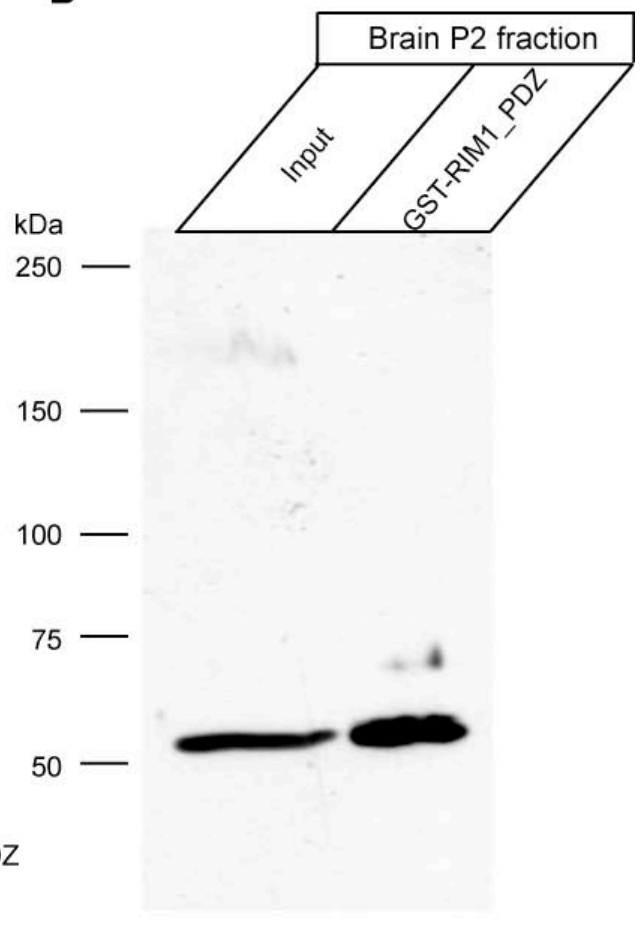

IB: anti- $\beta$-Tubulin

Figure 3.16 Binding of $\alpha$ - and $\beta$-tubulins to immobilized PDZ domain of RIM1 $\alpha$. (A) Proteins from rat or mouse brain membrane fraction (crude P2 synaptosomal preparation) were extracted with $1 \%$ CHAPS, and incubated with GST-RIM1_PDZ immobilized on glutathione-agarose beads. 2 bands $\sim 50 \mathrm{kD}$ appeared in the pulldown shown here with coomassie stain (S1 and S2 in lanes 2 and 3), and were absent from the GST-RIM1_PDZ sample without incubation with brain extract (lane 4). These bands were identified as $\alpha$ - and $\beta$-tubulins on mass spectrometric analysis. (B) Immunoblotting with monoclonal anti- $\beta$-tubulin antibody. $\beta$-tubulin is labelled in the brain membrane extract, and also in pulldown with GSTRIM1_PDZ. 


\subsection{Generation of $\alpha$-neurexin conditional knockout mice}

Cre-loxP recombination system (Kuhn et. al., 1995; Rajewsky et al., 1996) is used widely to generate conditional knockout of genes. The Cre recombinase enzyme is 35-kDa protein isolated from bacteriophage $\mathrm{P} 1$, which acts as a site specific DNA recombinase. The enzyme recognises 34-bp sequences termed loxP sites and causes excision of intervening DNA between two loxP sites arranged in the same orientation (Hoess and Abremski, 1984). The conditional mutants of some synaptic proteins (e.g. NCAM, TrkB, Munc18, Adenosine A1 receptor) have been made (Minichiello et al., 1999; Bukalo et al., 2004; Heeroma et al., 2004; Arrigoni et al., 2005). In some cases, this is done to demarcate the function of the protein in development from that in mature synapses. In other cases, conditional deletion is required because the deletion of protein in a conventional manner leads to early lethality of mutant mice. This applies in case of $\alpha$-neurexin KO mice, because $\alpha$-neurexin triple KOs die on the first day of birth. Therefore studies (as done in section 3.2) could not be performed in adult mice lacking all three $\alpha$-neurexins. To achieve conditional knockout of $\alpha$-neurexins, the first step involved generating a knock-in mouse line in which a pair of loxP sequence was introduced into neurexin $1 \alpha$ gene flanking the first coding exon.

\subsubsection{Characterization of genomic clones}

Three genomic clones of the 5' end of mouse neurexin $1 \alpha$ gene were available: pmYLL3-1b, pmYLL13-1 and pmYLL14\#A. These sequences had been cloned into pBluescript NotI site. The DNA of these genomic clones was analysed by analytical restriction digestion and compared to available physical maps of the genomic clones. The genomic clones were then sent for sequencing at the ends. The available physical maps showed the location of the first coding exon at the $3^{\prime}$ end of the clone pmYLL3-1b and continuing into the $5^{\prime}$ end of pmYLL13-1 due to the presence of an internal NotI site within the exon. This was confirmed by the sequence results obtained.

We designed the targeting vector to introduce loxP sites on either side of the first coding exon of neurexin $1 \alpha$ gene. This exon is the largest of all the exons of the gene and codes for the signal peptide as well as the first LNS domain and EGF domain. It was expected that the deletion of this exon would lead to complete loss of functional protein from the synapses. The same exon was deleted to generate conventional knockout of neurexin $1 \alpha$ (Geppert et. al., 1998) and lead to the loss of the complete protein (Geppert et. al., 1998, Missler et. al., 2003). 
The strategy for the knock-in mutation involved inserting loxP sites on either side of the first exon along with the selection marker. This can potentially interfere with the structure or expression of the gene, especially if these exogenous sequences are inadvertently inserted into an exon or in the promoter region. To rule out this possiblity the region covered by the genomic clones was searched for other unclassified exons. To find upstream $5^{\prime}$ exons, bovine neurexin1 $\alpha$ cDNA (GenBank accession number, L14855) was taken as it has the longest 5' untranslated region (5' UTR) of the different species. Using 5' UTR of bovine neurexin $1 \alpha$ cDNA as a query, mouse genome was searched through nucleotide BLAST program and yielded a good match (expect $=\mathrm{e}-106$, identity $=310 / 358,86 \%)$ in the region of mouse neurexin $1 \alpha$ gene about $3 \mathrm{~kb}$ upstream of the first coding exon (Figure 3.17). The matched region was then BLASTed against the mouse EST database giving multiple good matches (e.g. BY705510, BB630963, BY126766, BB644194, BB640878) confirming that this region is expressed in the mouse. This $5^{\prime}$ untranslated region (UTR) exon was accurately mapped on the gene and showed the correct splice donor site at its $3^{\prime}$ end. We then decided to place the $5^{\prime}$ loxP site at BamHI site between this upstream 5' UTR exon and the first coding exon. The site is also significantly away ( $>1 \mathrm{~kb}$ ) from both of these exons so as not to interfere with splice events. The next step was to search for any exon downstream of the the first coding exon sufficiently close to be of concern for the targeting strategy. Rat neurexin $1 \alpha$ protein sequence (GenBank accession number AAA41704.1, Ushkaryov et. al., 1992) was aligned tBLASTn with the mouse genome database. No exon aligned within $100 \mathrm{~kb}$ downstream of the first coding exon. Therefore there was little risk of exonic sequence disruption upon integration of selection marker downstream of the first coding exon. We decided to place the neomycin resistance gene along with the $3^{\prime}$ loxP at EcoRI site which is $2.2 \mathrm{~kb}$ from the end of the first coding exon (Figure 3.18).

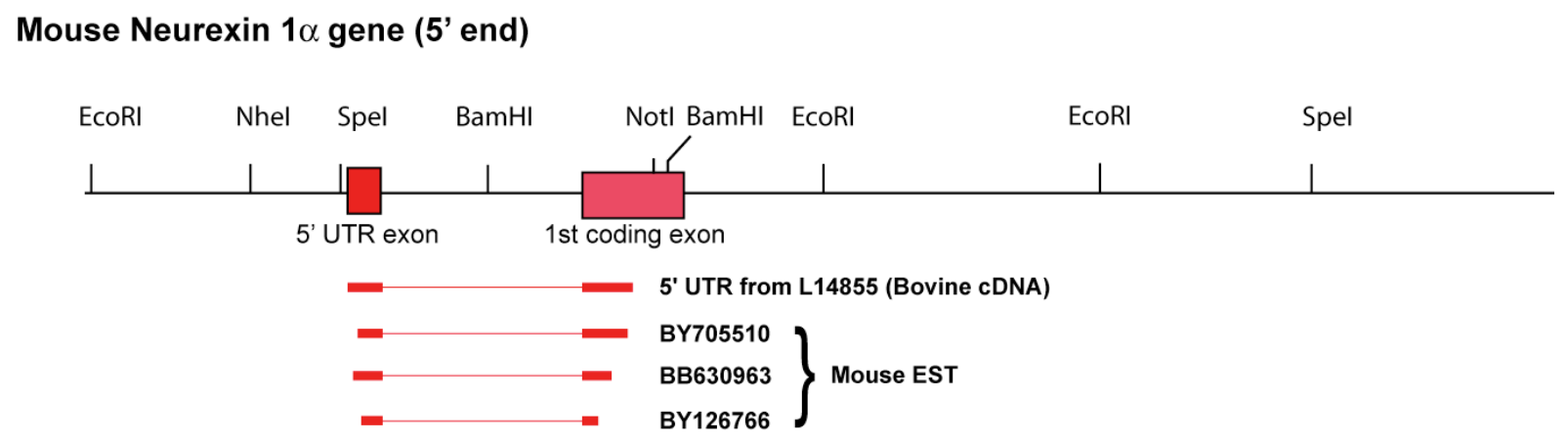

Figure 3.17 Structure of the $5^{\prime}$ end of the neurexin $1 \alpha$ gene. The $5^{\prime}$ UTR exon resides 3 $\mathrm{kb}$ upstream of 1 st coding exon. The ESTs from mouse database and the 5' UTR of bovine cDNA are shown aligned to the exons. Important restriction enzyme cutting sites are also shown. 
Wild type allele Neurexin $1 \alpha$

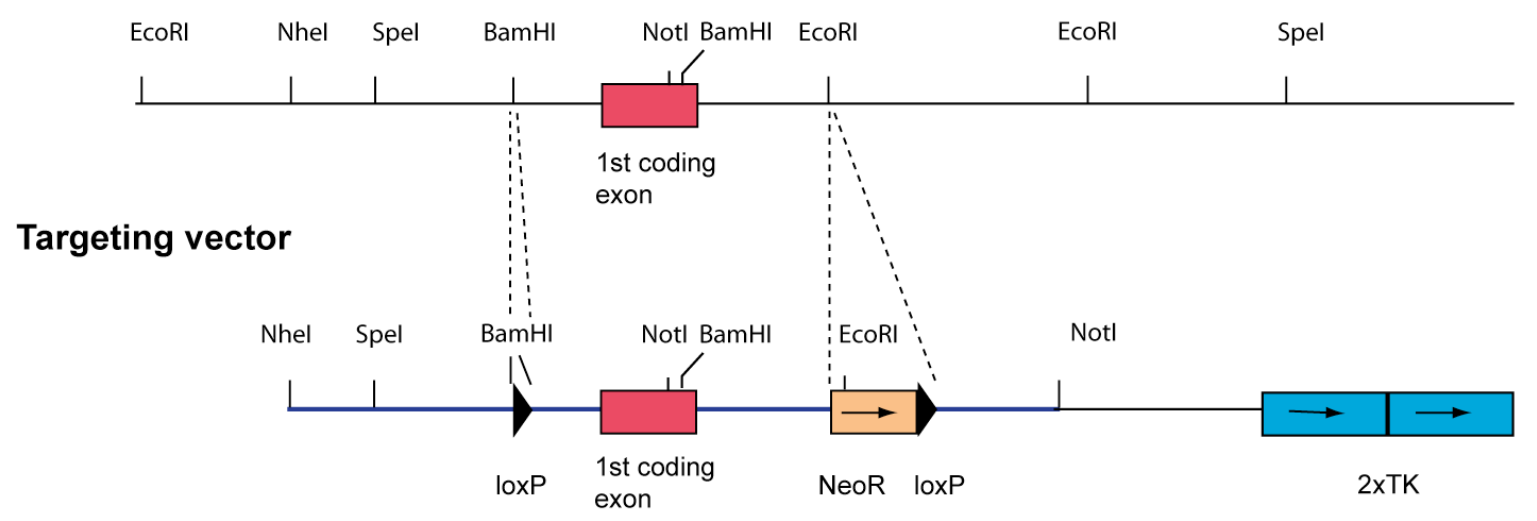

Knock-in allele

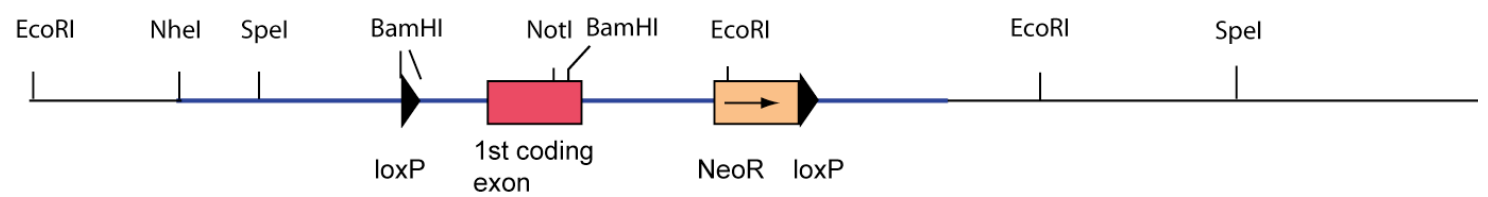

Figure 3.18 Targeting strategy for neurexin $1 \alpha$ knock-in mice. Top diagram: Structure of the $5^{\prime}$ end of the neurexin $1 \alpha$ gene with the first coding exon indicated in red. Middle diagram: The targeting vector constructed for generating knock-in mouse. The sequence of the trageting vector that is homologous to the endogenous gene is shown in purple. $5^{\prime}$ lox $\mathrm{P}$ site was introduced at BamHI site upstream of the first coding exon. NeoR gene and 3 ' loxP site was introduced at EcoRI site (by blunt end cloning) downstream of the first coding exon. Bottom diagram: Structure of the knock-in allele that results after successful homologous recombination of the wild-type allele with the targeting vector. $5^{\prime}$ and $3^{\prime}$ loxP sites as well as the NeoR cassette are introduced, but 2xTK cassette is excluded. NeoR = Neomycin resistance gene, $\mathrm{TK}=$ Thymidine kinase gene. Important restriction sites are also shown.

\subsubsection{Embryonic stem cell experiments}

Embryonic stem cells were cultured on a layer of feeder cells and were electroporated in two batches with neurexin $1 \alpha$ conditional targeting vector. The cells were then cultured on selective medium to eliminate non-recombinant clones. A total of 192 clones were picked up and propogated. Part of each clone's cells were frozen at $-80^{\circ} \mathrm{C}$ and the rest were used for DNA preparation.

To identify clones with homologous recombination, a southern blot strategy was designed. The strategy involved digesting the ES cell DNA with the enzyme NdeI and then probing with an outside probe. The outside probe would belong to the sequence downstream of the $3^{\prime}$ end of the genomic region included in the targeting vector or the sequence upstream to its $5^{\prime}$ end. It would provide the desirable shift in band size only when homologous recombination has taken place. Multiple fragments were tested for this purpose, however none of them gave a 
decent signal on the blot. Many of the probes gave a non-specific background, probably because of the presence of repetitive elements within the sequence. The part of neurexin $1 \alpha$ gene surrounding the first coding exon has multiple repetitive sequences that makes it very difficult to be included in the probe. Therefore it was decided to take a fragment from neomycin resistance cassette as a probe (Figure 3.19). Since this probe is internal to the targeting vector, it would give a positive signal on both homologous and non-homologous recombined clones. It was expected that an accurate estimation of the size of the bands on Southern Blot would give at least a preliminary identification of homologous recombined clones. $1 \mathrm{~kb}$ EcoRI-BamHI fragment from pTKNeolox (corresponding to a part of neomycin resistance cassette) was used as a probe. DNA of ES cell clones were digested with NdeI (one set of plates) and with EcoRI (second set of plates) and used for Southern blotting.

\section{Wild type allele}

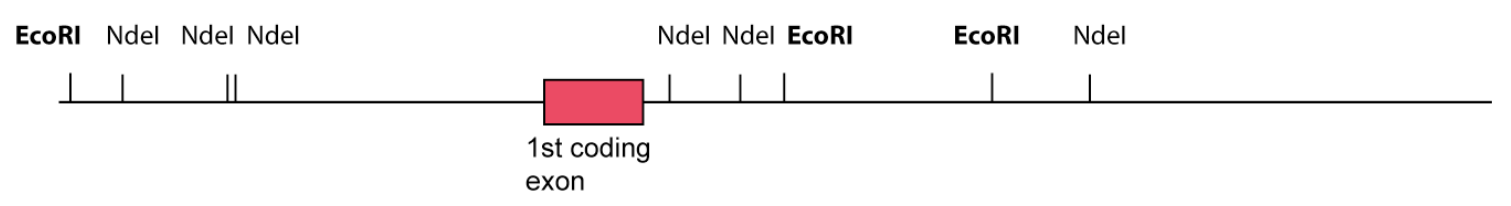

\section{Knock-in allele}

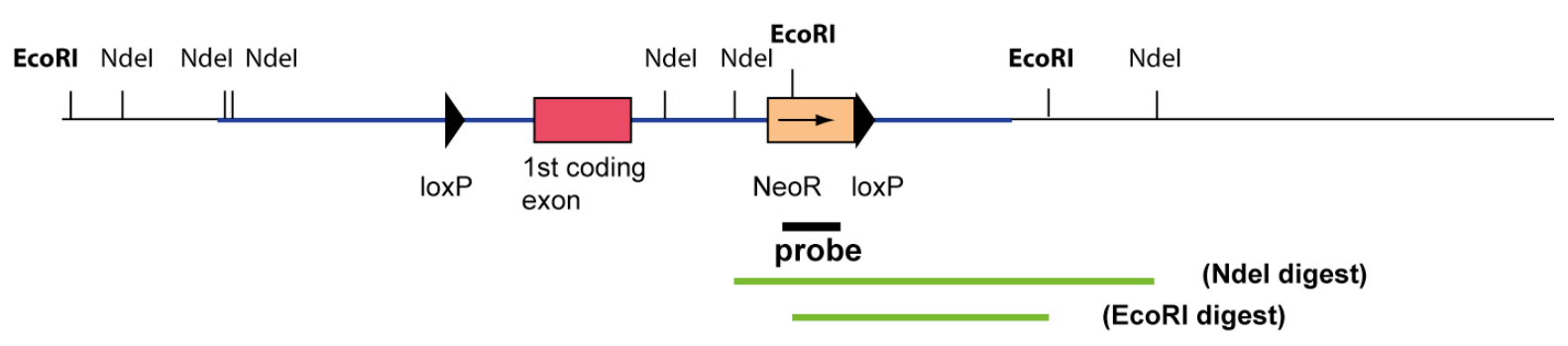

Figure 3.19. Southern blot strategy for screening ES cells. Southern blot strategy for screening embryonic stem cell clones using NeoR probe. DNA from ES cells to be digested either with Ndel or EcoRI. EcoRI-BamHI fragment $(\sim 1 \mathrm{~kb})$ from NeoR gene used as a probe. Top diagram: ES cells with no recombination with the targeting vector will not give any positive signal on the blot as they lack the neoR gene. Bottom diagram: Homologously recombinant clones will give a band of $6.5 \mathrm{~kb}$ with Ndel digest and $4 \mathrm{~kb}$ with EcoRl digest. The sequence of the trageting vector that is homologous to the endogenous gene is shown in purple. The sizes of the bands to be obtained on the blot are shown in green. Since the probe is internal to the targeting vector, non-homologous recombinant ES cell clones will also give signal on the blot of varying sizes. 
The expected band sizes in case of homologous recombination are given below:

\begin{tabular}{lc}
\hline & Band size \\
\hline Ndel digest & $6.5 \mathrm{~kb}$ \\
EcoRI digest & $4 \mathrm{~kb}$ \\
\hline
\end{tabular}

12 ES cell clones were selected using this strategy (data not shown). These were thawed and grown again and more DNA was obtained from them. The identity of the clones was retested using Southern Blot (Figure 3.20). 4 clones among these were identified to be the most likely candidates.

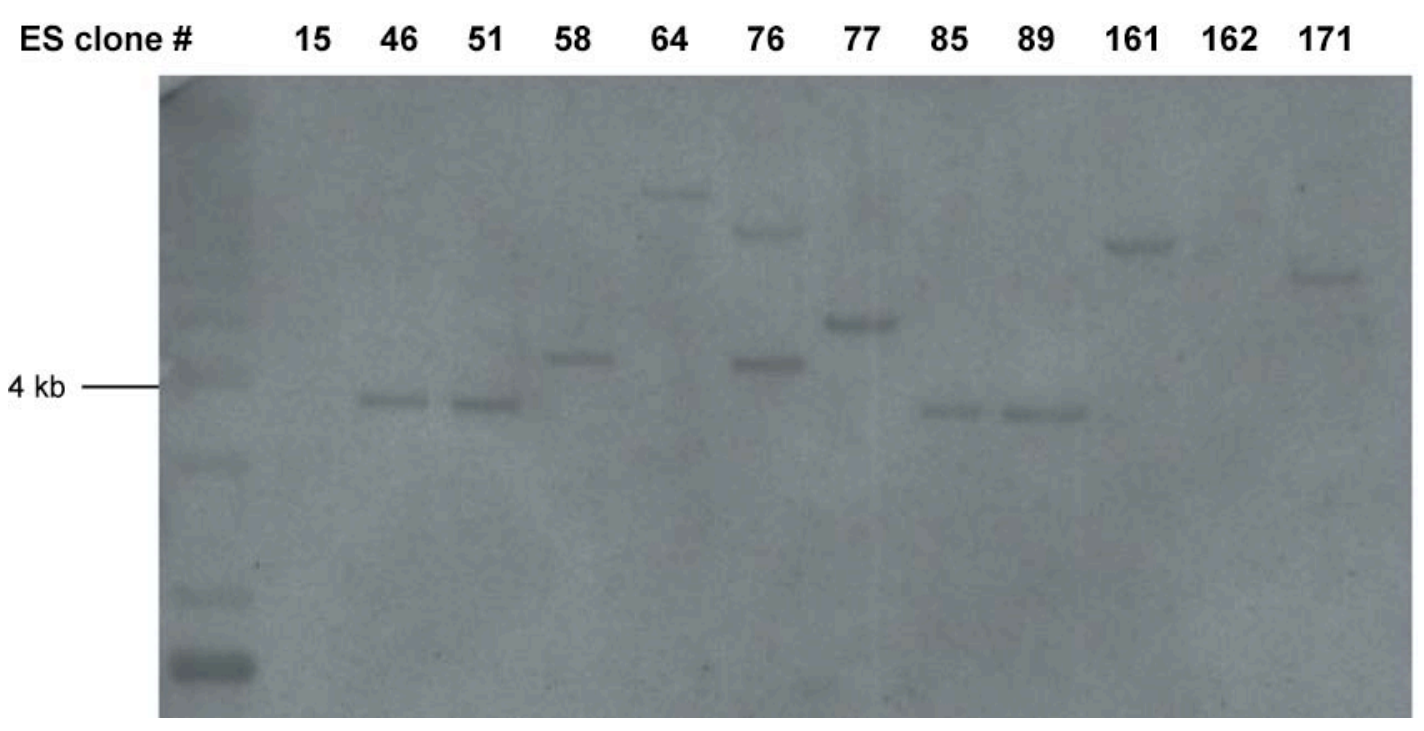

Figure 3.20. Southern blot screening of embryonic stem cell colonies. Southern blot of 12 selected ES cell colonies (see text). The DNA was digested with EcoRI and probed using NeoR probe. Since the probe was internal, it gave signal on both homologous and nonhomologous recombinant clones. Homologous recombinant clones should give a band of 4 kb. ES cell clones \#46, 51, 85 and 89 gave the band of correct size.

For final confirmation of homologous recombinant clones a PCR strategy was designed (Figure 3.21A). It used Expand Long Template PCR (Roche) which is especially optimized to amplify long segments of genomic DNA. 2 different reactions were devised as outlined below:

\section{Reaction 1}

Primers:

MM03-55/4874 (Forward primer that sits in the gene $5^{\prime}$ to the point of insertion of the selection marker) 
MM03-57/4897 (Reverse primer that sits in the gene outside and 3' to the sequence homologous to the targeting vector)

\begin{tabular}{lc}
\hline \multicolumn{2}{c}{ PCR product } \\
\hline Wild type & $3 \mathrm{~kb}$ \\
Homologous recombination & $4 \mathrm{~kb}$ \\
\hline
\end{tabular}

\section{Reaction 2}

Primers:

1948 (Forward primer that sits in the selection marker)

MM03-57/4897 (Reverse primer that sits in the gene 3' to the targeting vector homologous region)

\begin{tabular}{ll}
\hline \multicolumn{2}{c}{ PCR product } \\
\hline Wild type & No band \\
Homologous recombination & $3 \mathrm{~kb}$ \\
\hline
\end{tabular}

Since the reverse primer in both the reactions hybridized to gene sequence outside the trageting vector, the reactions gave a definitive conclusion about the homologous recombination.

Using this strategy it was confirmed that ES cell clones \# 51, 85 and 89 had homologous recombination of the neurexin $1 \alpha$ conditional targeting vector (Figure 3.21B). During reaction 1, ES cell clones \# 51, 85 and 89 produced both a wild type band ( $3 \mathrm{~kb})$ and a knock-in band (4 kb) implying homologous recombination. In contrast ES cell clones \# 15 and 71 gave only the wild type band implying that these clones are non-homologous recombinant. During reaction 2, only ES cell clones \# 51,85 and 89 produced a product, confirming that these clones are homologous recombinant. 
A

Wild type allele

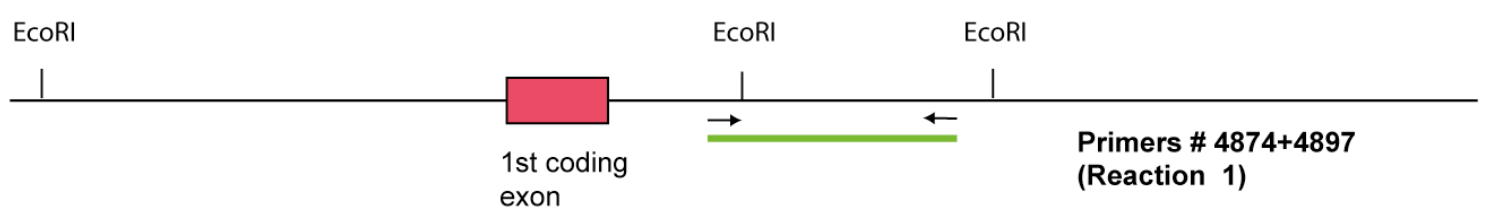

\section{Knock-in allele}

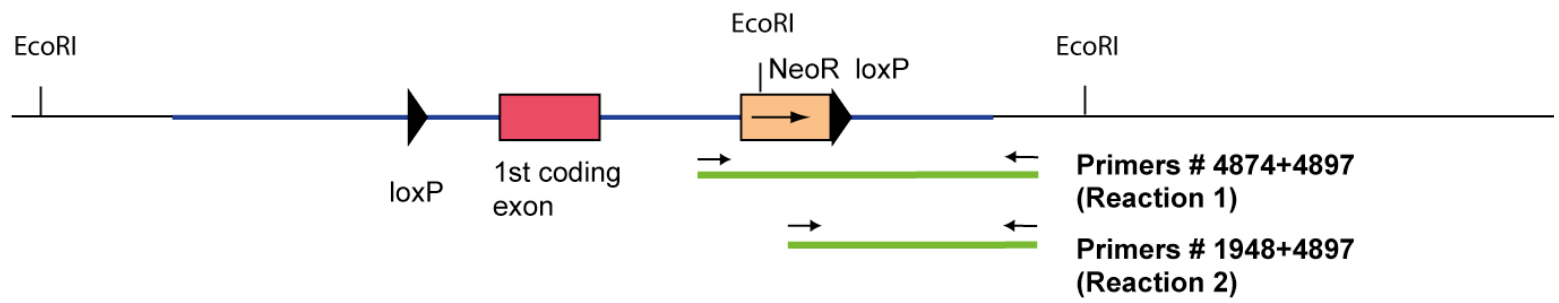

B

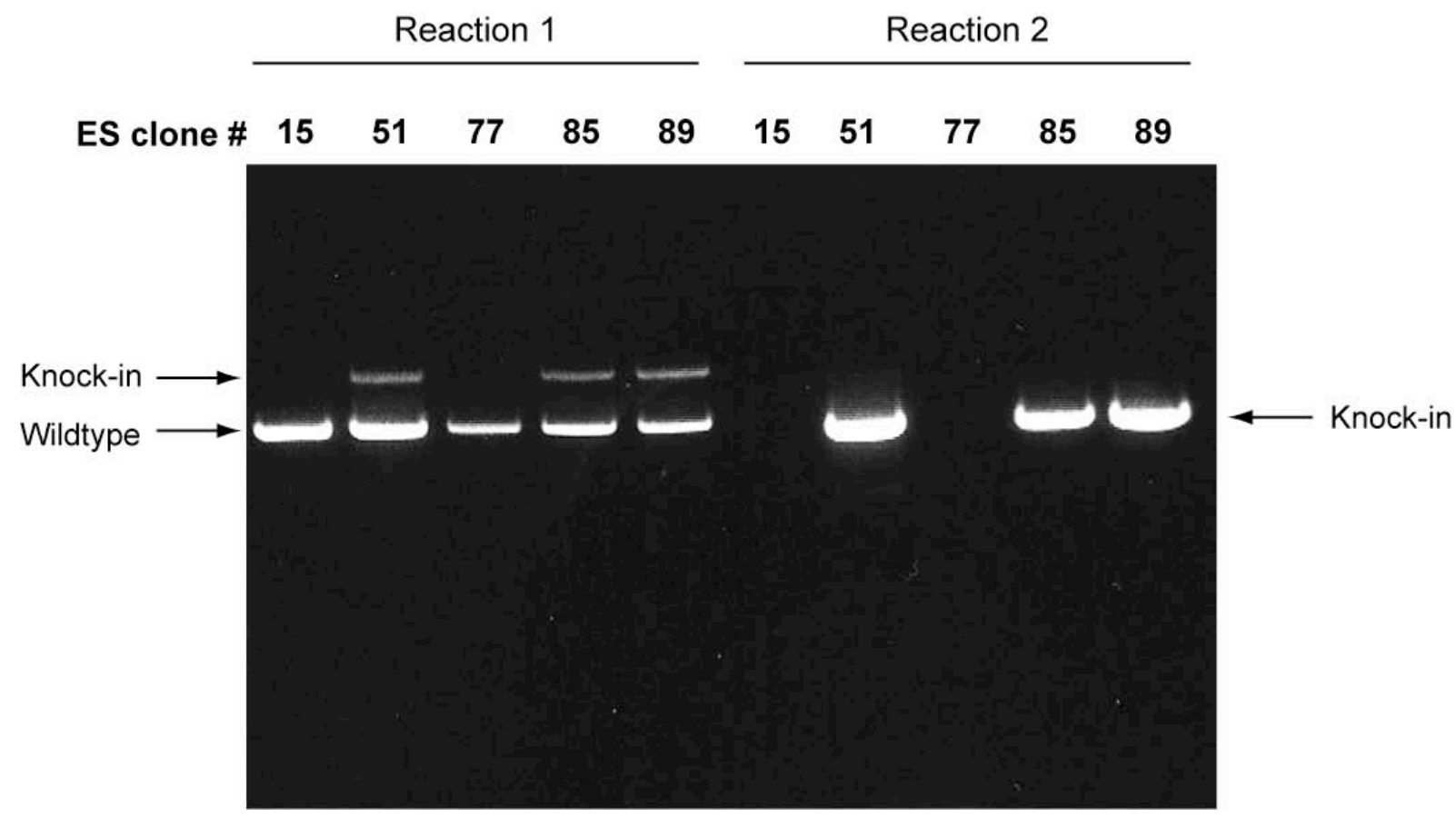

Figure 3.21. Long range-PCR for genotyping ES cells. (A) PCR based strategy to confirm homologous recombination in ES cell clones, and to genotype mutant mice at critical steps. It is based on two sets of primers, both sets included a reverse primer \#4897 that hybridize to the gene $3^{\prime}$ and outside the targeting vector homologous region. Top diagram: Wild type allele would give a $3 \mathrm{~kb}$ band with reaction 1 . Since it lacks the selection marker, there would be no product with reaction 2. Bottom diagram: Knock-in allele with homologous recombination would give a $4 \mathrm{~kb}$ band with reaction 1 (the size is increased from $3 \mathrm{~kb}$ because of the insertion of selection marker) and a $3 \mathrm{~kb}$ band with reaction 2 . The arrows represent PCR primers. The amplified region with both reactions is shown in green. (B) Long range-PCR was used to confirm the genotype of embryonic stem cell colonies. During reaction 1 (primers \#4874+4979), ES cell clones \# 51, 85 and 89 produced both a wild type band $(3 \mathrm{~kb})$ and a knock-in band $(4 \mathrm{~kb})$ implying that these clones are homologous recombinant. In contrast ES cell clones \# 15 and 71 gave only the wild type band implying non-homologous recombination. During reaction 2 (primers\#1948+4897), only ES cell clones \# 51, 85 and 89 produced a product, confirming that these clones are homologous recombinant. 


\subsubsection{Establishment of knock-in mouse line}

ES cells from clones\# 51, 85 and 89 were taken for microinjection into blastocysts at the Animal Facility of MPI Experimental Medicine, Göttingen. The ES cells were microinjected into blastocysts obtained from C57Black6 mice and chimeric blastocysts were then implanted into pseudopregnant mice. Many chimeric mice were born belonging to all the three ES cell clones. The chimeric mice show a mixture of brown colour (derived from ES cell strain) and black colour (derived from C57Black6 strain) on their skin. The percentage of recombinant genome could be roughly estimated by the ratio of the brown colour to black colour on the skin. The degree of chimerism ranged from $40 \%$ to $90 \%$ among these animals. When these mice got mature, male mice showing good chimerism were bred with virgin C57Black6 females. This led to the delivery of black as well as a high number of agouti mice. The generation of agouti mice represents germline transmission of microinjected ES cells. Agouti mice are either heterozygous with recombinant allele in all of their cells or they are homozygous for wild type allele. The brown skin colour of these mice is due to the function of skin pigmentation agouti gene.

After weaning of 64 agouti mice, biopsies were taken from their tails and the DNA was extracted for genotyping. Genotyping was done to identify those mice which are heterozygous for the recombinant allele. A PCR strategy was designed which involved amplification of small fragments of DNA (short range PCR) and included relatively less expensive Red Taq polymerase (Sigma). The strategy is illustrated in figure 3.22A . Two different reactions were devised as outlined below:

\section{Reaction 1}

Primers:

MM03-55/4874 (Forward primer that sits in the gene 5 ' to the point of insertion of the selection marker)

MM03-56/4875 (Reverse primer that sits in the gene 3' to the point of insertion of the selection marker)

Both primers are internal to the gene sequence homologous to the targeting vector.

\begin{tabular}{lc}
\hline & PCR product size \\
\hline Wild type & $0.35 \mathrm{~kb}$ \\
Knock-in allele & $1.3 \mathrm{~kb}$ \\
\hline
\end{tabular}




\section{Reaction 2}

Primers:

MM03-55/4874 (Forward primer that sits in the gene 5' to the point of insertion of the selection marker)

2875 (Reverse primer that sits in the selection marker of the targeting vector)

\begin{tabular}{lc}
\hline & PCR product size \\
\hline Wild type allele & No band \\
Knock-in allele & $0.8 \mathrm{~kb}$ \\
\hline
\end{tabular}

The results of the two PCR reactions done on the samples is shown in figure 3.22B. 28 mice were found to be heterozygous for the recombinant allele. Not all agouti mice carried the recombinant allele because recombinant ES cells were heterozygous and therefore only 50\% of germ cells derived from these ES cells would carry the recombinant allele. 
A

Wild type allele

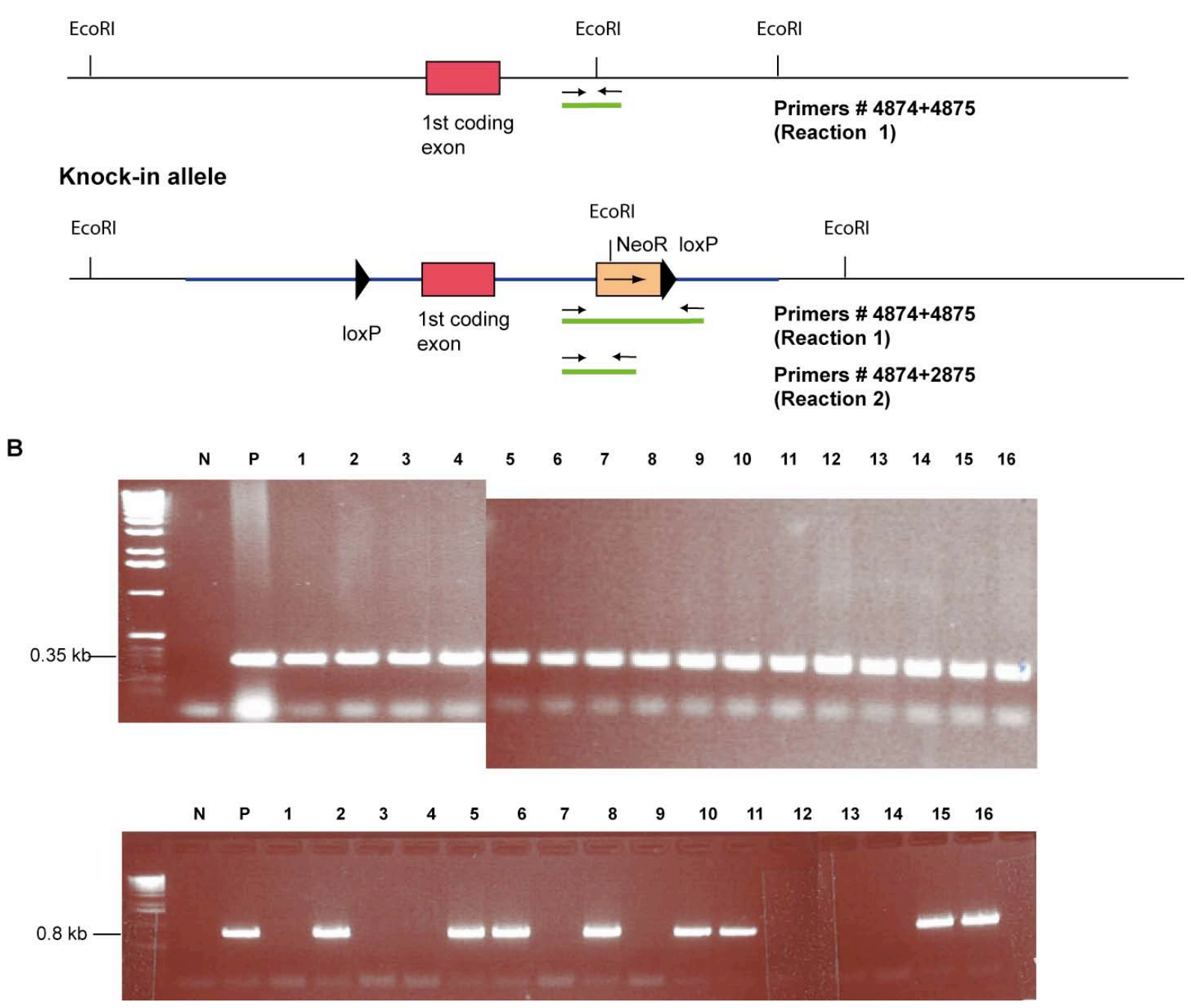

Figure 3.22 Genotyping of mice with short range-PCR. Regular genotyping of agouti mice as well as of their offsprings was done by PCR. (A) Strategy designed for short range-PCR. It is based on 2 sets of primers. Reaction 1 (using primers \#4874+4875) would give a $0.35 \mathrm{~kb}$ band in wild type allele and $1.3 \mathrm{~kb}$ band in knock-in allele. Reaction 2 (using primers \#4874+2875) would give a $0.8 \mathrm{~kb}$ band in knock-in allele but no product in wild type allele. The arrows represent PCR primers aligned to their region of hybridization. The amplification products are shown in green. The sequence of the gene included in the targeting vector is shown in purple. (B) Genotyping results of short range-PCR done on agouti mice. Top panel Results of PCR reaction 1 (primers \#4874+4875) from tail samples of 16 agouti mice show a wild type band $(0.35 \mathrm{~kb})$ in all samples. The mutant band can not be amplified under the reaction conditions used. Bottom panel Results of PCR reaction 2 (primers \#4874+2875) from tail samples of 16 agouti mice show a band $(0.8 \mathrm{~kb})$ in 9 agouti mice, implying that these are heterozygous knock-in mice. The genotype of some agouti mice which were found to be heterozygous knock-in by short range-PCR was then confirmed by long range-PCR on their tail samples. $N$ represents negative control (no template) and $P$ represents DNA from recombinant ES cells (as a positive control). The different gel pictures have been scaled appropriately for proper alignment. 
The heterozygous knock-in mice were bred with each other to obtain homozygous knock-in mice. The mice that were delivered were genotyped using short range PCR as described above. However to confirm the genotype, long range PCR was done on selected samples as shown in figure 3.23. The results clearly showed the successful achievement of homozygous knock-in mice, in which the knock-in allele completely replaces the wild type allele.

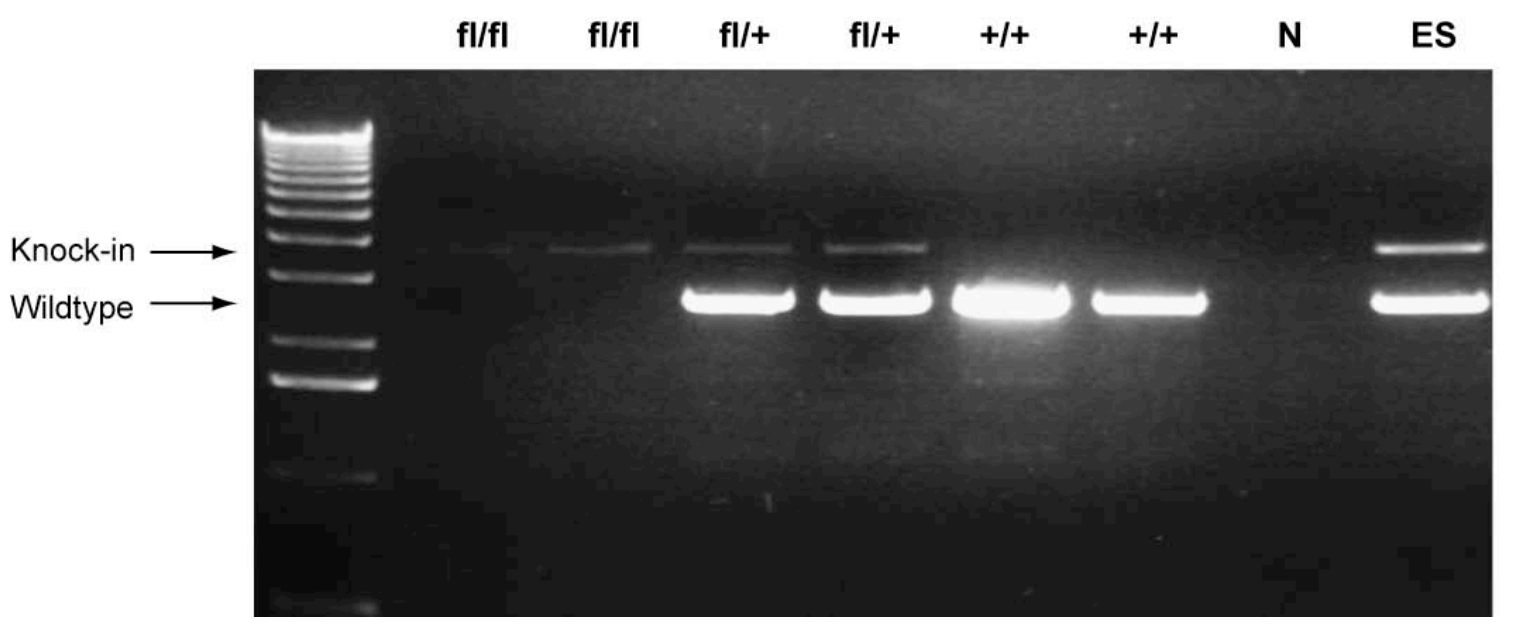

Figure 3.23. Genotyping of mice with long range-PCR. Long range-PCR (using primers \#4874+4979) was done on selected mice obtained from breedings between agouti mice. Wild type allele gives a $3 \mathrm{~kb}$ band and knock-in allele gives a $4 \mathrm{~kb}$ band. Lanes 1 and 2 represent samples from homozygous knock-in (fl/fl) mice, which show only knock-in band with complete disappearance of wild type band. Lanes 3 and 4 represent samples from heterozygous knock-in ( $\mathrm{fl} /+)$ mice, which show both wild type and knock-in bands. Lanes 5 and 6 represent samples from wild type $(+/+)$ mice, showing only the wild type product. Lane 7 is for negative control (no template) and lane 8 is a sample from heterozygous knock-in ES cell clone (as a positive control). The result shown here demonstrates the successful achievement of homozygous knock-in mice, in which the knock-in allele completely replaces the wild type allele.

\subsubsection{Establishment of conditional knockout mouse line}

Firstly, we wanted to know whether the knock-in allele is susceptible to cre-recombinase mediated recombination leading to a knockout. As a relatively rapid check of the efficiency of recombination of the mutated allele, we used the EIIa-cre transgenic line. In this mouse line the enzyme cre-recombinase is expressed under the control of the adenovirus EIIa promoter, which causes the expression of the recombinase in the early mouse embryo ubiquitously (Lakso et al., 1996). We crossed some homozygous knock-in mice with EIIa-cre ${ }^{+/ t g}$ transgenic mice. A short range PCR based strategy was devised to genotype the offsprings obtained to detect the knockout allele (Figure 3.24A). 
Primers:

MM04-33/6116 (Forward primer sitting in the neurexin $1 \alpha$ gene 5' to BamHI

site where 5' loxP has been inserted.)

MM04-34/6117 (Reverse primer sitting in the neurexin $1 \alpha$ gene 3 ' to the place of insertion of $3^{\prime}$ loxP)

\begin{tabular}{ll}
\hline & PCR product size \\
\hline Knockout & $0.3 \mathrm{~kb}$ \\
Wild type & $5.4 \mathrm{~kb}$ (too large to be \\
& amplified in the reaction \\
& conditions used). Thus no \\
& band. \\
& $6.4 \mathrm{~kb}$ (too large to be \\
Knock-in & amplified in the reaction \\
& conditions used). Thus no \\
& band. \\
\hline
\end{tabular}

Genotyping results showed the appearance of knockout band in all mice which were expressing cre-recombinase (Figure 3.24B). This implied that the knock-in allele is susceptible to cre-recombinase mediated recombination. However in many animals the knockin band persisted indicating to the fact that often the recombination achieved was partial.

Figure 3.24. Generation of conditional knockout of neurexin $1 \alpha$. (A) Schematic showing the conversion of knock-in allele into a knockout upon addition of the enzyme crerecombinase. The part of neurexin $1 \alpha$ gene (including the first coding exon) located between the two loxP sites in the knock-in allele would be excised. Also shown is the strategy to detect the knockout allele in mutant mice by short range-PCR. Primer \#6116 sits in the neurexin $1 \alpha$ gene $5^{\prime}$ to the site where $5^{\prime}$ loxP has been inserted. Primer \#6117 sits in the neurexin $1 \alpha$ gene $3^{\prime}$ to the place of insertion of $3^{\prime}$ loxP. In case of knockout, excision of intervening portion would bring the two primers closer and produce a $\sim 0.3 \mathrm{~kb}$ product. In case of wild type and knock-in allele, the distance between the two primers would be too large to be amplified using short range-PCR conditions. (B) Genotyping results of offsprings from knock-in mice (Nrxn $1 \alpha \mathrm{fl} / \mathrm{fl})$ bred with Ella-cre transgenic mice. Samples from all mice were positive for wild type reaction (using primers \#4874+4875). Mice sample \#1,3,4 and 5 produced a positive reaction for cre-recombinase (using primers \#7633+7634) as well as for knockout allele (using primers \#6116+6117). The mouse \#2 does not have cre and does not present a knockout reaction. These results showed that the knock-in allele is undergoing crerecombinase mediated recombination. $\mathrm{N}$ represents negative control (no template). 
A

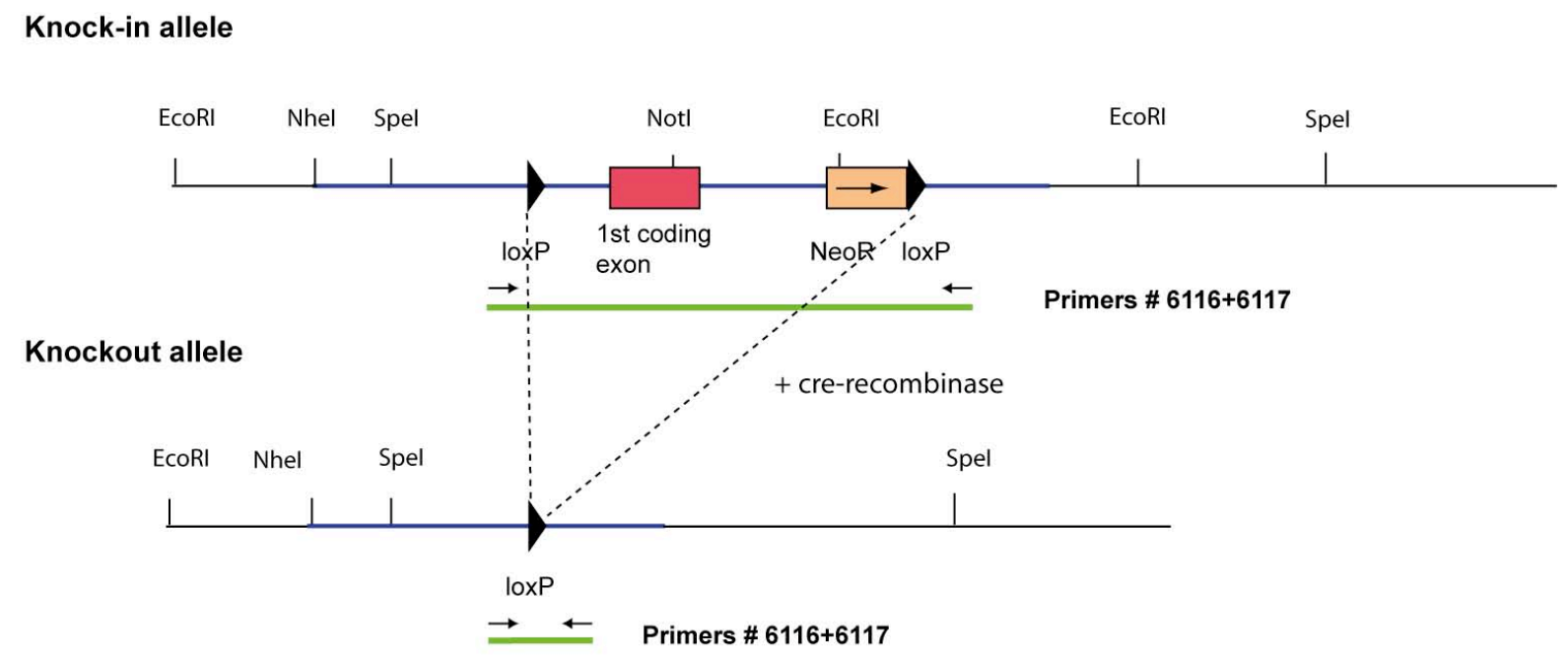

B

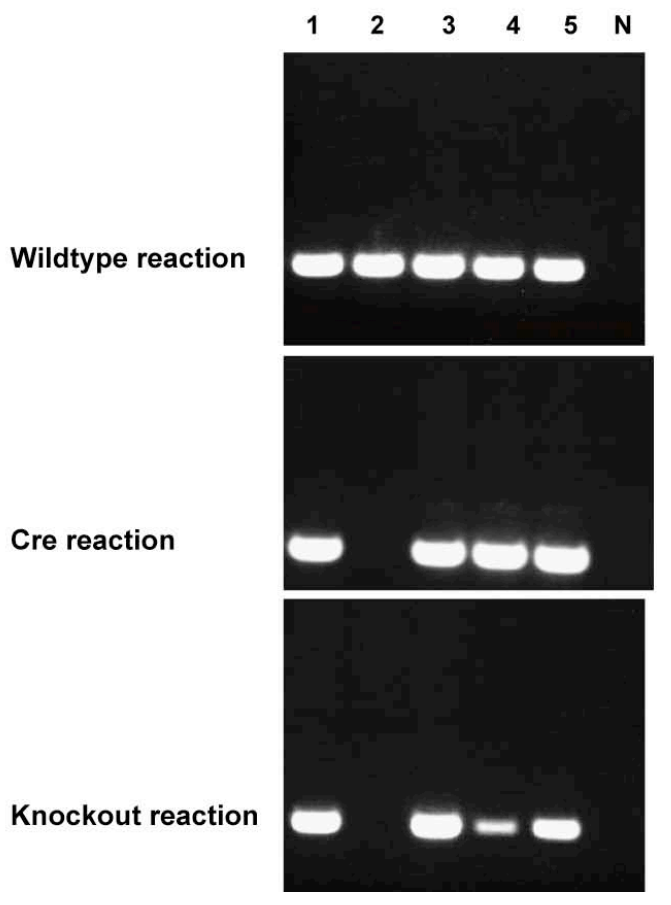

The ultimate aim of this conditional knockout project is to achieve complete deletion of $\alpha$ neurexins in a desired brain region in an adult animal. The presence of two other isoforms of $\alpha$-neurexins i.e. neurexin $2 \alpha$ and neurexin $3 \alpha$ complicates the issue. It was thus important to breed the neurexin $1 \alpha$ knock-in mice (Nrxn $1 \alpha \mathrm{fl} /+$ or Nrxn $1 \alpha \mathrm{fl} / \mathrm{fl}$ ) with Nrxn $2 \alpha / \mathrm{Nrxn} 3 \alpha$ double knockout mice so as to bring the knock-in allele in $\operatorname{Nrxn} 2 \alpha / \mathrm{Nrxn} 3 \alpha$ double knockout background. Then a cre-recombinase mediated deletion of neurexin $1 \alpha$ would cause a complete loss of $\alpha$-neurexins. We therefore crossed the neurexin $1 \alpha$ knock-in mice with Nrxn 
$1 \alpha+/-$ Nrxn $2 \alpha-/-$ Nrxn $3 \alpha+/-$ mice. The resultant progeny were genotyped regularly and bred among themselves. An important result appeared when some mice were found to have the genotype of Nrxn $1 \alpha \mathrm{fl} / \mathrm{fl} \operatorname{Nrxn} 2 \alpha-/-\operatorname{Nrxn} 3 \alpha-/-$. This implied that these mice were surviving only on the knock-in alleles in neurexin $1 \alpha$ gene. This is genetic evidence that the knock-in allele is functional in adult mice. This is an important result because the selection marker within knock-in mutation could potentially interfere with the expression of the endogenous gene (Pham et al., 1996; Meyers et al., 1998; Ren et al., 2002). Since mice with deletions of all three $\alpha$-neurexin genes do not survive their first day after birth, the survival of Nrxn $1 \alpha$ fl/fl Nrxn $2 \alpha-/-\operatorname{Nrxn} 3 \alpha-/-$ mice implied that the knock-in mutation that we introduced does not lead to functional inactivation of the neurexin $1 \alpha$ gene.

We then wanted to achieve deletion of neurexin $1 \alpha$ in hippocampus of adult mice. This was done to study synaptic transmission in the hippocampus of adult mice lacking all three $\alpha$ neurexins (similar to the studies on $\alpha$-neurexin double KOs, see section 3.2). We started breedings of mice (genotype obtained above) with CAMKII-cre transgenic line. In this mouse line the cre-recombinase is expressed under the control of the CAMKII promoter, which drives the expression of the recombinase in the mouse forebrain including the hippocampus at or after P20 (Minichiello et. al., 1999). The currently used breeding scheme is shown below, along with the progeny that will be used in electrophysiological experiments of synaptic transmission and plasticity in hippocampus.

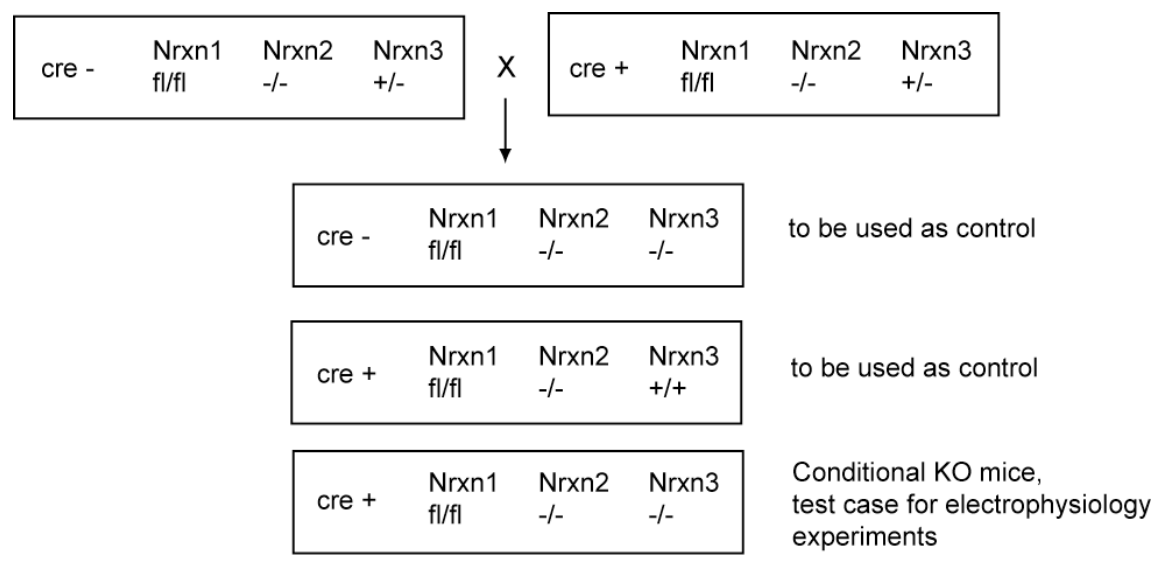

The studies on conditional triple KOs are expected to yield a stronger phenotype than $\alpha$ neurexin double KOs and might even uncover some novel defects. 


\section{DISCUSSION}

There is considerable heterogeneity among synapses (Atwood and Karunanithi, 2002). It is presently unclear which molecular processes instruct and regulate the development of diverse synapses. $\alpha$-Neurexins are synaptic cell adhesion molecules present at the presynaptic terminal. They are one of the candidates to mediate part of the diversity because of the following reasons. 1) Neurexins are localized at the presynaptic terminal and bind to postsynaptic molecules like neuroligins and dystroglycan, thus could transmit a retrograde signal from the postsynaptic to the presynaptic side. 2) Neurexins are expressed as hundreds of isoforms, and thus could potentially provide a combinatorial code for neuronal recognition. 3) Neurexins interact with multiple adaptor proteins in the presynaptic terminal, and therefore could participate at multiple steps in excitation-secretion coupling. 4) Previous analysis of $\alpha$ neurexin $\mathrm{KO}$ reveals their essential role in neurotransmitter release. In this $\mathrm{PhD}$ project, I further explored the function of $\alpha$-neurexins to better understand their role in regulation of synaptic transmission. I found that 1) $\alpha$-neurexins do not considerably alter the biophysical properties of $\mathrm{Ca}^{2+}$ channels, 2) various forms of short- and long-term synaptic plasticity are altered in $\alpha$-neurexin knockout mice, and 3) RIM1 $\alpha$ is an interaction partner of neurexins.

\subsection{Neurexin $1 \alpha$ does not alter the functional properties of N-type $\mathrm{Ca}^{2+}$ channels in HEK cells}

The deletion of $\alpha$-neurexins in mice caused a decrease in the sensitivity of neurotransmitter release to the blocker of $\mathrm{N}$-type $\left(\mathrm{Ca}_{\mathrm{v}} 2.2\right) \mathrm{Ca}^{2+}$ channels at neocortical and brainstem synapses (Missler et al., 2003). The transgenic neurexin $1 \alpha$ :HRP allele crossed into various $\alpha$-neurexin KO mice partly rescued this sensitivity (Zhang et al., 2005). Moreover whole-cell $\mathrm{Ca}^{2+}$ currents recorded from the soma of brainstem neurons were reduced in $\alpha$-neurexin knockouts. The density of all types of $\mathrm{Ca}^{2+}$ channel currents (L-, N- and P/Q-type) were reduced. N-type $\mathrm{Ca}^{2+}$ channels were the most affected and almost completely abolished. The transgenic neurexin $1 \alpha: H R P$ allele crossed into various $\alpha$-neurexin KO mice, partly rescued the decrease in whole-cell currents belonging to N-type and P/Q-type currents. This led to the hypothesis that $\alpha$-neurexins might be important regulators of the $\mathrm{Ca}^{2+}$ channel function at the presynaptic bouton. However there was no direct evidence for this hypothesis. It is very difficult to measure the activity of $\mathrm{Ca}^{2+}$ channels at the presynaptic terminal directly. The two systems which were used for the initial analysis of $\alpha$-neurexin KOs were neocortical slice cultures and 
acute brainstem slices. The presynaptic terminals in these systems are very small $(\sim 1 \mu \mathrm{m})$ and therefore patch-clamp recordings can not be performed on these.

Heterologous cell lines e.g. Human Embryonic Kidney (HEK293) cells provide an easily accessible system where the function of expressed voltage-gated channels can be studied. HEK293 cells are easy to grow and maintain. They provide good voltage-clamp conditions because they do not have extensive processes like those in neurons. This allows a much accurate determination of the biophysical properties of channels. Importantly, HEK293 cells express few endogenous high voltage-activated $\mathrm{Ca}^{2+}$ channels (Berjukow et al., 1996). Thus after expression, the activity of a particular type of $\mathrm{Ca}^{2+}$ channels can be studied in isolation without contamination with other types of currents. In addition, HEK293 cells lack most of the synaptic proteins and therefore the modulatory activity of a particular synaptic protein (or a combination of proteins) on $\mathrm{Ca}^{2+}$ currents can be studied without an influence of other proteins. We therefore decided to use HEK293 cells to address the question whether $\alpha$ neurexins modulate the density and functional properties of $\mathrm{N}$-type of $\mathrm{Ca}^{2+}$ channels.

We used the HEK_Ca 2.2 cell line which shows a stable expression of rabbit $\alpha 1 \mathrm{~B}$ (pore forming subunit of $\mathrm{Ca}_{\mathrm{v}} 2.2$ ), rabbit $\beta 3$ and rat $\alpha 2 \delta$ subunits of voltage-gated $\mathrm{Ca}^{2+}$ channels. Our experiment using HEK_Ca 2.2 cells showed that neurexin $1 \alpha$ does not change the density of $\mathrm{Ca}^{2+}$ channel currents. Since $\alpha$-neurexin $\mathrm{KO}$ mice display reduced density of $\mathrm{Ca}^{2+}$ channel currents in brainstem neurons, it was hypothesised that $\alpha$-neurexins might be involved in direct enhancement of $\mathrm{Ca}^{2+}$ current density. The results on HEK_Ca 2.2 cells show that this is not the case, at least not by a direct interaction between neurexins and $\mathrm{Ca}^{2+}$ channels. It is however possible that this interaction requires the presence of some intermediate proteins, which are present at the synapse but absent from HEK cells. Many synaptic proteins have been shown to interact biochemically with $\mathrm{N}$-type $\mathrm{Ca}^{2+}$ channels. MAGUK proteins, CASK and Mint1 bind to the C-terminus of $\mathrm{Ca}^{2+}$ channels (Maximov et al., 1999), and also have been shown to interact with neurexins (Hata et al., 1996; Butz et al., 1998; Biederer and Sudhof, 2000). In addition, CASK and Mint1 bind to each other and thus could potentially link neurexins and $\mathrm{Ca}^{2+}$ channels together. Our experiments in which CASK and Mint1 were expressed in HEK_Ca 2.2 cells along with neurexin $1 \alpha$ showed that the $\mathrm{Ca}^{2+}$ channel current density was not significantly enhanced in transfected cells as compared to control cells. In addition, neurexin $1 \alpha$ did not alter the activation or inactivation parameters of $\mathrm{Ca}^{2+}$ channel currents when expressed alone or with CASK and Mint1. Before interpreting these results 
some factors should be kept in mind. Firstly, the $\alpha 1 \mathrm{~B}$ subunit of $\mathrm{N}$-type $\mathrm{Ca}^{2+}$ channels as well as the accessory $\beta 3$ subunit that are stably expressed in HEK_Ca 2.2 cells are derived from rabbit, while the cDNA of neurexin $1 \alpha$ is from rat. It has been shown that different isoforms of each $\mathrm{Ca}^{2+}$ channel subunits display different properties, e.g. the $\mathrm{BI}$ isoform of $\alpha 1 \mathrm{~A}$, which was first derived from rabbit (Mori et al., 1991) binds to both syntaxin and SNAP-25, while the rbA isoform derived from rat (Starr et al., 1991) binds only to SNAP-25 and not to syntaxin (Rettig et al., 1996; Zhong et al., 1999). Therefore the lack of an influence of neurexins on $\mathrm{Ca}^{2+}$ currents in HEK_Ca 2.2 cells might be related to the isoform of $\mathrm{Ca}^{2+}$ channel subunits used. It might be important to investigate the same properties using another isoform. Secondly, the $\alpha 1 B$ subunit stably expressed in HEK_Ca 2.2 cells had an HA-tag at its N-terminus. This tag was fused to perform immunolocalization studies. However an epitope tag can influence the binding properties and function of $\mathrm{Ca}^{2+}$ channels.

We therefore used an untagged $\alpha 1 \mathrm{~B} \mathrm{Ca}^{2+}$ channel subunit along with $\beta 1 \mathrm{~b}$ and $\alpha 2 \delta$ accessory subunits, all subunits being derived from rat. Our experiments in tsA201 cells transiently transfected with these $\mathrm{Ca}^{2+}$ channel subunits showed that neurexin $1 \alpha$ did not enhance the current density of $\mathrm{Ca}^{2+}$ channel currents, measured with $\mathrm{Ba}^{2+}$ as charge carrier. The activation and inactivation parameters of currents were also not altered in the presence of neurexin $1 \alpha$. To investigate the possibility that the effect might be dependent on the type of charge carrier, we performed experiments replacing $\mathrm{Ba}^{2+}$ with $\mathrm{Ca}^{2+}$. We found again that neurexin $1 \alpha$ did not alter the density of $\mathrm{Ca}^{2+}$ channel currents. The measurement of activation properties showed that there was a small $(2.5 \mathrm{mV})$ but statistically significant shift in the half-activation potential of current in the hyperpolarized direction, in the presence of neurexin $1 \alpha$. Other activation parameters as well as inactivation properties were not altered. The shift in half-activation potential with neurexin $1 \alpha$ in the presence of $\mathrm{Ca}^{2+}$ is interesting. The leftward shift in activation gating could in principle provide a mechanism for higher availability of $\mathrm{Ca}^{2+}$ channels in response to an action potential. However the amount of shift obtained with neurexin $1 \alpha$ is small and occurs without an obvious increase in peak current density. Therefore it is unlikely that it could be of much physiological relevance.

The experiments in two systems, HEK_Ca 2.2 and tsA201 cells showed that neurexin $1 \alpha$ does not have a considerable effect on the functional properties of $\mathrm{N}$-type $\mathrm{Ca}^{2+}$ channels. It is important to note that a number of synaptic proteins have been shown to alter the properties of $\mathrm{Ca}^{2+}$ channels in these and similar systems. Syntaxin and SNAP-25 have been shown to 
inhibit the activity of $\mathrm{N}$ - and $\mathrm{P} / \mathrm{Q}$-type $\mathrm{Ca}^{2+}$ channels in Xenopus oocytes and tsA201 cells (Bezprozvanny et al., 1995; Wiser et al., 1996; Jarvis et al., 2000; Jarvis et al., 2001). This effect is mediated by a hyperpolarizing shift of steady-state inactivation of $\mathrm{Ca}^{2+}$ channel currents, leading to reduced availability for opening of these channels. The expression of cysteine string protein (CSP) in tsA201 cells reduces the density of $\mathrm{N}$-type $\mathrm{Ca}^{2+}$ channel currents probably caused by enhanced G-protein mediated inhibition (Magga et al., 2000). Metabotropic glutamate receptor mGluR1 causes a ligand-independent inhibition of P/Q-type $\mathrm{Ca}^{2+}$ channels when both are coexpressed in HEK293 cells (Kitano et al., 2003). All these observations imply that heterologous expression systems are useful for detecting a direct effect of synaptic proteins on $\mathrm{Ca}^{2+}$ channel function. With our experiments, it can not be ruled out that some other unknown protein is involved in linking $\mathrm{Ca}^{2+}$ channels to $\alpha$-neurexins, and its presence is required for the action of $\alpha$-neurexins on the $\mathrm{Ca}^{2+}$ channel currents in these systems. Our discovery that neurexins interact biochemically with RIM1 $\alpha$ is significant in this regard. It has been shown that RIMs interact directly with $\alpha 1 \mathrm{~B} \mathrm{Ca}^{2+}$ channel subunit through their C2A and C2B domain (Coppola et al., 2001). In addition RIMs interact with RIM-binding proteins (RBPs) which bind to the $\mathrm{Ca}^{2+}$ channel subunits $\alpha 1 \mathrm{~B}$ and $\alpha 1 \mathrm{D}$ (Hibino et al., 2002). Therfore RIMs and RBPs have the potential to link $\mathrm{Ca}^{2+}$ channel and neurexins together. Future experiments are needed to test whether $\alpha$-neurexins could affect the properties of $\mathrm{Ca}^{2+}$ channels in HEK cells when co-expressed with RIM and RBP.

Keeping the above possibility aside, our experiments indicate that $\alpha$-neurexins do not considerably modulate the functional properties of $\mathrm{N}$-type $\mathrm{Ca}^{2+}$ channels. This interpretation is consistent with a finding in the previous study (Zhang et al., 2005) that transgenic overexpression of neurexin $1 \alpha$ on a wildtype background did not increase the density of whole-cell $\mathrm{Ca}^{2+}$ currents in brainstem neurons. This implies that $\alpha$-neurexins do not directly enhance the $\mathrm{Ca}^{2+}$ channel function, rather the defect in $\mathrm{Ca}^{2+}$ channel activity seen in $\alpha$ neurexin $\mathrm{KO}$ mice is indirect, possibly on neuronal network function or homeostasis (see below). It is otherwise difficult to concieve how presynaptic $\alpha$-neurexins could influence whole-cell $\mathrm{Ca}^{2+}$ current density which is contributed mainly by somatodendritic $\mathrm{Ca}^{2+}$ channels.

Recent studies on pituitary slices derived from $\alpha$-neurexin $\mathrm{KO}$ mice revealed that the exocytosis of dense-core vesicles was impaired, without an alteration of the whole-cell $\mathrm{Ca}^{2+}$ current density (Dudanova, Sedej, Ahmad et al., manuscript submitted). This again confirms 
our experimental results that $\alpha$-neurexins do not modulate the current density of $\mathrm{Ca}^{2+}$ channels, and indicate that the phenotype of defective exocytosis is independent of alteration in $\mathrm{Ca}^{2+}$ channel biophysical properties. What then causes the defect in exocytosis in neuronal synapses and neuroendocrine cells seen in $\alpha$-neurexin KO mice? The most probable explanation is that deletion of $\alpha$-neurexins leads to a miscoupling of $\mathrm{Ca}^{2+}$ channels from the release machinery. When an action potential triggers the opening of presynaptic $\mathrm{Ca}^{2+}$ channels, there is a local increase in intracellular $\mathrm{Ca}^{2+}$. This increase in $\mathrm{Ca}^{2+}$ is very brief and restricted spatially, due to the presence of $\mathrm{Ca}^{2+}$ buffers (Meinrenken et al., 2002). Also the delay between $\mathrm{Ca}^{2+}$ influx and fusion of synaptic vesicles is very brief, in the range of 200$700 \mu$ s (Llinas et al., 1981, Borst and Sakmann, 1996; Yazejian et al., 1997). These observations imply that $\mathrm{Ca}^{2+}$ channels must be localized close to the fusion competent synaptic vesicles. Any alteration in $\mathrm{Ca}^{2+}$ channel-vesicle coupling could have profound effects on neurotransmitter release because the release depends in a non-linear fashion to $\mathrm{Ca}^{2+}$ concentration (Dodge and Rahamimoff, 1967; Bollmann et al., 2000; Schneggenburger and Neher, 2000). Impaired coupling of $\mathrm{Ca}^{2+}$ channels to the release machinery in $\alpha$-neurexin $\mathrm{KO}$ might explain the phenotype of impaired release. The reduced sensitivity of release to specific $\mathrm{Ca}^{2+}$ channel blockers in $\alpha$-neurexin $\mathrm{KO}$ mice argues in favour of this possibility.

\subsection{Impaired synaptic transmission at hippocampal Schaffer collateral-CA1 synapses in adult $\alpha$-neurexin double knockouts}

CA1 area of hippocampus has a relatively homogenous neuronal population, consisting of pyramidal cells and interneurons (Somogyi and Klausberger, 2005). The somata and dendrites of pyramidal cells are arranged in defined layers, and the extrinsic inputs to CA1 also have a well-defined laminar segregation. The main extrinsic input to CA1 pyramial cells is from Schaffer collaterals, which are axons from CA3 pyramidal neurons. The laminar arrangement of CA1 architecture lends itself well to extracellular recordings of synaptic transmission. Moreover, the Schaffer collateral-CA1 synapse has been extensively characterized and its properties regarding synaptic transmission and synaptic plasticity are well known. In addition, many studies have been performed on this synapse after deletion of various synaptic proteins, therefore providing a good platform for comparison of phenotypes. 
Our experiments on acute hippocampal slices from adult mice revealed that basal synaptic transmission is reduced in $\alpha$-neurexin double KOs. This shows that $\alpha$-neurexins are important for synaptic transmission in the hippocampus. Moreover it demonstrates that $\alpha$-neurexins are important to maintain synaptic transmission in adult animals. The previous experiments on $\alpha$ neurexin knockouts were performed in neocortical slice cultures and acute brainstem slices. In both cases, the animals from which slices were obtained were neonatal. Therefore our results in acute slices from adult animals are important in that they prove that synaptic transmission is still impaired when $\alpha$-neurexin $\mathrm{KO}$ mice reach adulthood.

\section{3}

\section{Altered short-term synaptic plasticity at hippocampal Schaffer collateral-CA1 synapses in adult $\alpha$-neurexin double knockouts}

The pattern of activity generated by a neural network depends on how synaptic strength changes with multiple stimuli (known as synaptic plasticity). The changes in synaptic strength depend on the pattern of stimulation. Various forms of short-term and long-term synaptic plasticity have been described, and mutiple molecules have been linked to them (Zucker and Regehr, 2002; Malenka and Bear, 2004; Garcia-Junco-Clemente et al., 2005). The role of $\alpha$ neurexins in synaptic plasticity was almost unknown. Previous studies gave an indication that synaptic plasticity might be altered in $\alpha$-neurexin $\mathrm{KO}$ mice. In neocortical slice cultures, depression in response to short trains at GABAergic synapses was increased in triple KOs as compared to controls (Missler et al., 2003). We wanted to investigate more extensively the properties of short-term and long-term synaptic plasticity at the glutamatergic Schaffer collateral-CA1 synapses.

Our experiments demonstrated that $\alpha$-neurexin double KO mice have enhanced paired-pulse facilitation (PPF) at short interstimulus intervals at Schaffer collateral-CA1 synapses. PPF is the shortest form of synaptic plasticity and lasts less than a second (Zucker and Regehr, 2002). It is caused by an action of $\mathrm{Ca}^{2+}$ remaining in the presynaptic terminal after the completion of a release event, called residual calcium $\left(\mathrm{Ca}_{\text {res }}\right)$. The residual $\mathrm{Ca}^{2+}\left(\mathrm{Ca}_{\text {res }}\right)$ signal persists for tens of milliseconds to seconds (Delaney et al., 1989; Regehr and Alturi, 1995; Feller et al., 1996; Helmchen et al., 1997). The $\mathrm{Ca}^{2+}$ that enters the presynaptic terminal upon a subsequent stimulus sums up with $\mathrm{Ca}_{\text {res }}$ remaining from the previous stimulus leading to a higher $\mathrm{Ca}^{2+}$ signal. This higher $\mathrm{Ca}^{2+}$ signal increases the probability of release, and underlies 
the facilitation seen on repeated stimulation (Katz and Miledi, 1968; Bittner, 1989; Zucker, 1989; Liu and Stanley, 1995). Alternatively, it has been proposed that $\mathrm{Ca}_{\text {res }}$ acts at another highly sensitive $\mathrm{Ca}^{2+}$-binding site distinct from that involved in triggering basal release (Atluri and Regehr, 1996; Zucker and Regehr, 2002). However a definite identity of this additional $\mathrm{Ca}^{2+}$ sensor was not proposed.

There is an inverse relationship between the degree of facilitation and the initial release probability (Debanne et al., 1996; Dobrunz and Stevens, 1997; Murthy et al., 1997; Jiang et al., 2000). Synapses which have low $P_{r}$ show higher PPF, as compared to synapses which have high $\mathrm{P}_{\mathrm{r}}$, which may even show paired-pulse depression (PPD). This is because when $\mathrm{P}_{\mathrm{r}}$ is high the readily releasable vesicle pool is significantly depleted following an action potential leading to reduced release during the subsequent stimulus, while under low $\mathrm{P}_{\mathrm{r}}$, the vesicle pool is minimally depleted and the vesicles are available to sense $\mathrm{Ca}_{\text {res }}$ (Zucker and Regehr, 2002; Xu-Friedman and Regehr, 2004). Indeed, the degree of PPF or PPD shown by a synapse is frequently used as an easily measured correlate of $\mathrm{P}_{\mathrm{r}}$.

The enhanced PPF seen at Schaffer collateral-CA1 synapses in $\alpha$-neurexin double KO mice might therefore be (at least partly) due to a reduction in the release probability at these synapses. In addition, this result indicates that the impaired release due to the deletion of $\alpha$ neurexins is caused by a presynaptic defect, namely a decrease in the release probability. This goes in line with earlier whole-cell patch-clamp studies done in neocortical slice cultures and acute brainstem slices of $\alpha$-neurexin KOs, where a decrease in evoked release was accompanied by a decrease in the frequency of spontaneous release, signifying a presynaptic defect.

We also investigated the frequency-dependent plasticity at Schaffer collateral-CA1 synapses in response to a $14 \mathrm{~Hz}$ train of stimuli. The results showed that there is enhanced facilitation in $\alpha$-neurexin double KOs during the train, as compared to control mice. This enhancement of frequency-dependent plasticity can also be explained on the basis of reduced initial release probability of synapses in $\alpha$-neurexin double KOs. However the explanation of paired-pulse and frequency-dependent plasticity solely on the basis of initial release probability is probably too simplistic. For example, mice lacking Rab3A show enhanced PPF in the absence of a reduction in the basal release probability (Geppert et al., 1997). Synapsin 1/2 double KO exhibit enhanced depression during high frequency stimulation, without any change in $\mathrm{P}_{\mathrm{r}}$ (Sun 
et al., 2006). RIM1 $\alpha$ KO mice show reduced $P_{r}$ along with enhanced PPF and enhanced frequency-dependent facilitation (Schoch et al., 2002; Calakos et al., 2004), however the enhanced facilitation was traced to a greater increase in the vesicular release probability $\left(\mathrm{P}_{\mathrm{vr}}\right)$ during the train of stimuli (Calakos et al., 2004).

As indicated above, the enhancement of PPF and frequency-dependent facilitation in $\alpha$ neurexin double $\mathrm{KO}$ mice observed here could be explained on the basis of reduced $\mathrm{P}_{\mathrm{r}}$. However two observations argue that additional factors are involved in the alteration of shortterm plasticity observed here. 1) Post-tetanic potentiation (PTP) was found to be unaltered in $\alpha$-neurexin double KOs in this study. PTP is also dependent on initial $\mathrm{P}_{\mathrm{r}}$, and the fact that it is unchanged indicates that deletion of $\alpha$-neurexins causes alterations that could not be explained on the basis of a single factor. 2) GABAergic synapses in neocortical slice cultures from $\alpha$-neurexin KOs showed enhanced depression in response to short trains of stimuli (Missler et al., 2003). This enhanced depression at inhibitory synapses contrasts to the enhanced facilitation that we saw at excitatory Schaffer collateral-CA1 synapses, and could not be explained on the basis of reduced $\mathrm{P}_{\mathrm{r}}$.

\subsection{LTP at hippocampal Schaffer collateral-CA1 synapses in adult $\alpha$-neurexin double knockouts}

Long-term potentiation (LTP) is a long lasting activity-dependent increase in the strength of synaptic transmission that can persist for many hours (Bliss and Lomo, 1973; Bliss and Collingridge, 1993; Malenka and Nicoll, 1999). This process is considered as a possible physiological substrate for long-term memory (Martin et al., 2000). At Schaffer collateralCA1 synapses of hippocampus, LTP is NMDA receptor-dependent (Bliss and Collingridge, 1993; Malenka and Nicoll, 1999; Malenka and Bear, 2004). We investigated whether along with changes in short-term plasticity, there is also an alteration in long-term plasticity at Schaffer collateral-CA1 syanpses in $\alpha$-neurexin KO mice. Our experiments with induction of LTP by high frequency stimulation demonstrated that LTP is enhanced in neurexin $1 \alpha / 2 \alpha$ double $\mathrm{KO}$ as compared to control mice. This result was surprising in the first instance because of two reasons. Firstly, the impaired basal release in $\alpha$-neurexin double KO would be expected to cause reduced release of glutamate during the trains, thereby causing reduced induction of LTP at the postsynaptic apparatus. Secondly, it was shown in an earlier study that 
in neocortical slice cultures, the NMDA/AMPA ratio at the excitatory synapses was reduced in $\alpha$-neurexin triple KOs as compared to controls (Kattenstroth et al., 2004). The first possibility does not take into account the release properties during the whole train of stimuli. We showed that in $\alpha$-neurexin double KOs, there is enhanced facilitation during the stimulus train. So the overall release during the train in $\alpha$-neurexin double KOs might be similar to or even higher than in control mice. This has been shown for RIM1 $\alpha \mathrm{KO}$ mice in which the postsynaptic $\mathrm{Ca}^{2+}$ signal in the CA1 dendritic spine in response to trains of stimuli was similar to that in control mice (Huang et al., 2005), even though the basal release probability was reduced (Schoch et al., 2002). Regarding NMDA/AMPA ratio, two factors have to be kept in mind. 1) The investigations in neocortical slice cultures for NMDA/AMPA ratio were done on $\alpha$-neurexin triple KOs. The effect on NMDA/AMPA ratio is expected to be lesser in $\alpha$ neurexin double KO mice which were used in the present study. 2) The induction protocol for LTP that we used was strong ( 4 x $100 \mathrm{~Hz}, 1 \mathrm{~s}$ each) and could have overridden a small impairment of NMDA receptors. The NMDA/AMPA ratio will be considered in more detail below.

Our experiments on LTP in the presence of DL-APV showed that the enhanced LTP in neurexin $1 \alpha / 2 \alpha$ double KO is NMDA receptor-dependent. The Schaffer collateral-CA1 synapses show NMDA receptor-dependent LTP. However at some synapses LTP is NMDA receptor-independent e.g. at hippocampal mossy fibre-CA3 synapses (Harris and Cotman, 1986; Johnston et al., 1992; Nicoll and Malenka, 1995), cerebellar parallel fibre synapses (Salin et al., 1996; Linden and Ahn, 1999), and corticothalamic synapses (Castro-Alamancos and Calcagnotto, 1999). The experiments with DL-APV confirmed that the enhanced LTP in neurexin $1 \alpha / 2 \alpha$ double KO was not because of the appearance of an NMDA receptorindependent component.

The primary cause of enhanced LTP in neurexin $1 \alpha / 2 \alpha$ double KO is found to be a reduction in the inhibitory synaptic transmission. In the presence of $\mathrm{GABA}_{\mathrm{A}}$ receptor antagonist bicuculline, we found that the LTP in neurexin $1 \alpha / 2 \alpha$ double KOs was similar to that in control mice. The activity of inhibitory synapses is known to keep neuronal excitability under control (Alger, 1991). Any change in inhibitory transmission can have profound effects on the synaptic plasticity at excitatory synapses. The blockade of GABAergic synapses using $\mathrm{GABA}_{\mathrm{A}}$ receptor antagonists enhances the induction of LTP in the CA1 region (Wigstrom and Gustafsson, 1983, 1985; Hsu et al., 1999). Antibody-dependent blocking of extracellular 
matrix molecule tenascin-R reduced perisomatic inhibition and enhanced LTP (Saghatelyan et al., 2000). A recent report showed that repeated exposure to cocaine enhanced the induction of LTP in rat midbrain slices through a reduction in GABA-mediated inhibition of neurons (Liu et al., 2005). Conversly, an enhanced GABAergic inhibition has been shown to underlie reduced LTP in Ts65Dn mice (transgenic model of Downs syndrome) (Kleschevnikov et al., 2004) and in transgenic mice with overexpression of extracellular matrix heparin-binding growth-associated molecule (Pavlov et al., 2006). Similarly antagonists of acetylcholine (Ye et al., 2001) or opioid receptors $\mu$ and $\delta-1$ (Bramham and Sarvey, 1996) suppress the induction of LTP by enhancing GABAergic transmission. All these observations imply that the level of inhibitory activity can have profound impact on LTP. The facilitated induction of LTP is probably related to the higher levels of dendritic depolarization attained in the presence of inhibitory blockade, leading to facilitated activation of NMDA receptors.

$\alpha$-neurexin KO mice have been shown to have impaired inhibitory GABAergic synaptic transmission in neocortex and brain stem (Missler et al., 2003). In addition, the number of inhibitory synapses are reduced in the neocortex of $\alpha$-neurexin KOs. A direct assessment of GABAergic activity in acute hippocampal slices has not been done in the present study, partly because the extracellular recordings are not suitable for this analysis. However all three $\alpha$ neurexins are expressed in CA1 interneurons (Ullrich et al., 1995), and their deletion is therefore expected to reduce release at GABAergic synapses onto CA1 pyramidal cells, similar to that in neocortex (Missler et al., 2003). The reduced inhibitory synaptic transmission in $\alpha$-neurexin double KO mice would facilitate the NMDA receptors by dendritic depolarization, leading to enhanced induction of LTP at excitatory Schaffer collateral-CA1 synapses. Pharmacological blockade of the GABAergic activity in control animals provides the same mechanism, thereby bringing the LTP in control animals to the similar level of neurexin $1 \alpha / 2 \alpha$ double KO mice.

Our LTP experiments also suggest a mechanism behind the reduced NMDA/AMPA ratio in $\alpha$-neurexin triple KOs as measured by whole-cell patch-clamp of neocortical pyramidal cells (Kattenstroth et al., 2004). Enhanced facilitation of NMDA receptors due to reduced inhibitory tone is potentially harmful for the cells, as NMDA receptors are permeable to $\mathrm{Ca}^{2+}$, and $\mathrm{Ca}^{2+}$ influx through NMDA receptors is believed to be neurotoxic (Choi et al., 1995). Therefore, homeostatic mechanisms exist to regulate the NMDA receptor activity (PerezOtano and Ehlers, 2005). The enhanced activity of NMDA receptors observed under reduced 
inhibitory transmission could therefore cause a compensatory reduction in NMDA receptor number/activity at the synapses. The support for this hypothesis comes from a study in which immunotoxin-mediated cell targeting was done to eliminate inhibitory Golgi cells in the cerebellum of transgenic mice. Golgi cell ablation led to a reduced NMDA/AMPA ratio at the granule cells (which recieve inhibitory input from Golgi cells) after chronic depletion of GABA neurotransmitter (Watanabe et al., 1998). In addition, pharmacological blockade of GABAergic activity for a week decreased synaptic targeting of NMDA receptors in hippocampal cultures (Crump et al., 2001). This indicates that the NMDA receptor number/activity is regulated in the long-term by the level of inhibitory tone in the network. The reduced NMDA/AMPA ratio in $\alpha$-neurexin triple KO neocortical slices could therefore reflect a compensatory decrease in the number or activity of NMDA receptors, measured independent of the inhibitory tone by voltage-clamp.

\subsection{Phenotype of $\alpha$-neurexin KOs shows partial resemblance to RIM1 $\alpha$ KO}

The comparison of phenotypes of different deletion mutant mice can yield important information about the processes in which these proteins are involved. We observed that the alterations in synaptic transmission and synaptic plasticity in $\alpha$-neurexin $\mathrm{KO}$ mice resembled aspects of phenotype in RIM1 $\alpha$ KO (Schoch et al., 2002; Calakos et al., 2004). In contrast, the phenotype of $\alpha$-neurexin $\mathrm{KO}$ is very different from that of other known interaction partners of neurexins, Mint1 (Ho et al., 2003) and CASK (Atasoy et al., 2005). Firstly, there is reduction in basal release at excitatory synapses in $\alpha$-neurexin KOs and RIM1 $\alpha$ KO. There was no evidence for altered basal release at excitatory synapses in Mint1 KOs based on experiments on short-term synaptic plasticity (Ho et al., 2003), although $\mathrm{P}_{\mathrm{r}}$ was not directly tested. The CASK KO showed normal evoked release at excitatory synapses (Atasoy et al., 2005) and $\mathrm{Ca}^{2+}$ currents in brainstem neurons (W Zhang, M Missler, TC Sudhof, unpublished observation). $\alpha$-neurexin and RIM1 $\alpha$ KOs, however, differ in terms of basal release at inhibitory synapses with $\alpha$-neurexin KOs showing pronounced defect and RIM1 $\alpha$ KO showing unchanged $\mathrm{P}_{\mathrm{r}}$. Secondly, $\alpha$-neurexin KOs show enhanced paired-pulse facilitation and increased frequency-dependent facilitation at excitatory Schaffer collateral-CA1 synapses, similar to RIM1 $\alpha$ KO. Mint1 KO exhibits normal PPF and frequency-dependent facilitation. Short-term plasticity has not been studied in CASK KO. Thirdly, the short-term 
plasticity at inhibitory synapses is similar between $\alpha$-neurexin KOs and RIM1 $\alpha$ KOs, with both showing enhanced depression. This is especially striking because this alteration contrasts the effect of these proteins on the basal release probability. Reduced $\mathrm{P}_{\mathrm{r}}$ in $\alpha$-neurexin KOs and normal $\mathrm{P}_{\mathrm{r}}$ in RIM1 $\alpha \mathrm{KO}$ at inhibitory synapses can not explain enhanced depression at these synapses. This phenotype also contrasts the enhanced facilitation observed at excitatory synapses in both KOs. Fourthly, our experiments show that LTP at Schaffer collateral-CA1 synapse is not dependent on $\alpha$-neurexins per se, as the enhancement of LTP that was observed was due to an indirect effect of $\alpha$-neurexins on inhibitory synaptic transmission. The E-LTP (early LTP) at Schaffer collateral-CA1 synapse has also been shown to be unchanged in RIM1 $\alpha$ KO. A recent report demonstrates a reduction in L-LTP (late PKA-dependent LTP) at Schaffer collateral-CA1 synapse in RIM1 $\alpha$ KO (Huang et al., 2005). L-LTP was not investigated in $\alpha$-neurexin KOs as also the mossy fibre LTP, which has been shown to be abolished in RIM1 $\alpha$ KO (Castillo et al., 2002). Future experiments are needed to investigate these forms of LTP in $\alpha$-neurexin KOs.

\subsection{RIM1 $\alpha$ is a novel interaction partner of $\alpha$ - and $\beta$-neurexins}

The considerable similarities between $\alpha$-neurexin KOs and RIM1 $\alpha$ KOs suggested that they might be involved in common signalling pathways, and possibly interact with each other. Our experiments using GST pulldown demonstrated that RIM1 $\alpha$ is indeed an interaction partner of $\alpha$ - and $\beta$-neurexins. The interaction is mediated by the $\mathrm{C}$-terminus of neurexins binding to the PDZ domain of RIM1 $\alpha$. Biochemical experiments have previously identified multiple interaction partners of synaptic proteins. The C-terminus of neurexins has been shown to bind to syntenin (Grootjans et al., 2000) and protein 4.1 (Biederer and Sudhof, 2001) as well as to modular adaptor proteins, CASK and Mint1 (Hata et al., 1996; Butz et al., 1998; Biederer and Sudhof, 2000). Several other interaction partners for CASK and Mint have also been described (Cohen et al., 1998; Hsueh et al., 1998; Setou et al., 2000; Tabuchi et al., 2002). The presence of multiple binding partners demonstrates that these molecules show considerable biochemical promiscuity and raises doubts about the physiological significance of their interactions. Indeed, the knockout mice of these proteins present very different phenotypes indicating that they do not participate in common signalling pathways. RIMs have also been shown to interact biochemically with multiple proteins including Munc13-1, Rab3, RBPs (RIM-binding proteins), synaptotagmin1 and $\alpha$-liprins (Wang et al., 1997, 2000; Betz et 
al., 2001; Wang et al., 2001; Schoch et al., 2002). Importantly, the RIM1 $\alpha$ PDZ domain binds to another protein belonging to the cytomatrix at the active zone (CAZ) called CAST/ERC2/ELKS (Ohtsuka et al., 2002; Wang et al., 2002). The identification of biochemical interaction between two proteins should be considered with caution. The biochemical methods such as GST pulldown require lysates from cells or native tissue, and the binding of proteins in the lysate is tested with immobilized proteins. The lysis procedure brings the proteins out of their native enviroment, and the interaction might be detected even though the proteins may not be localized to the same compartments in the native tissue. In addition, some proteins have "sticky" domains that can cause their binding to multiple interaction partners, e.g. syntaxin and synaptotagmin are known to bind promiscuously (Sudhof et al., 2004). Apart from GST pulldown, co-immunoprecipitation (co-IP) is another method to test the interaction between two proteins. This method utilizes an antibody against one protein, and tests whether the other protein can be precipitated with it. This method is believed to be better in detection of in-vivo complexes of proteins, however it can not be excluded that the proteins formed the complex after their extraction. In addition, the method requires that antibodies used for precipitation are specific. Recently other methods have been utilized to test protein-protein interaction including isothermal titration calorimetry (ITC) and nuclear magnetic resonance (NMR). It is suffice to say that biochemical experiments only indicate whether two proteins have the potential to interact, but it is then required to test the physiological significance of the interaction using other approaches. The comparison of phenotypes of knockout mice brings the evidence on a more solid ground. For example, the similarities in the phenotype of RIM1 $\alpha$ and Rab3A KO (Castillo et al., 2002; Schoch et al., 2002) indicated a physiological significance of RIM-Rab3 interaction, discovered earlier through biochemical means (Wang et al., 1997). In this context, our results showing considerable similarities between $\alpha$-neurexin and RIM1 $\alpha$ KOs, followed by the finding of a biochemical interaction between the two proteins provides an indication that the interaction between these proteins might be of physiological relevance. It will be important to test the localization of neurexins and RIM1 $\alpha$ in neurons and whether they colocalize at synapses. In addition, it will be helpful to design mutant clones that selectively interrupt neurexin-RIM interaction. A selective disruption of neurexin-RIM interaction could then be used to directly test its significance on synaptic structure and function.

To our knowledge, neurexins are the first synaptic cell adhesion molecule found to interact with a protein belonging to the cytomatrix at the active zone (CAZ) such as RIM1 $\alpha$. Thus this 
finding opens many possibilities provided that further experiments confirm the physiological importance of neurexin-RIM interaction . In that scenario, the following model could explain many results obtained in the present and previous studies on $\alpha$-neurexin $\mathrm{KO}$ mice.

The working model that I would like to propose has $\alpha$ - and $\beta$-neurexins form a transynaptic complex with postsynaptic cell adhesion molecules, such as neuroligins and dystroglycan. Neurexins guide the elements of active zone to localize at the right place, apposing the postsynaptic specialization. This occurs by the binding of neurexins presynaptically to active zone proteins including RIMs. RIMs guide the synaptic vesicles to the docking sites at the active zone (through interactions with Rab3 and synaptotagmin1) and also localize the $\mathrm{Ca}^{2+}$ channels at the active zone (through RIM-RBP-Ca ${ }^{2+}$ channel interaction). The docking and priming sites are formed by interaction between RIMs and other active zone proteins Munc13s and bassoon. Thus RIMs act as central organizers of active zone. The binding of neurexins to RIMs couples the transsynaptic cell adhesion to $\mathrm{Ca}^{2+}$ channels and sites of vesicle docking and fusion, and keeps the presynaptic machinery in register to the postsynaptic specialization. The deletion of $\alpha$-neurexins could lead to impaired localization of RIMs at the active zone. This would have two major consequences.

A) The localization of $\mathrm{Ca}^{2+}$ channels near the active zone would be disturbed leading to uncoupling of $\mathrm{Ca}^{2+}$ channel-release machinery. This could explain:

1. The impaired basal release at Schaffer collateral-CA1 synapses in hippocampus (section 3.1.1), neocortex and brainstem (Missler et al., 2003), and NMJ (Sons et al., 2006)

2. The enhanced PPF and frequency-dependent plasticity at Schaffer collateral-CA1 synapses, based on reduced release probability (section 3.1.2).

3. The decreased sensitivity of release to $\mathrm{Ca}^{2+}$ channel blockers (Missler et al., 2003)

B) The elements of docking and priming apparatus at the active zone would be misorganized. This could explain:

1. The impaired basal release at multiple synapses (see above).

2. The reduction in spontaneous release frequency at neocortical synapses (Missler et al., 2003).

3. The alterations in short-term plasticity independent of $\mathrm{P}_{\mathrm{r}}$, including the enhanced short-term depression at inhibitory synapses (Missler et al., 2003). 


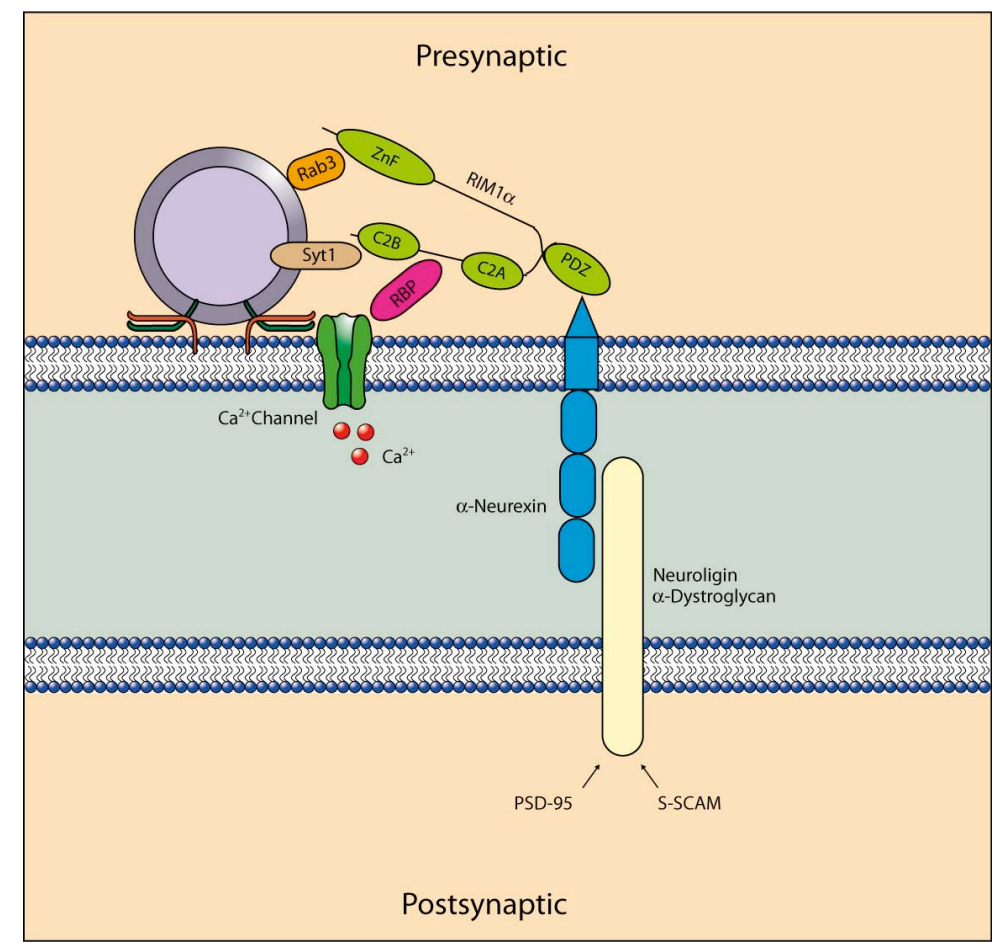

Figure 4.1. A model depicting the proposed role of neurexin-RIM interaction at the presynaptic terminal. The binding of neurexins to RIMs couples the transsynaptic cell adhesion to $\mathrm{Ca}^{2+}$ channels and sites of vesicle docking and fusion, and keeps the presynaptic active zone aligned to the postsynaptic specialization. See futher details in the text. Abbreviations: Syt1 (Synaptotagmin1), RBP (RIM-binding protein), ZnF (Zinc finger domain of RIM1 $\alpha$ ), PDZ (PDZ domain of RIM1 $\alpha$ ), C2A (C2A domain of RIM1 $\alpha$ ), C2B (C2B domain of RIM1 $\alpha$ ). The figure is not to scale.

Although our current working model explains many of the findings on $\alpha$-neurexin $\mathrm{KO}$ mice, more experiments are needed to confirm the proposed hypotheses and address open questions. The availability of knockout mice has contributed significantly to our understanding of synaptic function. However, the presence of proteins as multiple isoforms makes it difficult to investigate the full repertoire of a protein's function when only a particular isoform is deleted. For example, $\alpha$-RIMs exist as two isoforms (RIM1 $\alpha$ and RIM2 $\alpha$ ), therefore the generation of RIM $1 \alpha / 2 \alpha$ double $\mathrm{KO}$ is needed to understand in detail the properties of synaptic transmission that are dependent on RIMs. Similarly, the study of $\alpha$-neurexin function in adult $\mathrm{KO}$ mice (as done in this project) will be further advanced by the generation of $\alpha$-neurexin conditional triple $\mathrm{KO}$ mice that we have constructed during this project. The studies on $\alpha$ neurexin conditional triple KOs are expected to yield an even stronger phenotype and in addition uncover some novel defects. These mice could also be used for behavioural studies to identify the changes in behavioural parameters caused by the observed alterations in shortterm and long-term synaptic plasticity. Such correlative studies have been performed on 
knockout mice of NMDA receptor subunits (Nakazawa et al., 2002, 2003), CAMKII (Silva et al., 1996) and RIM1 $\alpha$ (Powell et al., 2004) among others. Such studies help in elucidating the importance of various forms of synaptic plasticity (disturbed in mutants) to behavioural parameters and provide the intriguing link between specific proteins and aspects of behaviour. 
This project investigated novel aspects of the function of $\alpha$-neurexins in neurotransmission and synaptic plasticity. Whole-cell patch-clamp studies on heterologous cells showed that neurexin $1 \alpha$ does not considerably modulate the current density as well as the activation and inactivation properties of recombinant N-type $\mathrm{Ca}^{2+}$ channels. The only effect that we found was a small leftward shift in half-maximal voltage of activation with neurexin $1 \alpha$ in the presence of $\mathrm{Ca}^{2+}$ as charge carrier, which is insufficient to explain the alteration in $\mathrm{Ca}^{2+}$ channel properties at synapses of $\alpha$-neurexin KO mice. Instead our results give way for the alternative hypothesis of the importance of $\alpha$-neurexins in coupling $\mathrm{Ca}^{2+}$ channels to the release machinery at the presynaptic terminal. Extracellular field potential recordings showed that both short-term and long-term synaptic plasticity were altered in adult $\alpha$-neurexin KO mice. Paired-pulse facilitation and frequency-dependent facilitation were increased in $\alpha$ neurexin double $\mathrm{KO}$ mice. This enhanced facilitation might be related to the decrease in the release probability in these mice, although involvement of other factors cannot be ruled out. In addition, LTP was increased in $\alpha$-neurexin double $\mathrm{KO}$ mice, and was found to be due to the reduced inhibitory synaptic transmission in these mice. Our biochemical experiments showed that RIM1 $\alpha$ is an interaction partner of neurexins. A disturbance of neurexin-RIM interaction might also be responsible for the changes in synaptic plasticity that we observed in $\alpha$-neurexin KO mice. Finally, we constructed a knock-in mouse line with floxed first exon of neurexin $1 \alpha$ to achieve conditional knockout of $\alpha$-neurexins in hippocampus of adult mice, that would allow a detailed analyis of $\mathrm{Ca}^{2+}$-dependent synaptic transmission and plasticity in adult mice lacking all three $\alpha$-neurexins. 


\section{REFERENCES}

Alger BE (1991). Gating of GABAergic inhibition in hippocampal pyramidal cells. Ann N Y Acad Sci, 627:249-63.

Allen C, Stevens CF (1994). An evaluation of causes for unreliability of synaptic transmission. Proc Natl Acad Sci U S A, 91:10380-10383

Arrigoni E, Crocker AJ, Saper CB, Greene RW, Scammell TE (2005). Deletion of presynaptic adenosine A1 receptors impairs the recovery of synaptic transmission after hypoxia. Neuroscience, 132:575-80.

Atasoy D, Schoch S, Nadasy KA, Ho A, Liu X, Nosyreva ED, Fernandez-Chacon R, Kavalali ET Sudhof TC (2005). Generation and analysis of CASK knock-out mice. Program No. 964.20.2005 Abstract viewer/itinerary planner. Washington, DC: Society for Neuroscience.

Atluri PP, Regehr WG (1996). Determinants of the time course of facilitation at the granule cell to Purkinje cell synapse. J Neurosci, 16:5661-71.

Atwood HL, Karunanithi S (2002). Diversification of synaptic strength: presynaptic elements. Nat Rev Neurosci, 3:497-516.

Beglopoulos V, Montag-Sallaz M, Rohlmann A, Piechotta K, Ahmad M, Montag D, Missler M (2005). Neurexophilin 3 is highly localized in cortical and cerebellar regions and is functionally important for sensorimotor gating and motor coordination. Mol Cell Biol, 25:7278-88.

Berjukow S, Doring F, Froschmayr M, Grabner M, Glossmann H, Hering S (1996). Endogenous calcium channels in human embryonic kidney (HEK293) cells. Br J Pharmacol, 118:748-54.

Berman HM, Westbrook J, Feng Z, Gilliland G, Bhat TN, Weissig H, Shindyalov IN, Bourne PE (2000). The Protein Data Bank. Nucleic Acids Res, 28:235-242.

Betz A, Thakur P, Junge HJ, Ashery U, Rhee JS, Scheuss V, Rosenmund C, Rettig J, Brose N 
(2001). Functional interaction of the active zone proteins Munc13-1 and RIM1 in synaptic vesicle priming. Neuron, 30:183-196.

Bezprozvanny I, Scheller RH, Tsien RW (1995). Functional impact of syntaxin on gating of N-type and Q-type calcium channels. Nature, 378:623-6.

Biederer T, Sudhof TC (2000). Mints as adaptors. Direct binding to neurexins and recruitment of munc18. J Biol Chem, 275:39803-39806.

Biederer T, Sudhof TC (2001). CASK and protein 4.1 support F-actin nucleation on neurexins. J Biol Chem, 276:47869-76.

Bittner GD (1989). Synaptic plasticity at the crayfish opener neuromuscular preparation. J Neurobiol, 20:386-408.

Bliss TV, Collingridge GL (1993). A synaptic model of memory: long-term potentiation in the hippocampus. Nature, 361:31-9.

Bliss TV, Lomo T (1973). Long-lasting potentiation of synaptic transmission in the dentate area of the anaesthetized rabbit following stimulation of the perforant path. J Physiol, 232:331-56.

Bollmann JH, Sakmann B, Borst JG (2000). Calcium sensitivity of glutamate release in a calyx-type terminal. Science, 289:953-7.

Borst JG, Sakmann B (1996). Calcium influx and transmitter release in a fast CNS synapse. Nature, 383:431-4.

Boucard AA, Chubykin AA, Comoletti D, Taylor P, Sudhof TC (2005). A splice code for trans-synaptic cell adhesion mediated by binding of neuroligin 1 to alpha- and beta-neurexins. Neuron, 48:229-236.

Bramham CR, Sarvey JM (1996). Endogenous activation of mu and delta-1 opioid receptors is required for long-term potentiation induction in the lateral perforant path: dependence on GABAergic inhibition. J Neurosci, 16:8123-31. 
Brose N (1999). Synaptic cell adhesion proteins and synaptogenesis in the mammalian central nervous system. Naturwissenschaften, 86:516-524

Bukalo O, Fentrop N, Lee AY, Salmen B, Law JW, Wotjak CT, Schweizer M, Dityatev A, Schachner M (2004). Conditional ablation of the neural cell adhesion molecule reduces precision of spatial learning, long-term potentiation, and depression in the CA1 subfield of mouse hippocampus. J Neurosci, 24:1565-77.

Butz S, Okamoto M, Sudhof TC (1998). A tripartite protein complex with the potential to couple synaptic vesicle exocytosis to cell adhesion in brain. Cell, 94:773-782

Cabin DE, Shimazu K, Murphy D, Cole NB, Gottschalk W, McIlwain KL, Orrison B, Chen A, Ellis CE, Paylor R, Lu B, Nussbaum RL (2002). Synaptic vesicle depletion correlates with attenuated synaptic responses to prolonged repetitive stimulation in mice lacking alphasynuclein. J Neurosci, 22:8797-807.

Calakos N, Schoch S, Sudhof TC, Malenka RC (2004). Multiple roles for the active zone protein RIM1alpha in late stages of neurotransmitter release. Neuron, 42:889-96.

Castillo PE, Schoch S, Schmitz F, Sudhof TC, Malenka RC (2002). RIM1alpha is required for presynaptic long-term potentiation. Nature, 415:327-30.

Castro-Alamancos MA, Calcagnotto ME (1999). Presynaptic long-term potentiation in corticothalamic synapses. J Neurosci, 19:9090-7.

Choi DW (1995). Calcium: still center-stage in hypoxic-ischemic neuronal death. Trends Neurosci, 18:58-60.

Chubykin AA, Liu X, Comoletti D, Tsigelny I, Taylor P, Sudhof TC (2005). Dissection of synapse induction by neuroligins: effect of a neuroligin mutation associated with autism. $\mathbf{J}$

Biol Chem, 280:22365-74.

Cohen AR, Woods DF, Marfatia SM, Walther Z, Chishti AH, Anderson JM (1998). Human CASK/LIN-2 binds syndecan- 2 and protein 4.1 and localizes to the basolateral membrane of epithelial cells. J Cell Biol, 142:129-38. 
Coppola T, Magnin-Luthi S, Perret-Menoud V, Gattesco S, Schiavo G, Regazzi R (2001). Direct interaction of the Rab3 effector RIM with $\mathrm{Ca} 2+$ channels, SNAP-25, and synaptotagmin. J Biol Chem, 276:32756-62.

Crump FT, Dillman KS, Craig AM (2001). cAMP-dependent protein kinase mediates activity-regulated synaptic targeting of NMDA receptors. J Neurosc, 21:5079-88.

Dean C, Scholl FG, Choih J, DeMaria S, Berger J, Isacoff E, Scheiffele P (2003). Neurexin mediates the assembly of presynaptic terminals. Nat Neurosci, 6:708-716.

Debanne D, Guerineau NC, Gahwiler BH, Thompson SM (1996). Paired-pulse facilitation and depression at unitary synapses in rat hippocampus: quantal fluctuation affects subsequent release. J Physiol, 491:163-76.

Delaney KR, Zucker RS, Tank DW (1989). Calcium in motor nerve terminals associated with posttetanic potentiation. J Neurosci, 9:3558-67.

Dobrunz LE, Stevens CF (1997). Heterogeneity of release probability, facilitation, and depletion at central synapses. Neuron, 18:995-1008.

Dodge FA Jr, Rahamimoff R (1967). Co-operative action a calcium ions in transmitter release at the neuromuscular junction. J Physiol, 193:419-32.

Dresbach T, Qualmann B, Kessels MM, Garner CC, Gundelfinger ED (2001). The presynaptic cytomatrix of brain synapses. Cell Mol Life Sci, 58:94-116

Feller MB, Delaney KR, Tank DW (1996). Presynaptic calcium dynamics at the frog retinotectal synapse. J Neurophysiol, 76:381-400.

Garcia-Junco-Clemente P, Linares-Clemente P, Fernandez-Chacon R (2005). Active zones for presynaptic plasticity in the brain. Mol Psychiatry, 10:185-200

Geppert M, Goda Y, Stevens CF, Sudhof TC (1997). The small GTP-binding protein Rab3A regulates a late step in synaptic vesicle fusion. Nature, 387:810-4. 
Geppert M, Khvotchev M, Krasnoperov V, Goda Y, Missler M, Hammer RE, Ichtchenko K, Petrenko AG, Sudhof TC (1998). Neurexin I alpha is a major alpha-latrotoxin receptor that cooperates in alpha-latrotoxin action. J Biol Chem, 273:1705-10.

Grootjans JJ, Reekmans G, Ceulemans H, David G (2000). Syntenin-syndecan binding requires syndecan-synteny and the co-operation of both PDZ domains of syntenin. J Biol Chem, 275:19933-41.

Gupta A, Wang Y, Markram H (2000). Organizing principles for a diversity of GABAergic interneurons and synapses in the neocortex. Science, 287:273-8

Harlow ML, Ress D, Stoschek A, Marshall RM, McMahan UJ (2001). The architecture of active zone material at the frog's neuromuscular junction. Nature, 409:479-84.

Harris EW, Cotman CW (1986). Long-term potentiation of guinea pig mossy fiber responses is not blocked by N-methyl D-aspartate antagonists. Neurosci Lett, 70:132-7.

Hata Y, Butz S, Sudhof TC (1996). CASK: a novel dlg/PSD95 homolog with an N-terminal calmodulin-dependent protein kinase domain identified by interaction with neurexins. $\mathrm{J}$ Neurosci, 16:2488-2494.

Heeroma JH, Roelandse M, Wierda K, van Aerde KI, Toonen RF, Hensbroek RA, Brussaard A, Matus A, Verhage M (2004). Trophic support delays but does not prevent cell-intrinsic degeneration of neurons deficient for munc18-1. Eur J Neurosci, 20:623-34.

Helmchen F, Borst JG, Sakmann B (1997). Calcium dynamics associated with a single action potential in a CNS presynaptic terminal. Biophys J, 72:1458-71.

Hessler NA, Shirke AM, Malinow R (1993). The probability of transmitter release at a mammalian central synapse. Nature, 366:569-572.

Hibino H, Pironkova R, Onwumere O, Vologodskaia M, Hudspeth AJ, Lesage F (2002). RIM binding proteins (RBPs) couple Rab3-interacting molecules (RIMs) to voltage-gated $\mathrm{Ca}^{2+}$ channels. Neuron, 34:411-23 
Ho A, Morishita W, Hammer RE, Malenka RC, Sudhof TC (2003). A role for Mints in transmitter release: Mint 1 knockout mice exhibit impaired GABAergic synaptic transmission. Proc Natl Acad Sci U S A, 100:1409-14.

Hoess RH, Abremski K (1984). Interaction of the bacteriophage P1 recombinase Cre with the recombining site loxP. Proc Natl Acad Sci U S A, 81:1026-9.

Hsu KS, Ho WC, Huang CC, Tsai JJ (1999). Prior short-term synaptic disinhibition facilitates long-term potentiation and suppresses long-term depression at CA1 hippocampal synapses. Eur J Neurosci, 11:4059-69.

Hsueh YP, Yang FC, Kharazia V, Naisbitt S, Cohen AR, Weinberg RJ, Sheng M (1998). Direct interaction of CASK/LIN-2 and syndecan heparan sulfate proteoglycan and their overlapping distribution in neuronal synapses. J Cell Biol, 142:139-151.

Huang YY, Zakharenko SS, Schoch S, Kaeser PS, Janz R, Sudhof TC, Siegelbaum SA, Kandel ER (2005). Genetic evidence for a protein-kinase-A-mediated presynaptic component in NMDA-receptor-dependent forms of long-term synaptic potentiation. Proc Natl Acad Sci U S A, 102:9365-70.

Hung AY, Sheng M (2002). PDZ domains: structural modules for protein complex assembly. J Biol Chem, 277:5699-5702

Ichtchenko K, Hata Y, Nguyen T, Ullrich B, Missler M, Moomaw C, Sudhof TC (1995) Neuroligin 1: a splice site-specific ligand for beta-neurexins. Cell, 81:435-443

Ichtchenko K, Nguyen T, Sudhof TC (1996). Structures, alternative splicing, and neurexin binding of multiple neuroligins. J Biol Chem, 271:2676-2682

Jahn R, Sudhof TC (1994). Synaptic vesicles and exocytosis. Annu. Rev. Neurosci, 17: 219246

Jarvis SE, Magga JM, Beedle AM, Braun JE, Zamponi GW (2000). G protein modulation of $\mathrm{N}$-type calcium channels is facilitated by physical interactions between syntaxin $1 \mathrm{~A}$ and Gbetagamma. J Biol Chem, 275:6388-94. 
Jarvis SE, Zamponi GW (2001). Distinct molecular determinants govern syntaxin 1Amediated inactivation and G-protein inhibition of N-type calcium channels. J Neurosci, 21:2939-48.

Jiang L, Sun S, Nedergaard M, Kang J (2000). Paired-pulse modulation at individual GABAergic synapses in rat hippocampus. J Physiol, 523:425-39.

Johnston D (1992). NMDA-receptor independent LTP. Neurochem Int, 20:461-2.

Kattenstroth G, Tantalaki E, Sudhof TC, Gottmann K, Missler M (2004). Postsynaptic Nmethyl-D-aspartate receptor function requires alpha-neurexins. Proc Natl Acad Sci U S A, 101:2607-12.

Katz B, Miledi R (1968). The role of calcium in neuromuscular facilitation. J Physiol, 195:481-92.

Kitano J, Nishida M, Itsukaichi Y, Minami I, Ogawa M, Hirano T, Mori Y, Nakanishi S (2003). Direct interaction and functional coupling between metabotropic glutamate receptor subtype 1 and voltage-sensitive Cav2.1 $\mathrm{Ca}^{2+}$ channel. J Biol Chem, 278:25101-8.

Kleschevnikov AM, Belichenko PV, Villar AJ, Epstein CJ, Malenka RC, Mobley WC (2004). Hippocampal long-term potentiation suppressed by increased inhibition in the Ts65Dn mouse, a genetic model of Down syndrome. J Neurosci, 24:8153-60.

Kuhn R, Schwenk F, Aguet M, Rajewsky K (1995). Inducible gene targeting in mice. Science, 269:1427-9.

Lakso M, Pichel JG, Gorman JR, Sauer B, Okamoto Y, Lee E, Alt FW, Westphal H (1996). Efficient in vivo manipulation of mouse genomic sequences at the zygote stage. Proc Natl Acad Sci U S A, 93:5860-5.

Landis DM, Hall AK, Weinstein LA, Reese TS (1988). The organisation of cytoplasm at the presynaptic active zone of a central nervous system synapse. Neuron, 1:201-209

Linden DJ, Ahn S (1999). Activation of presynaptic cAMP-dependent protein kinase is 
required for induction of cerebellar long-term potentiation. J Neurosci, 19:10221-7.

Liu QS, Pu L, Poo MM (2005). Repeated cocaine exposure in vivo facilitates LTP induction in midbrain dopamine neurons. Nature, 437:1027-31.

Liu Y, Stanley EF (1995). Calcium binding sites of the transmitter release mechanism: clues from short-term facilitation. J Physiol, 89:163-6.

Llinas R, Steinberg IZ, Walton K (1981). Relationship between presynaptic calcium current and postsynaptic potential in squid giant synapse. Biophys J, 33:323-51.

Lu J, Li H, Wang Y, Sudhof TC, Rizo J (2005). Solution structure of the RIM1alpha PDZ domain in complex with an ELKS1b C-terminal peptide. J Mol Biol, 352:455-466.

Magga JM, Jarvis SE, Arnot MI, Zamponi GW, Braun JE (2000). Cysteine string protein regulates G protein modulation of N-type calcium channels. Neuron, 28:195-204.

Malenka RC, Bear MF (2004). LTP and LTD: an embarrassment of riches. Neuron, 44:5-21.

Malenka RC, Nicoll RA (1999). Long-term potentiation--a decade of progress? Science, 285:1870-4.

Martin SJ, Grimwood PD, Morris RG (2000). Synaptic plasticity and memory: an evaluation of the hypothesis. Annu Rev Neurosci, 23:649-711.

Maximov A, Sudhof TC, Bezprozvanny I (1999). Association of neuronal calcium channels with modular adaptor proteins. J Biol Chem, 274:24453-24456

Meinrenken CJ, Borst JG, Sakmann B (2002). Calcium secretion coupling at calyx of held governed by nonuniform channel-vesicle topography. J Neurosci, 22:1648-67.

Meyers EN, Lewandoski M, Martin GR (1998). An Fgf8 mutant allelic series generated by Cre- and Flp-mediated recombination. Nat Genet, 18:136-41.

Minichiello L, Korte M, Wolfer D, Kuhn R, Unsicker K, Cestari V, Rossi-Arnaud C, Lipp 
HP, Bonhoeffer T, Klein R (1999). Essential role for TrkB receptors in hippocampusmediated learning. Neuron, 24:401-14.

Missler M (2003). Synaptic cell adhesion goes functional. Trends Neurosci, 26:176-8.

Missler M, Fernandez-Chacon R, Sudhof TC (1998a). The making of neurexins. J Neurochem, 71:1339-1347

Missler M, Hammer RE, Sudhof TC (1998b). Neurexophilin binding to alpha-neurexins. A single LNS domain functions as an independently folding ligand-binding unit. J Biol Chem, 273:34716-23.

Missler M, Sudhof TC (1998a). Neurexophilins form a conserved family of neuropeptide-like glycoproteins. J Neurosci, 18:3630-3638

Missler M, Sudhof TC (1998b). Neurexins: three genes and 1001 products. Trends in Genetics, 14:20-26

Missler M, Zhang W, Rohlmann A, Kattenstroth G, Hammer RE, Gottmann K, Sudhof TC (2003). Alpha-neurexins couple Ca2+ channels to synaptic vesicle exocytosis. Nature, 423:939-48.

Mori Y, Friedrich T, Kim MS, Mikami A, Nakai J, Ruth P, Bosse E, Hofmann F, Flockerzi V, Furuichi T, et al (1991). Primary structure and functional expression from complementary DNA of a brain calcium channel. Nature, 350:398-402.

Muller M, Somjen GG (1999). Intrinsic optical signals in rat hippocampal slices during hypoxia-induced spreading depression-like depolarization. J. Neurophysiol, 82: 1818-1231.

Murthy VN, Sejnowski TJ, Stevens CF (1997). Heterogeneous release properties of visualized individual hippocampal synapses. Neuron, 18:599-612.

Nakazawa K, Quirk MC, Chitwood RA, Watanabe M, Yeckel MF, Sun LD, Kato A, Carr CA, Johnston D, Wilson MA, Tonegawa S (2002). Requirement for hippocampal CA3 NMDA receptors in associative memory recall. Science, 297:211-8. 
Nakazawa K, Sun LD, Quirk MC, Rondi-Reig L, Wilson MA, Tonegawa S (2003). Hippocampal CA3 NMDA receptors are crucial for memory acquisition of one-time experience. Neuron, 38:305-15.

Nicoll RA, Malenka RC (1995). Contrasting properties of two forms of long-term potentiation in the hippocampus. Nature, 377:115-8.

Ohtsuka T, Takao-Rikitsu E, Inoue E, Inoue M, Takeuchi M, Matsubara K, DeguchiTawarada M, Satoh K, Morimoto K, Nakanishi H, Takai Y (2002). Cast, a novel protein of the cytomatrix at the active zone of synapses that forms a ternary complex with RIM1. J. Cell Biol, 158:577-90.

Pavlov I, Rauvala H, Taira T (2006). Enhanced hippocampal gabaergic inhibition in mice overexpressing heparin-binding growth-associated molecule. Neuroscience, epub ahead of print, doi:10.1016/j.neuroscience.2005.11.070.

Perez-Otano I, Ehlers MD (2005). Homeostatic plasticity and NMDA receptor trafficking. Trends Neurosci, 28:229-38.

Pham CT, MacIvor DM, Hug BA, Heusel JW, Ley TJ (1996). Long-range disruption of gene expression by a selectable marker cassette. Proc Natl Acad Sci U S A, 93:13090-5.

Powell CM, Schoch S, Monteggia L, Barrot M, Matos MF, Feldmann N, Sudhof TC, Nestler EJ (2004). The presynaptic active zone protein RIM1alpha is critical for normal learning and memory. Neuron, 42:143-53.

Puschel AW, Betz H (1995). Neurexins are differentially expressed in the embryonic nervous system of mice. J Neurosci, 15:2849-56.

Rajewsky K, Gu H, Kuhn R, Betz UA, Muller W, Roes J, Schwenk F (1996). Conditional gene targeting. J Clin Invest, 98:600-3. 
Regehr WG and Stevens CF (2001). Physiology of synaptic transmission and short-term plasticity. In Synapses, ed. Cowan et al., The John Hophins University Press, pp. 135-175

Regehr WG, Atluri PP (1995). Calcium transients in cerebellar granule cell presynaptic terminals. Biophys J, 68:2156-70.

Ren SY, Angrand PO, Rijli FM (2002). Targeted insertion results in a rhombomere 2-specific Hoxa2 knockdown and ectopic activation of Hoxa1 expression. Dev Dyn, 225:305-15.

Rettig J, Sheng ZH, Kim DK, Hodson CD, Snutch TP, Catterall WA (1996). Isoform-specific interaction of the alpha1A subunits of brain $\mathrm{Ca} 2+$ channels with the presynaptic proteins syntaxin and SNAP-25. Proc Natl Acad Sci USA, 93:7363-8

Reyes A, Lujan R, Rozov A, Burnashev N, Somogyi P, Sakmann B (1998). Target-cellspecific facilitation and depression in neocortical circuits. Nat Neurosci, 1:279-285

Rosenmund C, Clements JD, Westbrook GL (1993). Nonuniform probability of glutamate release at a hippocampal synapse. Science, 262:754-757

Rowen L, Young J, Birditt B, Kaur A, Madan A, Philipps DL, Qin S, Minx P, Wilson RK, Hood L, Graveley BR (2002). Analysis of the human neurexin genes: alternative splicing and the generation of protein diversity. Genomics, 79:587-597

Rozov A, Burnashev N, Sakmann B, Neher E (2001). Transmitter release modulation by intracellular $\mathrm{Ca} 2+$ buffers in facilitating and depressing nerve terminals of pyramidal cells in layer $2 / 3$ of the rat neocortex indicates a target cell-specific difference in presynaptic calcium dynamics. J Physiol, 531:807-826

Saghatelyan AK, Gorissen S, Albert M, Hertlein B, Schachner M, Dityatev A (2000). The extracellular matrix molecule tenascin-R and its HNK-1 carbohydrate modulate perisomatic inhibition and long-term potentiation in the CA1 region of the hippocampus. Eur J Neurosci, $12: 3331-42$.

Salin PA, Malenka RC, Nicoll RA (1996). Cyclic AMP mediates a presynaptic form of LTP at cerebellar parallel fiber synapses. Neuron, 16:797-803. 
Scanziani M, Gahwiler BH, Charpak S (1998). Target cell-specific modulation of transmitter release at terminals from a single axon. Proc Natl Acad Sci U S A., 95:12004-12009

Scheiffele P (2003). Cell-cell signaling during synapse formation in the CNS. Annu Rev Neurosci, 26:485-508

Schneggenburger R, Neher E (2000). Intracellular calcium dependence of transmitter release rates at a fast central synapse. Nature, 406:889-93.

Schoch S, Castillo PE, Jo T, Mukherjee K, Geppert M, Wang Y, Schmitz F, Malenka RC, Sudhof TC (2002). RIM1 $\alpha$ forms a protein scaffold for regulating neurotransmitter release at the active zone. Nature, 415:321-326

Schulz PE, Fitzgibbons JC (1997). Differing mechanisms of expression for short- and longterm potentiation. J Neurophysiol, 78:321-34.

Setou M, Nakagawa T, Seog DH, Hirokawa N (2000). Kinesin superfamily motor protein KIF17 and mLin-10 in NMDA receptor- containing vesicle transport. Science, 288:17961802.

Silva AJ, Rosahl TW, Chapman PF, Marowitz Z, Friedman E, Frankland PW, Cestari V, Cioffi D, Sudhof TC, Bourtchuladze R (1996). Impaired learning in mice with abnormal short-lived plasticity. Curr Biol, 6:1509-18.

Somogyi P, Klausberger T (2005). Defined types of cortical interneurone structure space and spike timing in the hippocampus. J Physiol, 562:9-26.

Song JY, Ichtchenko K, Sudhof TC, Brose N (1999). Neuroligin 1 is a postsynaptic celladhesion molecule of excitatory synapses. Proc Natl Acad Sci U S A, 96:1100-1105

Sons MS, Busche N, Strenzke N, Moser T, Ernsberger U, Mooren FC, Zhang W, Ahmad M, Steffens H, Schomburg ED, Plomp JJ, Missler M (2006). $\alpha$-Neurexins are required for efficient transmitter release and synaptic homeostasis at the mouse neuromuscular junction. Neuroscience, 138:433-46. 
Starr TV, Prystay W, Snutch TP (1991). Primary structure of a calcium channel that is highly expressed in the rat cerebellum. Proc Natl Acad Sci U S A, 88:5621-5.

Sudhof TC (2004). The synaptic vesicle cycle. Annu Rev Neurosci, 27:509-47

Sugita S, Khvochtev M, Sudhof TC (1999). Neurexins are functional alpha-latrotoxin receptors. Neuron, 22:489-496

Sugita S, Saito F, Tang J, Satz J, Campbell K, Sudhof TC (2001). A stoichiometric complex of neurexins and dystroglycan in brain. J Cell Biol, 154:435-445

Sun J, Bronk P, Liu X, Han W, Sudhof TC (2006). Synapsins regulate use-dependent synaptic plasticity in the calyx of Held by a $\mathrm{Ca} 2+/$ calmodulin-dependent pathway. Proc Natl Acad Sci U S A, 103:2880-2885.

Tabuchi K, Biederer T, Butz S, Sudhof TC (2002). CASK participates in alternative tripartite complexes in which Mint 1 competes for binding with caskin 1, a novel CASK-binding protein. J Neurosci, 22:4264-73.

Tabuchi K, Sudhof TC (2002). Structure and evolution of neurexin genes: insight into the mechanism of alternative splicing. Genomics, 79:849-59.

Tao HW, Poo M (2001). Retrograde signaling at central synapses. Proc Natl Acad Sci U S A, 98:11009-15.

Ullrich B, Ushkaryov YA, Sudhof TC (1995). Cartography of neurexins: more than 1000 isoforms generated by alternative splicing and expressed in distinct subsets of neurons. Neuron, 14:497-507

Ushkaryov YA, Petrenko AG, Geppert M, Sudhof TC (1992). Neurexins: synaptic cell surface proteins related to the alpha-latrotoxin receptor and laminin. Science, 257:50-56.

Wang X, Hu B, Zimmermann B, Kilimann MW (2001). Rim1 and rabphilin-3 bind Rab3GTP by composite determinants partially related through $\mathrm{N}$-terminal $\alpha$-helix motifs. J. Biol.Chem, 276:32480-88. 
Wang Y, Liu X, Biederer T, Sudhof TC (2002). A family of RIM-binding proteins regulated by alternative splicing: implications for the genesis of synaptic active zones. Proc Natl Acad Sci USA, 99:14464-69

Wang Y, Okamoto M, Schmitz F, Hofman K, Sudhof TC (1997). RIM: a putative Rab3effector in regulating synaptic vesicle fusion. Nature, 388:593-98

Wang Y, Sugita S, Sudhof TC (2000). The RIM/NIM family of neuronal C2 domain proteins. Interactions with Rab3 and a new class of Src homology 3 domain proteins. J.Biol. Chem, 75:20033-44.

Watanabe D, Inokawa H, Hashimoto K, Suzuki N, Kano M, Shigemoto R, Hirano T, Toyama K, Kaneko S, Yokoi M, Moriyoshi K, Suzuki M, Kobayashi K, Nagatsu T, Kreitman RJ, Pastan I, Nakanishi S (1998). Ablation of cerebellar Golgi cells disrupts synaptic integration involving GABA inhibition and NMDA receptor activation in motor coordination. Cell, 95:17-27.

Wigstrom H, Gustafsson B (1983). Facilitated induction of hippocampal long-lasting potentiation during blockade of inhibition. Nature, 301:603-4.

Wigstrom H, Gustafsson B (1985). Facilitation of hippocampal long-lasting potentiation by GABA antagonists. Acta Physiol Scand, 125:159-72.

Wilson RI, Nicoll RA (2002). Endocannabinoid signaling in the brain. Science, 296:678-82.

Wiser O, Bennett MK, Atlas D (1996). Functional interaction of syntaxin and SNAP-25 with voltage-sensitive L- and N-type Ca2+ channels. EMBO J, 15:4100-10.

Xu-Friedman MA, Regehr WG (2004). Structural contributions to short-term synaptic plasticity. Physiol Rev, 84:69-85.

Yamagata M, Sanes JR, Weiner JA (2003). Synaptic adhesion molecules. Curr. Opin. Cell Biol, 15:621-632

Yazejian B, Sun XP, Grinnell AD (2000). Tracking presynaptic Ca2+ dynamics during 
neurotransmitter release with Ca2+-activated K+ channels. Nat Neurosci, 3:566-71.

Ye L, Qi JS, Qiao JT (2001). Long-term potentiation in hippocampus of rats is enhanced by endogenous acetylcholine in a way that is independent of N-methyl-D-aspartate receptors. Neurosci Lett, 300:145-8.

Zhang W, Rohlmann A, Sargsyan V, Aramuni G, Hammer RE, Sudhof TC, Missler M (2005). Extracellular domains of alpha-neurexins participate in regulating synaptic transmission by selectively affecting N- and P/Q-type Ca2+ channels. J Neurosci, 25:4330-42.

Zhong H, Yokoyama CT, Scheuer T, Catterall WA (1999). Reciprocal regulation of P/Q-type Ca2+ channels by SNAP-25, syntaxin and synaptotagmin. Nat Neurosci, 2:939-41.

Zucker RS (1999). Calcium- and activity-dependent synaptic plasticity. Curr Opin Neurobiol, 9:305-13.

Zucker RS, Regehr WG (2002). Short-term synaptic plasticity. Annu Rev Physiol, 64:355405. 


\section{Acknowledgements}

I would like to express my gratitude to my thesis supervisor Prof. Markus Missler for his wonderful support and encouragement throughout this project and for giving me the opportunity to work in his laboratory.

I am thankful to Prof. Detlev Schild for providing me the opportunity to perform patch-clamp experiments in his laboratory and for developing the acquisition and evaluation program for patch-clamp data.

I am indebted to Prof. Michael Mueller for providing me the opportunity to perform extracellular recordings in his laboratory and for the great help and support he provided.

I would like to thank Prof. Nils Brose along with Prof. Markus Missler and Prof. Detlev Schild for their support as my thesis committee members.

I would like to thank all the members of Missler lab (Irina Dudanova, Eva Eismann, Richard Fairless, Sandra Gerke, Martin Klose, Henriette Masius, Kerstin Piechotta, Carsten Reissner and Astrid Rohlmann) for providing such a good working atmosphere and for helping me whenever I needed assistance. I would like to acknowledge Sandra Gerke, technical assistant in our lab for her help including the regular genotyping of mutant mice. I would also like to thank the members of Schild lab and Mueller lab for accepting me just like their labmate and providing me every help that I asked.

I would like to thank the administrative staff of the Neuroscience Graduate Program for their support in administrative matters and making the living in Goettingen so easy.

I am grateful to my friends in Goettingen, Abdul Jabbar, Malik, Nashat and Tabrez for making the stay in Goettingen so enjoyable, and for wonderful discussions on scientific and non-scientific topics. I am also thankful to my friends in Aligarh who have provided me with their love and support even when I am not there.

No words are sufficient to express my gratitude to my father (Mr. Abdul Matin), my mother (Mrs. Saiyada Khatoon) and my sisters (Dr. Humera Khatoon and Sarah Khatoon) for their constant love and encouragement. Their love has kept me going through the difficulties that 
came my way. Finally, I would like to thank my wife (Roshi Fatma) for giving me that smile on reaching home that removes all the tiredness of the day. 


\section{Curriculum Vitae}

\section{Personal information}

Name:

Date of birth:

Sex:

Nationality:

Present address:

Phone:

Email address:

\section{Education}

October 2002-March 2006:
Mohiuddin Ahmad

$9^{\text {th }}$ January, 1977

Male

Indian

Ginsterweg 12, WE 89, 37077 Goettingen, Germany (+49) 01797073135

mahmad1@gwdg.de; mohi_ahmad@yahoo.com

Ph.D. work in the laboratory of Professor Markus Missler

Center for Physiology and Pathophysiology Georg-August University of Goettingen, Goettingen, Germany

October 2001-September 2002: International Neuroscience Graduate Program (First Phase)

Georg-August University of Goettingen and International Max Planck Research School, Germany

July 1994-December 2000:

Bachelor of Medicine and Bachelor of Surgery (MBBS) Aligarh Muslim University, Aligarh, India

\section{Stipends/Scholarships/Prizes}

Georg-Christoph-Lichtenberg Stipendium, Government of Lower Saxony, Germany (20022005)

Max Planck Stipendium, IMPRS (2001-2002)

University Gold Medal in Surgery, AMU, India (1999)

University Gold Medal in Anatomy, AMU, India (1996)

University Merit Scholarships, AMU, India (1994-95, 1996-97, 1997-98) 


\section{Publications}

Beglopoulos V, Montag-Sallaz M, Rohlmann A, Piechotta K, Ahmad M, Montag D, Missler M (2005). Neurexophilin 3 is highly localized in cortical and cerebellar regions and is functionally important for sensorimotor gating and motor coordination. Mol Cell Biol., 25:7278-88.

Sons MS, Busche N, Strenzke N, Moser T, Ernsberger U, Mooren FC, Zhang W, Ahmad M, Steffens H, Schomburg ED, Plomp JJ, Missler M (2006). alpha-Neurexins are required for efficient transmitter release and synaptic homeostasis at the mouse neuromuscular junction. Neuroscience, 138, 433-46

Dudanova I*, Sedej S*, Ahmad M*, Masius H, Zhang W, Riedl D, Angenstein F, Schild D, Rupnik M, Missler M. Important contribution of $\alpha$-neurexins to neurohormone release and the role of voltage-dependent $\mathrm{Ca}^{2+}$ channels. Manuscript submitted (to Neuron).

* Dudanova I, Sedej S and Ahmad M contributed equally to the work.

Ahmad M, Reissner C, Muller M, Missler M. Altered synaptic plasticity at hippocampal synapses and biochemical binding reveals interaction of $\alpha$-neurexins with RIM1 $\alpha$. Manuscript in preparation.

\section{$\underline{\text { Posters }}$}

Altered synaptic plasticity at hippocampal CA3-CA1 synapses in $\alpha$-neurexin knockout mice. Presented at: Current trends in Biomedicina workshop: Imaging synapses: From individual molecules to brain circuits, Baeza, Spain, October 2-5, 2005.

Studying the regulation of high-voltage activated (HVA) calcium channels by alpha-neurexins in mammalian cell lines. Presented at: Neurizons, Max-Planck Institute for Experimental Medicine, Göttingen, November 12-14, 2004 
Generation and characterization of stable HEK293 cell lines expressing high-voltage activated (HVA) Ca2+ channels. Presented at: Synaptic transmission: From ion channels to neuronal network function, Max-Planck Institute for Biophysical Chemistry, Göttingen, June 3-6, 2004 
